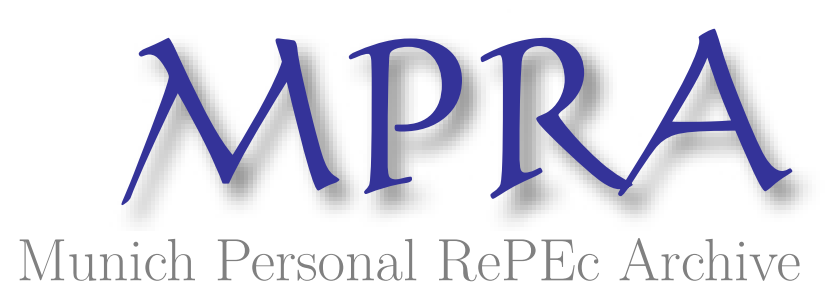

\title{
Forecast ranked tailored equity portfolios
}

Buncic, Daniel and Stern, Cord

Sveriges Riksbank, IBM

25 November 2018

Online at https://mpra.ub.uni-muenchen.de/90382/

MPRA Paper No. 90382, posted 11 Dec 2018 15:15 UTC 


\title{
Forecast ranked tailored equity portfolios*
}

\author{
Daniel Buncic" \\ Sveriges Riksbank \\ Cord Stern $\#$ \\ $I B M$
}

First Version: April 13, 2018

This Version (ranked.port.5b): December 5, 2018

\begin{abstract}
We use a dynamic model averaging (DMA) approach to construct forecasts of individual equity returns for a large cross-section of stocks contained in the SP500, FTSE100, DAX30, CAC40 and SPX30 headline indices, taking value, momentum, and quality factors as predictor variables. Fixing the set of 'forgetting factors' in the DMA prediction framework, we show that highly significant return forecasts relative to the historic average benchmark are obtained for 173 (281) individual equities at the 1\% (5\%) level, from a total of 895 stocks. These statistical forecast improvements also translate into considerable economic gains, producing out-of-sample $R^{2}$ values above 5\% (10\%) for 283 (166) of the 895 individual stocks. Equally weighted long only portfolios constructed from a ranking of the best $25 \%$ forecasts in each headline index can generate sizable returns in excess of a passive investment strategy in that index itself, even when transaction costs and risk taking are accounted for.
\end{abstract}

Keywords: Active factor models, model averaging and selection, computational finance, quantitative equity investing, stock selection strategies, return-based factor models.

JEL Classification: C11, C52, G11, G15, G17, F37.

${ }^{\star}$ Part of this paper was written while Daniel Buncic was visiting the research department (FOE) at the Riksbank. We are grateful to Zeno Adams, Roland Füss, Marcial Messmer, Katja Gisler, and seminar participants at the University of St. Gallen for stimulating discussions and comments on the paper. The opinions expressed in this article are the sole responsibility of the authors and should not be interpreted as reflecting the views of Sveriges Riksbank.

"Corresponding author. Banking Division, Financial Stability Department, Sveriges Riksbank, SE-103 37, Stockholm, Sweden. Email: daniel.buncic@riksbank.se. Web: http:/ /www.danielbuncic.com.

\#Email: Cord.Stern@ch.ibm.com. 


\title{
Forecast ranked tailored equity portfolios
}

\begin{abstract}
We use a dynamic model averaging (DMA) approach to construct forecasts of individual equity returns for a large cross-section of stocks contained in the SP500, FTSE100, DAX30, CAC40 and SPX30 headline indices, taking value, momentum, and quality factors as predictor variables. Fixing the set of 'forgetting factors' in the DMA prediction framework, we show that highly significant return forecasts relative to the historic average benchmark are obtained for 173 (281) individual equities at the 1\% (5\%) level, from a total of 895 stocks. These statistical forecast improvements also translate into considerable economic gains, producing out-of-sample $R^{2}$ values above 5\% (10\%) for 283 (166) of the 895 individual stocks. Equally weighted long only portfolios constructed from a ranking of the best $25 \%$ forecasts in each headline index can generate sizable returns in excess of a passive investment strategy in that index itself, even when transaction costs and risk taking are accounted for.
\end{abstract}

Keywords: Active factor models, model averaging and selection, computational finance, quantitative equity investing, stock selection strategies, return-based factor models.

JEL Classification: C11, C52, G11, G15, G17, F37. 


\section{Introduction}

This paper proposes a novel approach to construct tailored equity portfolios. We employ a highly flexible and robust dynamic model combination (or averaging) approach to compute return forecasts of individual equities from a factor based regressor set for stocks contained in a broad cross-section of international equity indices. We then rank the individual equities based on their forecast performance relative to a simple random walk (or historic average) benchmark forecast from 'best' to 'worst', and take the top 25\% of equities in each constituent index to form equally weighted long only portfolios. Transaction (or portfolio) re-balancing costs are explicitly accounted for through a simple mark-up price.

Our motivation for employing a dynamic model averaging (DMA) approach for the prediction of individual stock returns is due to the following. First, as the recent study by Linnainmaa and Roberts (2018) shows, the importance, and thereby the predictive content, of various pricing factors has substantially changed over time. Classic factor models, which implicitly rely on static factor loadings, are often only able to capture return relations over short sample periods. Moreover, a point forcefully made by Linnainmaa and Roberts (2018) is that many of the 'significant' factors are merely due to $p$-hacking and fail to remain 'significant' when evaluated over a larger sample period that does not contain the original sample over which the factor was discovered (see also Harvey et al. (2015) and Hou et al. (2017)).

Second, and perhaps more importantly, the way we implement DMA is purposefully designed to prevent $p$-hacking or data snooping. There are only two 'free' parameters that need to be specified in the model. These are the two 'forgetting factors' that, respectively, determine the degree of equally weighted model averaging and the rate of smoothing over time. ${ }^{1}$ Since the literature on model averaging prescribes what values to consider for monthly data (see Raftery et al. (2010) and Koop and Korobilis (2012)), there is very little room to fine-tune these param-

\footnotetext{
${ }^{1}$ In fact, there is one more parameter that needs to be set in the specification of the exponentially weighted moving average (EWMA) process for the time varying volatilities. Nevertheless, since there are direct guidelines from RiskMetrics (1996) (see Table 5.9 on page 100) to use a decay factor of 0.94 for daily data and 0.97 for monthly data, it is impossible to tune these values without the reader noticing that they are not aligned with the RiskMetrics (1996) recommendation.
} 
eters to obtain a better fit of the model. Furthermore, to minimize the risk of data snooping, we use the same 'forgetting factors' for all 895 individual equity returns that are predicted in the cross-section and do not adjust these separately for each stock.

Averaging across a large number of models, as devised in the seminal work of Bates and Granger (1969) and implemented in the frequentist and Bayesian model averaging literature, allows one to explicitly mitigate 'model risk', that is, the idea of relying on one 'true' data generating process for the empirical series of interest. Moreover, West and Harrison (1997) have argued that allowing for time varying parameters can proxy for omitted variable bias and possible 'lo$\mathrm{cal}^{\prime}$ non-linearities in the relationship between the dependent variable and its predictors. In the finance literature, several authors have advocated the use of model averaging for return forecasting. For instance, Pastor and Stambaugh (2000) use Bayesian model averaging and shrinkage for return and covariance forecasting. Similarly, Garlappi et al. (2007) offer a comprehensive overview of the use of model averaging approaches in portfolio management. Dynamic model averaging has the extra advantage of detecting changes in the underlying time-series dynamics of the processes in real time.

Our paper is related to a broader literature on return predictability. It is related to the time series predictability literature (see Rapach et al. (2010), Moskowitz et al. (2012),Neely et al. (2014), Rapach et al. (2016), Buncic and Tischhauser (2017), Goyal and Jegadeesh (2018), and others) as it uses the time series dimension to construct forecasts of individual equity returns from a set of value, momentum and quality factors. But it is also related to the cross-sectional return predictability literature because we employ a cross-sectional sort of the individual stocks to obtain a ranking. ${ }^{2}$ Nevertheless, contrary to the existing cross-sectional return predictability literature which relies upon current or lagged observed characteristics such as value, momentum or any of the other factors that have been proposed, we create a forward looking ranking based on the stocks expected or predictive performance. This fundamentally distinguishes our approach

\footnotetext{
${ }^{2}$ The literature on cross-sectional return predictability is large. A comprehensive review of the various pricing factors that have been propose and their performance for cross-sectional return predictability is offered in Harvey et al. (2015) and Linnainmaa and Roberts (2018).
} 
from existing cross-sectional return predictability studies.

Using individual equity returns from a large cross-section of stocks contained in the SP500, FTS100, DAX30, CAC40 and SPX30 headline indices with value, momentum, and quality factors as predictor variables, we show that our proposed dynamic model generates accurate outof-sample forecasts. More specifically, for the considered out-of-sample forecast evaluation and portfolio construction period from 2011:06 to 2015:07, statistically significant point forecasts for 173 (281) individual equities at the 1\% (5\%) level are obtained from a total of 895 stocks. We show further that these statistical gains in the forecasts of the individual stocks translate into considerable economic gains, producing out-of-sample $R^{2}$ values above 5\% (10\%) for 283 (166) of the 895 individual stocks. A trading strategy that constructs long only portfolios for the best $25 \%$ forecasts in each headline index can generate sizable returns in excess of a passive investment strategy in that index itself, even when transaction costs and risk taking are accounted for.

The remainder of the paper is organized as follows. In Section 2 we describe our proposed dynamic model averaging framework to be used for the prediction of the individual stocks. The data that is used in the analysis and the statistical forecast evaluation are presented in Section 3 and Section 4, respectively. In Section 5 we outline how we construct the portfolios and how transaction costs are accounted for in the trading strategy. The trading strategy is evaluated in Section 6 . Section 7 concludes the study.

\section{Modelling approach}

Our dynamic model averaging and selection framework is implemented as follows. For simplicity, we outline the modelling approach for a single equity $i$ to avoid confusion and needing to introduce extra notation to describe the model. We therefore do not use an additional subscript $i$ to index each individual equity that is modelled in the description of the model that follows below. 
Let $r_{t}$ denote the return series (of some equity $i$ ) to be predicted at time period $t$. Also, let $\mathbf{x}_{t-1}$ be a $(1 \times K)$ vector that contains the full set of $k$ predictors plus an intercept term $(K=k+1)$, and let $m=1, \ldots, M$ denote the model index, where $M=2^{k}$ is the total number of possible (linear) model combinations, given $k$ regressors. The set of predictors contained in the $m^{\text {th }}$ model is denoted by $\mathbf{x}_{t-1}^{(m)}$, with the dimension of $\mathbf{x}_{t-1}^{(m)}$ being $\left(1 \times K_{m}\right)$. The two equations that make up the dynamic modelling framework (for a single model $m$ ) are:

$$
\begin{array}{r}
\text { Measurement : } r_{t}=\mathbf{x}_{t-1}^{(m)} \boldsymbol{\beta}_{t}^{(m)}+u_{t}^{(m)} \\
\text { State }: \boldsymbol{\beta}_{t}^{(m)}=\boldsymbol{\beta}_{t-1}^{(m)}+\boldsymbol{\epsilon}_{t}^{(m)},
\end{array}
$$

where (1a) and (1b) are measurement and state equations, respectively. The two disturbance terms $u_{t}^{(m)}$ and $\boldsymbol{\epsilon}_{t}^{(m)}$ in (1) are jointly Multivariate Normal (MN) distributed, uncorrelated with each other and over time, that is:

$$
\left[\begin{array}{c}
u_{t}^{(m)} \\
\boldsymbol{\epsilon}_{t}^{(m)}
\end{array}\right] \sim \mathrm{MN}\left(\left[\begin{array}{l}
0 \\
\mathbf{0}
\end{array}\right],\left[\begin{array}{cc}
H_{t}^{(m)} & 0 \\
\mathbf{0} & \boldsymbol{Q}_{t}^{(m)}
\end{array}\right]\right),
$$

where $H_{t}^{(m)}$ and $Q_{t}^{(m)}$ are the variance and covariance matrix of the measurement and state equations, respectively.

Given $H_{t}^{(m)}$ and $Q_{t}^{(m)}$ (and one specific model $m$ ), the system in (1) takes the form of a standard state-space model, so that we can extract or 'filter' the time varying parameters $\boldsymbol{\beta}_{t}^{(m)}$ as 'latent states' using standard Kalman Filter recursions. One-step ahead forecasts and forecast errors are available as a by product of the Kalman Filter. The Kalman Filter recursions are:

$$
\begin{aligned}
\text { Prediction : } & \hat{\boldsymbol{\beta}}_{t \mid t-1}^{(m)}=\hat{\boldsymbol{\beta}}_{t-1 \mid t-1}^{(m)} \\
& \boldsymbol{P}_{t \mid t-1}^{(m)}=\boldsymbol{P}_{t-1 \mid t-1}^{(m)}+\boldsymbol{Q}_{t}^{(m)} \\
& \hat{r}_{t \mid t-1}^{(m)}=\mathbf{x}_{t-1}^{(m)} \hat{\boldsymbol{\beta}}_{t \mid t-1}^{(m)} \\
\text { Prediction errors : } & \hat{u}_{t}^{(m)}=\left(r_{t}-\hat{r}_{t \mid t-1}^{(m)}\right)
\end{aligned}
$$




$$
\begin{aligned}
\text { MSE of prediction errors : } & F_{t}^{(m)}=\mathbf{x}_{t-1}^{(m)} \boldsymbol{P}_{t \mid t-1}^{(m)} \mathbf{x}_{t-1}^{\top(m)}+H_{t}^{(m)} \\
\text { Kalman Gain: } & \boldsymbol{G}_{t}^{(m)}=\boldsymbol{P}_{t \mid t-1}^{(m)} \mathbf{x}_{t-1}^{\top(m)} / F_{t}^{(m)} \\
\text { Updating: } & \hat{\boldsymbol{\beta}}_{t \mid t}^{(m)}=\hat{\boldsymbol{\beta}}_{t \mid t-1}^{(m)}+\boldsymbol{G}_{t}^{(m)}\left(r_{t}-\hat{r}_{t \mid t-1}^{(m)}\right) \\
& \boldsymbol{P}_{t \mid t}^{(m)}=\boldsymbol{P}_{t-1 \mid t-1}^{(m)}-\boldsymbol{G}_{t}^{(m)} \mathbf{x}_{t-1}^{(m)} \boldsymbol{P}_{t-1 \mid t-1}^{(m)},
\end{aligned}
$$

where $\hat{\boldsymbol{\beta}}_{t \mid t-1}^{(m)}=\mathbb{E}_{t-1}\left(\boldsymbol{\beta}_{t}^{(m)}\right), \mathbb{E}_{t-1}(\cdot)$ is the expectation taken with respect to a time $t-1$ information set denoted by $\mathcal{I}_{t-1}$, and $\boldsymbol{P}_{t \mid t-1}^{(m)}$ is the mean square error (MSE) of $\hat{\boldsymbol{\beta}}_{t \mid t-1}^{(m)}$. Model $m$ forecasts given $\mathcal{I}_{t-1}$ are denoted by $\hat{r}_{t \mid t-1}^{(m)}$. One-step ahead forecast errors are $\hat{u}_{t}^{(m)}$. The associated MSE is denoted by $F_{t}^{(m)}$. The terms $\hat{\boldsymbol{\beta}}_{t \mid t}^{(m)}$ and $\boldsymbol{P}_{t \mid t}^{(m)}$ are updated (or time $t$ ) estimates of the latent states $\boldsymbol{\beta}_{t}^{(m)}$ and their corresponding MSEs.

As is evident from above, the Kalman Filter recursions in (3) are conditional on $H_{t}^{(m)}$ and $\boldsymbol{Q}_{t}^{(m)}$ (and model $m$ ). Rather then estimate $H_{t}^{(m)}$ and $\boldsymbol{Q}_{t}^{(m)}$, we follow the literature and make two simplifying assumptions. The first is to replace $\boldsymbol{P}_{t \mid t-1}^{(m)}$ in (3a) by

$$
\boldsymbol{P}_{t \mid t-1}^{(m)}=\frac{1}{\lambda} \boldsymbol{P}_{t-1 \mid t-1}^{(m)}
$$

where $\lambda \in[0,1]$. This approximation implies that $\boldsymbol{Q}_{t}^{(m)}=\left(\lambda^{-1}-1\right) \boldsymbol{P}_{t-1 \mid t-1}^{(m)}$. The $\lambda$ parameter is commonly referred to as a 'forgetting factor', since it captures how many observations are effectively used for estimation. The second simplifying assumption is to use an exponentially weighted moving average (EWMA) estimate for the volatility term $H_{t}^{(m)}$, taking the form:

$$
H_{t}^{(m)}=\kappa H_{t-1}^{(m)}+(1-\kappa) \hat{u}_{t-1}^{2(m)}
$$

where $\kappa \in[0,1]$ is the EWMA smoothing parameter. Note here that an EWMA model is a restricted integrated $\operatorname{GARCH}(1,1)$. The restriction is that the intercept term is fixed at 0 , rather then estimated. ${ }^{3}$

\footnotetext{
${ }^{3} \mathrm{GARCH}$ models are known to be difficult to beat benchmarks in forecasting evaluations. One alternative model that does seem to produce consistently superior forecasts to a GARCH benchmark model is the Heterogeneous AutoRegressive (HAR) model of Corsi (2009), in particular, augmented versions of it (see for instance, Corsi et al.
} 


\subsection{Model weighting, averaging, and selection}

The Kalman Filter relations in (3) are for the single model case (that is, model $m$ ). Model averaging is implemented by weighting the forecasts by their respective predictive model probabilities. To clarify this, define $\pi_{t \mid t-1}^{(m)}$ as the probability of model $m$ given information up to time $t-1$, which we write as:

$$
\pi_{t \mid t-1}^{(m)}=\operatorname{Pr}\left(\mathcal{M}_{t}=m \mid \mathcal{I}_{t-1}\right)
$$

where $\mathcal{M}_{t}$ denotes the model set at time $t$. The DMA forecast of $r_{t}$, given information up to time $t-1$, written as $\mathbb{E}\left(r_{t} \mid \mathcal{I}_{t-1}\right)$, is then computed as:

$$
\hat{r}_{t \mid t-1}^{(\mathrm{DMA})}=\sum_{m=1}^{M} \hat{r}_{t \mid t-1}^{(m)} \pi_{t \mid t-1}^{(m)},
$$

that is, as the weighted average of the forecasts from all possible models, $\left\{\hat{r}_{t \mid t-1}^{(m)}\right\}_{m=1}^{M}$, with the averaging weights being the predictive probabilities $\left\{\pi_{t \mid t-1}^{(m)}\right\}_{m=1}^{M}$.

To make the construction of the DMA forecasts in (7) feasible, we need prediction and updating recursions for the model probability $\pi$. Following Raftery et al. (2010) and Koop and Korobilis (2012), these prediction and updating equations are constructed as:

$$
\begin{aligned}
& \text { Model Probability Prediction : } \pi_{t \mid t-1}^{(m)}=\frac{\pi_{t-1 \mid t-1}^{\alpha(m)}}{\sum_{j=1}^{M} \pi_{t-1 \mid t-1}^{\alpha(j)}} \\
& \text { Model Probability Updating : } \pi_{t \mid t}^{(m)}=\frac{\pi_{t \mid t-1}^{(m)} f_{\mathrm{N}}^{(m)}\left(r_{t} \mid \mathcal{I}_{t-1}\right)}{\sum_{j=1}^{M} \pi_{t \mid t-1}^{(j)} f_{\mathrm{N}}^{(j)}\left(r_{t} \mid \mathcal{I}_{t-1}\right)},
\end{aligned}
$$

where $f_{\mathrm{N}}^{(m)}\left(r_{t} \mid \mathcal{I}_{t-1}\right)$ is the predictive density of $r_{t}$, given model $m$ and information up to time $t-1$, and $\pi_{0 \mid 0}^{(m)}$ is an initial or prior model probability needed to start the recursions. The relation in (8a) is used as an approximation to the model probability prediction to avoid having to specify an $M \times M$ dimensional model probability transition matrix, which would make model (2010, 2012), Corsi and Renó (2012) and Buncic and Gisler $(2016,2017)$ for recent empirical evidence). 
prediction computationally infeasible when $M$ is large. The $\alpha$ parameter in (8a) is also defined over the $[0,1]$ interval and interpreted as a 'forgetting factor', however, now in the model space.

As a byproduct to the (dynamic) model averaged forecasts, we also form forecasts of $r_{t}$ based on the best performing model at time $t-1$. This dynamic model selection forecast (abbreviated as DMS henceforth) is obtained by selecting the model $m$ with the highest predicted probability, ie., $\max _{\pi}\left\{\pi_{t \mid t-1}^{(m)}\right\}_{m=1}^{M}$. The DMS forecasts are denoted by $\hat{r}_{t \mid t-1}^{(\mathrm{DMS})}$.

\subsection{Priors and calibrated parameters}

The DMA/DMS modelling approach requires the specification of priors for the time varying parameter vector $\hat{\boldsymbol{\beta}}_{0 \mid 0}^{(m)}$ and model probabilities $\pi_{0 \mid 0}^{(m)}$ for the Kalman Filter to be initialised. We set a shrinkage prior for the parameters, that is, we set $\hat{\boldsymbol{\beta}}_{0 \mid 0}^{(m)}$ equal to the $\left(K_{m} \times 1\right)$ dimensional zero vector and $\boldsymbol{P}_{0 \mid 0}^{(m)}$ to a $\left(K_{m} \times K_{m}\right)$ dimensional identity matrix scaled by $1 / \lambda$. For the model probabilities $\pi_{0 \mid 0}^{(m)}$ we use an uninformative prior such that all models have equally likely probabilities of being included, viz, $\pi_{0 \mid 0}^{m}=\frac{1}{M}, \forall m=1, \ldots, M$. We further need to set the forgetting factors $\alpha$ and $\lambda$, as well as the EWMA smoothing parameter $\kappa$. We follow the recommendation of Raftery et al. (2010) and specify $\alpha=0.95$ and $\lambda=0.99$, which offers a balance between parameter stability and model flexibility. The EWMA smoothing parameter $\kappa$ is set to 0.97 , inline with the recommendation by RiskMetrics (1996) for monthly data. These parameter calibrations are intentionally kept the same across all individual equities that are modelled and are not 'fine-tuned' to improve the fits. ${ }^{4}$

\subsection{Forecasts based on alternative models}

To complement our DMA/DMS modelling and forecasting framework, we include two additional approaches in our analysis. As pointed out by Raftery et al. (2010), the first one of these turns out to be a special case of DMA/DMS and is obtained by setting the forgetting factors $\alpha$ and $\lambda$ to unity. Following Raftery et al. (2010), we will refer to these models simply as Bayesian

\footnotetext{
${ }^{4}$ See also Raftery et al. (2010), Koop and Korobilis (2012), Buncic and Moretto (2015), Buncic and Piras (2016), among others, on the choice of forgetting factors and their influence on model fit.
} 
Model Averaging and Selection methods, which are abbreviated as BMA and BMS, respectively. Model Averaging has a long history in the statistics literature, going back to the seminal work of Leamer (1974) and Hoeting et al. (1999). In this context, BMA can be thought of as a precursor to DMA. The second alternative model that we employ is a recursively estimated 'kitchen sink' model, which includes all $\mathbf{x}_{t-1}$ regressors as control variables in the prediction model. Due to its simple structure, this model is estimated by ordinary least squares (OLS) and updated at each time period as new information becomes available.

There exist other stock selection models which use similar factors, but different modelling frameworks. For instance, Bloch et al. (1993) and Guerard et al. (2015) use robust regression techniques such as weighted latent roots models to select stocks, while Beaton and Tukey (1974) use a bi-square criterion. Despite these alternative approaches, we will restrict our evaluation analysis to the ones listed above.

\section{Data}

We apply our forecast rank tailored portfolio construction methodology to equities from five major stock price indices for which sufficiently detailed accounting data are available. These are: i) Deutscher Aktienindex (DAX), ii) Cotation Assistée en Continu (CAC), iii) Financial Times Stock Exchange 100 Index (FTSE), iv) Swiss Market Index (SMI), v) Standard \& Poor's 500 (SPX). Our selection of equity indices is driven by the reliability of detailed corporate accounting data, consistent use of accounting standards, and availability of data. All corporate accounting and equity price data are obtained from Bloomberg. ${ }^{5}$ The corporate accounting data were retrieved at a monthly frequency, while the equity price data are converted from daily Bloomberg prices (PXLAST) to end-of-month data, using the last trading day of the month for the monthly series. The time frame of our empirical analysis is from 2009:06 to 2015:07.

We follow standard practice in the literature and use a $1 / 3$ in-sample and $2 / 3$ out-of-sample

\footnotetext{
${ }^{5}$ For simplicity and due to limited information on revisions in corporate accounting data, we disregard possible revisions in these data, and use the latest published data as of July 2015.
} 
split. We require at least 25 time series observations of the corporate accounting data for a stock to be included in the analysis. For the investment strategy, we consider all stocks that are a component of the respective equity index at the date the investment decision is made. In the section below we describe and motivate our predictor variables upon which the forecasts will be based.

\subsection{Predictor variables}

Factor models, as popularised by Ross (1976), assume that the expected return of any security is a linear combination of a systematic and an idiosyncratic factor. For instance, the capital asset pricing model (CAPM) of Sharpe (1964) is an asset pricing model with only one factor, the beta of the stock, which measures the stocks' systematic sensitivity to the market. The CAPM was modified by Fama and French (1992) in the size and value dimension, while the four factor model of Carhart (1997) allows for momentum as another additional factor to be included.

We use three different groups of factors as predictor variables to obtain information about the driving force behind a stock's price movements. These three factor groups are: $i$ ) a value factor group, ii) a quality factor group, and iii) a momentum factor group.

The value factor group consists of the Price to Earnings (PE) ratio, the Cash-Flow to Price (CFP) ratio, and the Sales to Price (SP) ratio. The PE ratio has a long history as a value factor, going back to fundamental valuations as outlined in Graham (1934). The study by Easton et al. (1992) found a strong correlation between earnings and stock returns, especially when considering longer term horizons. Bloch et al. (1993), Haugen and Baker (2010) and Guerard et al. (2013) show that the use of value ratios such as the Cash-Flow to Price or the Sales to Price ratio have predictive power for stock returns in their cross-sectional analysis.

The momentum factor group consists of three relative momentum factors, that is, relative to a 36 month moving average to capture possible local trend effects. These are the relative strength of: Price to Earnings (RPE), Cash-Flow to Price (RCFP) and Sales to Price (RSP). Notice here that we follow the factor pricing literature and focus on momentum in earnings, cash- 
flow, and sales (deflated by prices), rather then on price momentum (see, for instance, Hou et al. (2017) for a range of different momentum factors that are used in this literature). We take a moving average of the ratios to construct a local trend with the intention of removing the effect of local low frequency movements from the momentum series.

The quality factor group consists of three variables constructed by Bloomberg that show analyst's consensus one year-ahead price targets. More specifically, the first quality variable is the one year-ahead target price (TP). The second is the analysts' revision to the one yearahead target price from the previous period (TPR), expressed as a percentage of the initial target price from the previous period. The third quality factor is defined as a negative rating revision (RRN), which is a binary variable that is equal to 1 if the consensus rating outlook is negative (downward revision), and 0 otherwise.

In Table 1, we list all three groups of factor variables that we use as predictors, with short names listed in column one, a longer description in column two, and their exact calculation is shown in column three. For the remainder of the analysis, we combine these three groups of factor variables to form the predictor variable $\mathbf{x}_{t}^{(i)}$ at time $t$, for stock $i$. That is, $\mathbf{x}_{t}^{(i)}$ is defined as:

$$
\mathbf{x}_{t}^{(i)}=\left[\mathrm{PE}_{t}^{(i)}, \mathrm{CFP}_{t}^{(i)}, \mathrm{SP}_{t}^{(i)}, \mathrm{RPE}_{t}^{(i)}, \mathrm{RCFP}_{t}^{(i)}, \mathrm{RSP}_{t}^{(i)}, \mathrm{TP}_{t}^{(i)} \mathrm{TPR}_{t}^{(i)} \mathrm{RRN}_{t}^{(i)}\right]
$$

To alleviate problems with extreme outliers in the accounting data, we Winsorize the data at the $[.01, .99]$ interval. Also, the value factors (ie., the PE, CFP, and SP variables) are transformed by using the monotonic and continuous log-modulus transformation of John and Draper (1980). ${ }^{6}$ The log-modulus is, in contrast to a standard log transformation, continuous around zero and applicable to values below zero. It is thus useful for series with possibly negative values. As with a standard log-transform, the log-modulus transform increases normality, and mitigates (any remaining) outliers in the data.

In Figure 1 and Table 2 we provide histograms and summary statistics of the predictor vari-

\footnotetext{
${ }^{6}$ That is, the log-modulus transform on variable $\aleph$ is defined as: $\log -\bmod (\aleph)=\operatorname{sign}(\aleph) \times \log (\aleph+1)$.
} 
ables. Our intention here is to give the reader a brief visual description of the data, without discussing the series in any greater detail to conserve space. These histograms and statistics are provided jointly across all companies and over the entire sample period that we consider. Note here, that although we analyse the data for every company separately and not cross-sectionally, the information of the combined data may seem of limited value. However, the histograms in Figure 1 provide a quick overview of the predictor variables' distributions in terms of location, scale and outlying observations.

In Table 2, we report means, medians, and standard deviations, as well as information coefficients (ICs) for each predictor variable. The IC is defined as the Spearman correlation coefficient between a factor at time $t$ and next period's equity return (see, for instance, Grinold and Kahn (2000) for more details and its use in finance). The IC is commonly used as a preliminary indicator of the forecasting ability of a factor (Hua and Qian, 2004). From the results reported in Table 2, we can see that the magnitude of the ICs are in line with other studies. For instance, Guerard et al. (2015) report an IC of 0.037 for the Earnings-to-Price ratio, and for the combined consensus analyst forecast an IC value of 0.04 , which is consistent with our findings of -0.02 for the PE (note the inverse definition here) and our range of -0.01 to 0.04 for the analyst forecast variables (RRN, TP, TPR), respectively. The signs of the ICs are also according to our expectations from a valuation perspective.

\section{Forecast evaluation}

Our dataset spans the sample period from 2009:05 to 2015:07. We use a standard 1/3 in-sample and $2 / 3$ out-of-sample split in our model evaluation. This leaves us with 24 in-sample date points and 50 out-of-sample (OOS) data points over which the models can be evaluated. Note here that we intentionally allow for a larger out-of-sample evaluation period, as our objective is out-of-sample forecasting and portfolio construction. Also, recall that both, DMA/DMS and BMA/BMS, do not contain any parameters to be estimated. All 'forgetting factors' as well as 
the EWMA smoothing parameter are calibrated following recommendations in earlier studies. The choice of a shorter in-sample period should therefore not affect our forecasting results in a negative way. Note here again that we do not tailor the 'forgetting factor' parameters to the individual equities of interest, but keep them the same across all 896 stocks that are forecasted. This leaves no room to fine-tune these parameters to improve our out-of-sample results.

\subsection{Evaluation setting and criteria}

We assess the out-of-sample forecast performance of our proposed modelling approach by following the mainstream finance literature. That is, we employ the methods used by Rapach et al. (2013), Neely et al. (2014), Buncic and Piras (2016), Buncic and Tischhauser (2017) and many others and evaluate the forecasts in terms of the Campbell and Thompson (2008) out-of-sample $R^{2}$ (denoted by $R_{O O S}^{2}$ henceforth) and the Clark and West (2007) Mean Squared Forecast Error (MSFE) adjusted $t$-statistic, which we denote by CW - statistic henceforth. In line with recent practices (see Campbell and Thompson (2008), Goyal and Welch (2008) and others), we use the recursively estimated historic average (HA) as the benchmark model for each equity return.

To formalise the notation used below, let $\hat{e}_{t+1 \mid t}^{\left(\ell^{*}\right)}$ denote the (one-step ahead) forecast errors from prediction model $\ell^{*}$, where $\ell^{*}=\{\mathrm{HA}, \ell\}$ and $\ell=\{\mathrm{DMA}, \mathrm{DMS}, \mathrm{BMA}, \mathrm{BMS}, \mathrm{OLS}\} .^{7}$ These forecast errors are computed as:

$$
\hat{e}_{t+1 \mid t}^{\left(\ell^{*}\right)}=\left(r_{t+1}-\hat{r}_{t+1 \mid t}^{\left(\ell^{*}\right)}\right)
$$

with corresponding MSFEs being

$$
\operatorname{MSFE}^{\left(\ell^{*}\right)}=\frac{1}{T_{O O S}} \sum_{t=T_{I S}}^{T} \hat{e}_{t+1 \mid t^{\prime}}^{2\left(\ell^{*}\right)}
$$

where $T_{O O S}$ and $T_{I S}$ denote, respectively, the number of out-of-sample and in-sample observa-

\footnotetext{
${ }^{7}$ This applies again to each equity $i$, but for matters of convenience in notation, we do not index over the individual equities that are included.
} 
tions. The Campbell and Thompson (2008) $R_{\text {OOS }}^{2(\ell)}$ for model $\ell$, relative to the HA forecast is then computed as:

$$
R_{\text {OOS }}^{2(\ell)}=1-\frac{\operatorname{MSFE}^{(\ell)}}{\operatorname{MSFE}^{(\mathrm{HA})}} .
$$

Intuitively, the $R_{O O S}^{2(\ell)}$ statistic in (12) measures the reduction in the MSFE of the proposed model relative to the HA benchmark model, with $R_{O O S}^{2}>0\left(R_{O O S}^{2}<0\right)$ being an indication that the proposed model performs better (worse) than the benchmark model.

The Clark and West (2007) $t$-statistic is computed (again relative to the HA model) as:

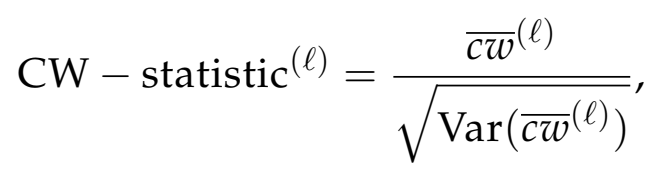

where ${\overline{c w^{(\ell)}}}^{(\ell)} T_{\text {OOS }}^{-1} \sum_{t=T_{I S}}^{T} c w_{t+1}^{(\ell)}$ and $\operatorname{Var}\left({\overline{c w^{(\ell)}}}^{(\ell)}\right.$ is the variance of the sample mean, which is obtained as the heteroskedasticity and autocorrelation (HAC) robust $t$-statistic on the intercept term from a regression of $c w_{t+1}^{(\ell)}$ on a constant. The $c w_{t+1}^{(\ell)}$ sequence is constructed as:

$$
c w_{t+1}^{(\ell)}=\left[\hat{e}_{t+1 \mid t}^{2(\mathrm{HA})}-\hat{e}_{t+1 \mid t}^{2(\ell)}\right]+\left[\hat{r}_{t+1 \mid t}^{(\mathrm{HA})}-\hat{r}_{t+1 \mid t}^{(\ell)}\right]^{2}
$$

The CW - statistic implements a test of the null hypothesis that the MSFE of the benchmark HA model is equal to the MSFE of the forecasts from model $\ell$, against the one sided alternative that the benchmark's MSFE is greater than that of model $\ell$. A rejection of the null hypothesis hence suggests that forecasts from model $\ell$ are (on average) significantly better than the historic average. $^{8}$

In addition to the out-of-sample $R^{2}$ and the CW - statistic, we also compute and plot the cumulative difference of the squared forecast errors from the HA and $\ell$ models' forecasts over the out-of-sample period. This cumulative difference (denoted by cumSFE) is commonly used in the equity premium forecasting literature as a tool to highlight the predictive performance of

\footnotetext{
${ }^{8}$ It should be highlighted here that the $\mathrm{CW}$ - statistic is particularly suitable in the given context, as it is designed for a comparison of nested (forecasting) models. Our benchmark model is the HA model, which can be obtained from any of the proposed models by just including a constant term in the prediction model.
} 
the proposed model relative to a benchmark over time (see Goyal and Welch (2008) and Rapach et al. (2013), among many others). In our setting, this difference is computed as:

$$
\operatorname{cumSFE}_{t+1}^{(\ell)}=\sum_{t=T_{I S}}^{T_{\mathrm{OOS}}}\left(\hat{e}_{t+1 \mid t}^{2(\mathrm{HA})}-\hat{e}_{t+1 \mid t}^{2(\ell)}\right)
$$

where a value of $\operatorname{cumSFE}_{t+1}^{(\ell)}$ above zero suggests that the forecasts of the HA benchmark are worse than those of model $\ell$.

\subsection{Forecast evaluation results}

Aggregate out-of-sample $R^{2}$ values of Campbell and Thompson (2008) $\left(R_{\text {OOS }}^{2(\ell)}\right)$ for all 5 models $\ell=\{$ DMA, DMS, BMA, BMS, OLS $\}$ over the evaluation period from 2011:06 to 2015:07 are presented in Table 3. The first column of Table 3 shows the indices of interest, together with $\leftarrow$ Table 3 about here the number of individual stocks included in each index $(N)$. Columns two to six provide the average $R_{O O S}^{2(\ell)}$ values for the 5 forecasting methods employed. Note that these $R_{O O S}^{2(\ell)}$ values are relative to the historic average (HA) benchmark, as defined in (12), so that a positive value suggests an improvement of the considered model over the HA benchmark. The averages that are provided here are simple, equally weighted arithmetic means, and are provided as a summary measure only. They do not take account of the market capitalisation of the individual stocks in the indices.

Looking over the results presented in Table 3, one can initially notice how poorly the OLS based 'kitchen sink' model, which is based on all regressors and an expanding estimation window, performs. All $R_{O O S}^{2}$ values, whether they are averaged over the 896 stocks that are available, or when aggregated to the individual index level, are decisively negative, suggesting a substantially worse performance than the historic average. The four model averaging/selection based approaches, whether dynamic or static, vastly outperform the 'kitchen sink' model. Overall, model averaging appears to perform slightly better than model selection, with the static approach (BMA/BMS), where the forgetting factors are set to unity, producing marginally larger 
improvements. These aggregate results can be confirmed at the individual company level from Table 4.

In Table 4, we present MSFEs for each individual equity that is included in the five indices. In columns one and two of Table 4, we list the index of interest as well as the Bloomberg Ticker name of the individual firm that is analysed. In columns three to seven, the MSFEs of the 5 different forecasting models are reported, showing also the levels of statistical significance of the improvement in the MSFEs based on the Clark and West (2007) $t$-statistics (CW - statistics), which are annotated using standard asterisk notation. ${ }^{9}$ From the disaggregate results in Table 4 it is evident that the predictive improvements are fairly evenly spread over the 5 different indices, that they are sizeable, with most MSFE reductions in the $7 \%$ to $17 \%$ range, and that they are significant (mainly) at the $1 \%$ and $5 \%$ level. Note here also that, from the DMA results, there are 336, 281, and 173 individual equities that have significantly smaller MSFEs than the benchmark HA model at the $10 \%, 5 \%$, and 1\% levels, respectively. With 896 stocks to test and a nominal test size of $1 \%$, one would normally expect about 9 false positives on average, ie., rejections of the null hypothesis when it is true. The improvements that we present here are thus unlikely to be due to chance or $p$-hacking, that is, due to the large number of tests that are performed. Note here again that we do not modify the model parameters, the 'forgetting factors', in the DMA framework, but keep these fixed for all individual equities that are predicted.

Overall, our results suggest that the DMA forecasting approach performs favourably across the 896 stocks, with improvements similar in magnitude to the principal component and reduced rank forecasting models employed by Deistler and Hamann (2005). Deistler and Hamann (2005) focus on a set of 7 banking stocks listed on the EURO STOXX50 exchange, using a daily frequency. They report out-of-sample $R^{2}$ values of up to $3.2 \%$ for the best performing principal component model, and up to $10 \%$ for the best reduced rank model, with averages of $1 \%$ and $8.29 \%$, respectively. Compared to our sample of 896 stocks, we can see that the DMA approach provides forecast improvements in line with those attained with the PCA model by Deistler

\footnotetext{
${ }^{9}$ We follow the convention in the empirical finance literature and use $\left\{{ }^{*},{ }^{* *},{ }^{* *}\right\}$ to denote significance at the $10 \%, 5 \%$, and $1 \%$, respectively, using one sided (upper tail) $t$-tests.
} 
and Hamann (2005), but performs noticeably worse than their preferred reduced rank model. It should be pointed out here though that we have a much broader and more heterogeneous set of firms included in the 5 equity indices that we analyze. Having only 7 banking stocks makes it possible to choose the predictor variables included in $\mathbf{x}_{t}$ to be highly relevant for banks specifically, rather than relying on a small set of more broadly relevant financial ratios for valuation.

Before we discuss how the equity portfolios are constructed with our framework, we provide a final visual impression of the out-of-sample forecast performance of the proposed modelling approach of the individual stocks by showing plots of the empirical distributions (histograms) of the $R_{O O S}^{2}$ values of all 896 equities that are analyzed in Figure 2. As can be seen from Figure 2, all four subplots show highly positively skewed $R_{O O S}^{2}$ values, suggesting that the presented models and predictor variables (factors) produce particularly good forecasts for some equities. For instance, from the DMA results, 283, 166 and 81 forecasts produce $R_{O O S}^{2}$ values above $5 \%, 10 \%$ and $15 \%$, respectively. Thus, for nearly $10 \%$ of the stocks, that is, for 81

equities, the $R_{O O S}^{2}$ values are above 15 percentage points. This is a substantial improvement. It highlights that, at the cross-sectional level, large gains in forecast accuracy can be obtained for some equities when a flexible prediction model is utilized.

\section{Portfolio construction}

We now describe how the predictions from our proposed forecasting models can be used to build a trading strategy based on combining and weighting the factors. Our main intention here is to assess empirically what economic gains one can achieve from using our forecast rank tailored portfolio construction methodology. There exists a wide variety of methods to evaluate the performance of factors, with some of these relying on portfolio sorts, factor models, or factor portfolios in more general (see Fabozzi et al. (2010) for an extensive discussion of selection criteria).

Many approaches apply naive portfolio sorts, where factor weighting is static. Stocks are 
grouped into quintiles or deciles, in which the constructed factor portfolio replicates the respective factor influence. By examining the return behavior of the portfolio, the return performance across time and in the cross-section can be used to gain information on the excess return attached to each factor. Although such approaches are intuitive and widely employed, they fail to account for the time varying relative performance of the factors and the cross-correlation of these factors. As discussed earlier, Linnainmaa and Roberts (2018) have recently raised the point that many well known factors fail to produce consistent excess returns when different time periods are employed in the evaluation windows. ${ }^{10}$

To test our proposed forecast ranked portfolio construction framework's economic significance, we implement a long only equity strategy based on the forecasts form our purposed models, and follow the three step portfolio construction procedure outlined in Grinold and Kahn (2000). ${ }^{11}$ That is, we initially predict the returns, then we construct the portfolio, and last we evaluate the performance out-of-sample. Note here that the forecasts presented in Section 4 form the basis of our ranking mechanism.

\subsection{Timing, ranking and trading strategy}

The portfolio evaluation period is chosen to be in line with the statistical forecast evaluation period used in Section 4, that is, from 2011:06 to 2015:07. We compute the portfolio values from end-of-month closing prices. For each time period in the evaluation, we rank the individual equities of each index according to their projected values at time $t$, that is, we sort along the predicted returns $\hat{r}_{t+1 \mid t}$ from highest to lowest. We then construct a portfolio of the stocks with the highest predicted return $\hat{r}_{t+1 \mid t}$. For each index we invest equally in the top $25 \%$ of the

\footnotetext{
${ }^{10}$ In Bloch et al. (1993), a comparison of different regression methods for cross sectional factor weighting is provided, which discusses multi-collinearity concerns and the effect of outlier distortion on portfolio evaluation results. Bloch et al. (1993) compare ordinary least squares (OLS) and robust regression techniques with Beaton and Tukey's (1974) bi-square criterion, latent roots and weighted latent roots (WLRR) models. Using the predicted values for a mean-variance portfolio optimization problem, they show that WLRR based portfolios are able to outperform OLS based ones by generating higher Sharpe ratios.

${ }^{11}$ We present results for DMA/DMS only, although the results from the BMA/BMS approach yield similar portfolio performance, much in line with what we found from the statistical evaluation. To avoid repetition, we only present the results from the DMA/DMS frameworks.
} 
forecast-ranked constituents. This means that in each equity index portfolio we hold 10 stocks in the CAC, 7 stocks in the DAX and the SMI, 125 stocks in the SPX, and 25 stocks in the FTSE.

In our simplified, synthetic trading model, all trades are executed at the beginning of the month before markets open, using the previous month's closing prices as given. The portfolio is initially created on June 1, 2011 and then re-balanced every first day of the month over the portfolio evaluation period. We assume that any dividends or earnings that are distributed are re-invested at the current price at the beginning of each month when the portfolio is rebalanced.

\subsection{Transaction costs}

Portfolio turnover involved in active management can produce large transaction costs that could render re-balancing inefficient by nullifying any gains that the statistical superiority of our stock selection framework generates. To account for portfolio re-balancing costs in our trading strategy, we include a general measure of transaction costs in the evaluation of the constructed portfolios, following an approach similar to that of Guerard et al. (2015). Explicit costs such as commissions, market fees, clearing and settlement costs, are combined with implicit costs such as compensation for inventory, liquidity and other costs into one 'cost factor'. Estimates of this one 'cost factor' are provided by Elkins and McSherry (2016) in a subscription based database, which is also used in other studies. For instance, Pollin and Heintz (2011) compute average two-way (buy-sell) transaction costs of 47.3 basis points (bps) for U.S. stocks, and $57.2 \mathrm{bps}$ for U.K stocks over the period from January 2009 to December 2011 using the Elkins and McSherry (2016) database. For the SPX, Brandes et al. (2012) find transaction costs of 40 bps to be appropriate. In international dimensions, Domowitz et al. (2001) compare transaction costs in 1998 to 2000 across global markets and report a global mean of 60 bps.

Although some of these figures seem outdated, they indicate that international trading costs are approximately between 40 to $60 \mathrm{bps}$. Based on these studies, we use a simple trading cost model that assumes a fixed price of 50 bps per trade, thereby disregarding any variation across 
international markets, and the possible influence of scale effects on the cost of a trade. At any time $t$, the cost of executing a trade of value $\delta$ (ie., the quantity times the price, irrespective of whether it is a buy or sell order) is computed as 50 bps times the value of the trade, that is, $0.005 \times \delta$. Initial investment costs are assumed to be the same for the passive benchmark index investment strategy and the active portfolio strategy based on the forecasts from the DMA/DMS models. Conceptually, our approach to tackle transaction costs is different from Focardi et al. (2016), who calculate a break-even transaction costs given a simulated trading result, whereas we assume a fixed fee linked to each transaction. They find for the long-only strategy break-even transaction cost to be between 15 and 46 basis points, which is somewhat smaller than our more conservatively chosen transaction cost of $50 \mathrm{bps}$.

\subsection{Trading strategy evaluation}

We evaluate the performance of the trading strategy by reporting a set of summary results for each forecasting model's constructed portfolio and the respective benchmark index. That is, we compute the annualized mean return, the annualized standard deviation, the maximum drawdown, the portfolio's benchmark Alpha, and the information ratio. In the notation that follows, we use $\iota=\{$ DAX, SPX, FTSE, CAC, SMI $\}$ to denote the index of interest, and $\mathcal{S}=\{$ DMA, DMS $\}$ for the forecasting model or portfolio construction strategy. The maximum drawdown (MDD) is defined as the peak monthly loss in each reported year of the out-ofsample period, that is:

$$
\operatorname{MDD}(\mathcal{S}, \iota)=\max _{\tau \in\left(T_{0}, \mathcal{T}_{T}\right)}\left[\max _{t \in\left(\mathcal{T}_{0}, \tau\right\}}\left\{\mathcal{V}_{t}(\mathcal{S}, \iota)-\mathcal{V}_{\tau}(\mathcal{S}, \iota)\right\}\right]
$$

where $\mathcal{T}$ indices the period of interest, and $\mathcal{V}_{t}(\mathcal{S}, \iota)$ is the value of the portfolio at time $t$, of strategy $\mathcal{S}$ and index of interest $\iota$. MDD thus measures the downside risk of the portfolio strategy, and can be compared to the MDD of the respective benchmark index.

The (ex-post) benchmark Alpha is obtained by regressing the return of strategy $\mathcal{S}$ and index 
of interest $\iota$ on the return of the corresponding benchmark index $\iota$. More specifically, we have the relations:

$$
r_{t}(\mathcal{S}, \iota)=\alpha(\mathcal{S}, \iota)+\beta r_{t}(\iota)+\epsilon_{t}
$$

The term $\alpha(\mathcal{S}, \iota)$ in (17) captures the extra return one obtains from following the portfolio construction strategy $\mathcal{S}$, which is in excess of the return of the (passive) benchmark investment in index $\iota$.

The information ratio (IR) is constructed as:

$$
\operatorname{IR}(\mathcal{S}, \iota)=\frac{\alpha(\mathcal{S}, \iota)}{\sigma(\mathcal{S}, \iota)}
$$

where $\sigma(\mathcal{S}, \iota)$ denotes the annualized standard deviation of the excess return of strategy $\mathcal{S}$ (in excess of the investment benchmark index, also known as the 'tracking error'), and $\alpha(\mathcal{S}, \iota)$ is the benchmark Alpha from (17). The IR summarizes the risk-adjusted performance of the active management strategy. It can be perceived as an indicator of the 'value added' of the active strategy $\mathcal{S}$. The use of IR is widespread in the portfolio management literature. For instance, Sharpe (1994) recommends the IR over the Sharpe ratio to evaluate the performance of an active portfolio. Grinold and Kahn (2000) view the maximization of IR as the main objective of active portfolio management. All values that we report in the tables below are annualized values over the out-of-sample values from 2011:06 to 2015:07.

\section{Trading Strategy Results}

We now present the portfolio evaluation results. In Panels (a) and (b) of Figure 3 we plot the relative performance of our DMA, respectively, DMS based strategy against a passive investment in the index. That is, the performance of the forecast ranked portfolios is benchmarked against the passive indices $\iota=\{\mathrm{DAX}, \mathrm{SPX}, \mathrm{FTSE}, \mathrm{CAC}, \mathrm{SMI}\}$, with all plots in Figure 3 showing the cumulative return (or total value) of the portfolios over the out-of-sample period from 2011:06 
to 2015:07 in excess of their respective passive indices. The value of the portfolio is normalized to unity in 2011:06. Transaction costs are explicitly accounted for, following the procedure described in Section 5.2.

As can be seen from the plots in Figure 3, our forecast based strategies, irrespective of whether DMA or DMS is used as the framework that generates the predictions and hence rankings of the models, can outperform the passive benchmark indices of the FTSE, SPX and, at times, of the CAC. Our active strategy performs particularly well for the portfolio of the FTSE index, yielding a cumulative gain factor of approximately 1.4 and 1.3 for DMA and DMS based forecast ranks, respectively. For the SPX, cumulative returns are positive only from the second half of 2013 onwards, but remain positive until the end of the out-of-sample period in 2015:07. The performance relative to the index is thus noticeably weaker. For the CAC, the models perform well for most of the out-of-sample period, in particular for the first few years following 2011, but drop off towards the end of the sample, with some noticeable drawdown visible in the DMA ranked portfolio from the end of 2013 onwards. The DMS ranked portfolio seem to perform best (relative to DMA) for stocks of the CAC index.

The overall performance of our tailored portfolios for the SMI and the DAX are disappointing. Both active strategies are not able to outperform a passive investment in these respective benchmark indices. Although we do not report the results here, this is also true even when transaction costs are reduced. We have investigated whether adjusting the size of the transaction costs would alter this conclusion substantially, that is, by dropping transaction costs to 25 bps, $10 \mathrm{bps}$, and finally $0 \mathrm{bps}$. However, the results do not change markedly enough to generate gains in the order of magnitude observed for the other three indices. ${ }^{12}$ Evidently, the SMI and the DAX are the two indices with the smallest number of constituent stocks, while the CAC is the third smallest. As outlined earlier, using the top 25\% ranked forecasts from the DMA/DMS prediction models results in 7 stocks to be included in the SMI and DAX tailored portfolios, and 10 stocks in the CAC. It could thus be the case that the relatively poor performance is

\footnotetext{
${ }^{12}$ To conserve space, we do not report these results here, but make them available upon request.
} 
due to the stock selection being already extremely concentrated in these indices, offering less variability overall. One should also note that the DAX and the SMI indices have rebounded much stronger than any of the other 3 indices since the end of the financial crisis, with global equity prices bottoming out in March 2009. As such, these two indices present a difficult to beat benchmark.

The choice of the prediction model when constructing the portfolios, that is, being based on either model averaging or model selection, appears to be of less importance for the overall performance of the portfolios that are constructed. Particulary for the FTSE and the SPX, the overall co-movement and direction in the DMA and DMS based portfolios are largely aligned for much of the out-of-sample period. For the DAX and SMI, the DMS based strategy seems to perform marginally worse overall, nevertheless yielding somewhat higher returns than the DMA based strategy at the beginning of the sample, while ending in the same negative range at the end of the five year period. A noticeable difference in the performance of DMS relative to DMA is only visible for the CAC, where the DMS based strategy outperforms its DMA counterpart. DMS based cumulative returns are nearly uniformly above those from DMA over the entire out-of-sample period, where a decisively higher portfolio value of about 1.2 as opposed to 1.1 at the end of the evaluation period is reached.

\subsection{Detailed results at the index level}

In Table 5 we offer a more detailed overview of the performance of the DMA/DMS based portfolio ranking strategies. The table is arranged in the following column blocks. Under column 1 and 2, the index of interest and the time period (Year) that is analysed are shown. The time period column is aggregated in rows to a total value over the entire out-of-sample period marked by 'All' in the table, as well as annual aggregates for each year from 2011 to 2015. Column blocks (3-5), (6-8), and (9-11) list, respectively, the annualized return, the annualized standard deviation, and the maximum drawdown as defined in (16) for the indices of interest $\iota=\{\mathrm{DAX}, \mathrm{SPX}, \mathrm{FTSE}, \mathrm{CAC}, \mathrm{SMI}\}$, as well as the corresponding DMA/DMS forecast 
ranked portfolios on those indices. The last two column blocks under the headings 'Alpha' and 'Info. Ratio' report the respective benchmark Alpha and the information ratio (IR) as defined in (17) and (18), which are computed relative to the index of interest $\iota$. These are reported only over the full sample period, with corresponding robust $t$-statistics in parenthesis.

Recall that the benchmark 'Alpha' gives the excess return relative to a passive investment index benchmark, but does not adjust the excess return for the risk associated with the portfolio. The information ratio (IR) corrects for this risk by deflating by the tracking error. The tracking error computed as the annualized standard deviation of the excess return of the portfolio measures this risk. Given that the tracking error cannot become negative, a positive IR implies that the tailored portfolio outperforms its passive underlying benchmark index, which means that a risk averse investor receives greater utility from the forecast based stock selection.

Focusing initially on the IRs, we can see that the active portfolio selection strategies based on DMA/DMS forecasts add economic value, with the only obvious exception being the strategies on the CAC. On average, these are zero (or even negative) over the out-of-sample period, as is evident from the 'All' row. This result is interesting and in stark contrast to the finding from Figure 3, where the active DMS based strategy was found to outperform the passive index. Examining the corresponding 'Alpha' values, it seems that the relative performance has to be due to the 'Beta' of the portfolio, that is, its co-movement with the market. For the SMI, the magnitude of the economic value added is almost zero, where an 'Alpha' of $1 \%$ for the DMA/DMS based active strategies is attained. For the DAX, SPX, and FTSE, the Alpha's are 7\%, 4\%, and up to $11 \%$ when a DMA based portfolio ranking strategy is used for all three indices.

Interestingly, the standard deviations of the actively managed strategies have a range of values that are more or less in line with those from the passive benchmark indices, with average differences being of an order of magnitude of less than one percentage point. In some years, for instance, in 2015 the standard deviations of the DMA/DMS based portfolios are less than the passive benchmark indices for SPX and FTSE, but yield a higher return. For the DAX and CAC, the standard deviation of the active strategies are equal to those from the benchmark, with 
returns again higher over the full out-of-sample period. This illustrates some of the attractive features that can be obtained with our forecast ranked tailored portfolios. Not only can risk be contained, but it can be done with a minimal loss in (expected) return, with returns in some years even outperforming the benchmark.

Utilizing a comparable factor set, albeit with a static rather than a dynamic forecasting approach, but with a more complex mean-variance optimizing portfolio mechanism, Guerard et al. (2015) are able to achieve IRs of a similar (or slightly higher) magnitude for the SPX. For their main model which lies on the efficient frontier during the 1999 to 2011 period, they report IRs between 0.44 and 0.78 , depending on the chosen calibration of one of the tuning parameters. Given this result, it may be possible to further extend our naive equal-weighting based portfolio sorting by implementing a more advanced portfolio optimization framework. Nevertheless, we leave this avenue for potential future work.

\section{Conclusion}

This paper introduces a novel approach to construct equity portfolios. We employ the highly flexible and robust dynamic model averaging (DMA) framework of Raftery et al. (2010) and Koop and Korobilis (2012) to construct return forecasts of a large cross-section of individual stocks contained in the SP500, FTSE100, DAX30, CAC40 and SPX30 headline indices using value, momentum, and quality factors as predictor variables. Given the individual forecasts, we rank the equities from best performing to least - relative to a historic average benchmark and then take the top quartile of the best stocks for each index to construct an equally weighted long only portfolio. Based on this ranking and weighting, we form our so called forecast ranked tailed equity portfolios, and evaluate the performance of these portfolio relative to its own passive benchmark index.

We find that, using a given set of fixed forgetting factors in the DMA prediction framework, highly significant return forecasts relative to the historic average benchmark are obtained for 
173 (281) stocks at the $1 \%(5 \%)$ level for a one-month ahead forecast horizon. These statistical improvements in forecast accuracy are furthermore economically meaningful, producing out-of-sample $R^{2}$ values above 5\% (10\%) for 283 (166) of the 895 individual stocks. Constructing equally weighted long portfolios from the top $25 \%$ ranked stocks of the forecasts in each headline index generates sizable returns in excess of a passive investment strategy for some indices. These results hold even when transaction costs are accounted for, and when we adjust the excess returns for the embedded risks of that strategy. 


\section{References}

Bates, John M. and Clive W. J. Granger (1969): “The Combination of Forecasts," Operations Research Quarterly, 20(4), 451-468.

Beaton, Albert E. and John W. Tukey (1974): “The fitting of power series, meaning polynomials, illustrated on band-spectroscopic data," Technometrics, 16(2), 147-185.

Bloch, M., John B. Guerard, Harry M. Markowitz, Petra Todd and Ganlin Xu (1993): “A comparison of some aspects of the U.S. and Japanese equity markets," Japan and the World Economy, 5(1), 3-26.

Brandes, Yossi, Ian Domowitz and Vitaly Serbin (2012): “Transaction Costs and Equity Portfolio Capacity Analysis," in The Oxford Handbook of Quantitative Asset Management, edited by Bernd Scherer, Kenneth Winston and Kenneth James Winston, Oxford University Press, 398-420.

Buncic, Daniel and Katja I.M. Gisler (2016): "Global Equity Market Volatility Spillovers: A Broader Role for the United States," International Journal of Forecasting, 32(4), 1317-1339.

(2017): “The role of jumps and leverage in forecasting volatility in international equity markets," Journal of International Money and Finance, 79(December), 1-19.

Buncic, Daniel and Carlo Moretto (2015): "Forecasting Copper Prices with Dynamic Averaging and Selection Models," North American Journal of Economics and Finance, 33(1), 1-38.

Buncic, Daniel and Gion Donat Piras (2016): "Heterogenous Agents, the Financial Crisis and Exchange Rate Predictability," Journal of International Money and Finance, 60(February), 313-359.

Buncic, Daniel and Martin Tischhauser (2017): "Macroeconomic factors and equity premium predictability," International Review of Economics and Finance, 51(September), 621-644.

Campbell, John Y. and Samuel B. Thompson (2008): "Predicting Excess Stock Returns Out of Sample: Can Anything Beat the Historical Average?" Review of Financial Studies, 21(4), 1509-1531.

Carhart, Mark M. (1997): “On persistence in mutual fund performance,” Journal of Finance, 52(1), 57-82.

Clark, Todd E. and Kenneth D. West (2007): “Approximately normal tests for equal predictive accuracy in nested models," Journal of Econometrics, 138(1), 291-311.

Corsi, Fulvio (2009): “A Simple Approximate Long-Memory Model of Realized Volatility," Journal of Financial Econometrics, 7(2), 174-196.

Corsi, Fulvio, Francesco Audrino and Roberto Renó (2012): “HAR Modeling for Realized Volatility Forecasting," in Handbook of Volatility Models and their Applications, edited by Luc Bauwens, Christian Hafner and Sebastien Laurent, John Wiley and Sons, Inc., 363-382.

Corsi, Fulvio, Davide Pirino and Roberto Ren (2010): "Threshold bipower variation and the impact of jumps on volatility forecasting," Journal of Econometrics, 159(2), 276-288.

Corsi, Fulvio and Roberto Renó (2012): “Discrete-time volatility forecasting with persistent leverage effect and the link with continuous-time volatility modeling," Journal of Business and Economic Statistics, 30(3), 368-380. 
Deistler, Manfred and Eva Hamann (2005): “Identification of Factor Models for Forecasting Returns," Journal of Financial Econometrics, 3(2), 256-281.

Domowitz, Ian, Jack Glen and Ananth Madhavan (2001): "Global equity trading costs," ITG White Paper, May 2001.

Easton, Peter D., Trevor S. Harris and James A. Ohlson (1992): “Aggregate accounting earnings can explain most of security returns: The case of long return intervals," Journal of Accounting and Economics, 15(2-3), 119-142.

Elkins and McSherry (2016): “Global Equity Trading Cost Analysis," Subscription Service. Accessed on Jan 15, 2016. Available from: http://www2.westsussex.gov.uk/ds/cttee/pen/pen230714i4B.pdf.

Fabozzi, Frank J., Sergio M. Focardi, Petter N. Kolm and Joseph A. Cerniglia (2010): "Factor-Based Trading Strategies II: Cross-Sectional Models and Trading Strategies," in Quantitative equity investing: Techniques and strategies, edited by Frank J. Fabozzi, Sergio M. Focardi and Petter N. Kolm, John Wiley \& Sons, 269-310.

Fama, Eugene F. and Kenneth R. French (1992): “The cross-section of expected stock returns," Journal of Finance, 47(2), 427-465.

Focardi, Sergio, Frank Fabozzi and Ivan Mitov (2016): “A new approach to statistical arbitrage: Strategies based on dynamic factor models of prices and their performance," Journal of Banking and Finance, 65, $134-155$.

Garlappi, L., R. Uppal and T. Wang (2007): "Portfolio selection with parameter and model uncertainty: A multi-prior approach," Review of Financial Studies, 20(1), 41-81.

Goyal, Amit and Narasimhan Jegadeesh (2018): “Cross-Sectional and Time-Series Tests of Return Predictability: What Is the Difference?" Review of Financial Studies, 31(5), 1784-1824.

Goyal, Amit and Ivo Welch (2008): "A Comprehensive look at the Empirical Performance of Equity Premium Prediction," Review of Financial Studies, 21(4), 1455-1508.

Graham, Benjamin (1934): Security Analysis, McGraw-Hill.

Grinold, Richard C. and Ronald N. Kahn (2000): Active portfolio management, Volume 2, McGraw-Hill, New York.

Guerard, John B., Harry Markowitz and GanLin Xu (2015): “Earnings forecasting in a global stock selection model and efficient portfolio construction and management," International Journal of Forecasting, 31(2), 550-560.

Guerard, John B., S.T. Rachev and B. Shao (2013): "Efficient global portfolios: Big data and investment universes." IBM Journal of Research and Development, 57(5), 11:1 - 11:11.

Harvey, Campbell R., Yan Liu and Heqing Zhu (2015): “... and the Cross-Section of Expected Returns," Review of Financial Studies, 29(1), 5-68.

Haugen, R. and N. Baker (2010): Handbook of portfolio construction: contemporary applications of Markowitz techniques, Springer Science. 
Hoeting, Jennifer A., David Madigan, Adrian E. Raftery and Chris T. Volinsky (1999): “Bayesian Model Averaging: A Tutorial," Statistical Science, 14(4), 382-417.

Hou, Kewei, Chen Xue and Lu Zhang (2017): "Replicating Anomalies," NBER Working Paper No. 23394, National Bureau of Economic Research.

Hua, Ronald and Edward Qian (2004): "Active Risk and Information Ratio," Journal of Investment Management, 2, 115.

John, J. A. and N. R. Draper (1980): “An Alternative Family of Transformations," Journal of the Royal Statistical Society Series C, 29(2), 190-197.

Koop, Gary and Dimitris Korobilis (2012): “Forecasting Inflation using Dynamic Model Averaging," International Economic Review, 53(3), 867-886.

Leamer, Edward E. (1974): "False Models and Post-Data Model Construction," Journal of the American Statistical Association, 69(345), 122-131.

Linnainmaa, Juhani and Michael R. Roberts (2018): "The History of the Cross-Section of Stock Returns," Review of Financial Studies, 31(7), 2606-2649.

Moskowitz, Tobias J., Yao Hua Ooi and Lasse Heje Pedersen (2012): “Time series momentum," Journal of Financial Economics, 104(2), 228-250.

Neely, Christopher J., David E. Rapach, Jun Tu and Guofu Zhou (2014): "Forecasting the Equity Risk Premium: The Role of Technical Indicators," Management Science, 60(7), 1772-1791.

Pastor, Lubos and Robert Stambaugh (2000): “Comparing asset pricing models: an investment perspective," Journal of Financial Economics, 56(3), 335-381.

Pollin, Robert and James Heintz (2011): "Transaction Costs, Trading Elasticities and the Revenue Potential of Financial Transaction Taxes for the United States," Research Brief, Political Economy Research Institute. Available from: http://www.peri.umass.edu/fileadmin/pdf/research_brief/PERI_FTT_ Research_Brief.pdf.

Raftery, Adrian E., Miroslav Kárný and Pavel Ettler (2010): “Online Prediction under Model Uncertainty via Dynamic Model Averaging: Application to a Cold Rolling Mill," Technometrics, 52(1), 52-66.

Rapach, David E., Matthew C. Ringgenberg and Guofu Zhou (2016): "Short interest and aggregate stock returns," Journal of Financial Economics, 121(1), 46-65.

Rapach, David E., Jack K. Strauss and Guofu Zhou (2010): “Out-of-Sample Equity Premium Prediction: Combination Forecasts and Links to the Real Economy," Review of Financial Studies, 23(2), 821-862.

(2013): “International Stock Return Predictability: What Is the Role of the United States?" Journal of Finance, 68(4), 1633-1662.

RiskMetrics (1996): “RiskMetrics: Technical Document, 4th Edition," J.P. Morgan and Reuters. Available from: https:/ / www.msci.com/documents/10199/5915b101-4206-4ba0-aee2-3449d5c7e95a.

Ross, Stephen A. (1976): "The arbitrage theory of capital asset pricing," Journal of Economic Theory, 13(3), 341-360. 
Sharpe, William F (1964): "Capital asset prices: A theory of market equilibrium under conditions of risk," Journal of Finance, 19(3), 425-442. (1994): “The Sharpe Ratio," Journal of Portfolio Management, 21(1), 49-58.

West, Mike and Jeff Harrison (1997): Bayesian Forecasting and Dynamic Models, Springer Verlag. 


\section{Figures and Tables}

Table 1: Description and calculation of predictor variables

\begin{tabular}{|c|c|c|}
\hline Short name & Full name & Calculation \\
\hline \multicolumn{3}{|r|}{ Value } \\
\hline PE & Price to earnings & $\begin{array}{l}\text { Price (end-of-month) relative to annualized earnings per share trailing } \\
\text { twelve-month as stated in the most recent quarterly report. }\end{array}$ \\
\hline CFP & Cash flow to price & $\begin{array}{l}\text { Cash-Flow as stated in the most recent quarterly report (if not available, } \\
\text { earnings plus depreciation) relative to Price (end-of-month). }\end{array}$ \\
\hline SP & Sales to price & Sales per share (most recent quarter) relative to Price (end-of-month). \\
\hline \multicolumn{3}{|r|}{ Momentum } \\
\hline RPE & Relative Price to Earnings & PE relative to the 36-month moving average of PE. \\
\hline RCFP & Relative Cash-Flow to Price & CFP relative to the 36 -month moving mean of CFP. \\
\hline RSP & Relative Sales to Price & SP relative to the 36-month moving mean of SP. \\
\hline \multicolumn{3}{|r|}{ Quality } \\
\hline TP & One year ahead Target Price & $\begin{array}{l}\text { One year forward consensus target price of analysts, as calculated by } \\
\text { Bloomberg relative to current price in period } t \text {. }\end{array}$ \\
\hline TPR & One year ahead TP revision & $\begin{array}{l}\text { Revision (relative) to target price of previous period, computed as: } \\
T P_{t} / T P_{t-1}-1 \text {. }\end{array}$ \\
\hline RRN & Negative rating revision & $\begin{array}{l}\text { Binary variable which is equal to } 1 \text { if a downward (consensus) analyst } \\
\text { rating revision in period } t-1 \text { occurs, } 0 \text { otherwise. }\end{array}$ \\
\hline
\end{tabular}

Notes: This table shows the predictor variables that are used in the forecasting models. The first column shows the short names of the predictor variables, followed by the long names in column two, and a detailed descriptions of the construction of the predictors in column three. 


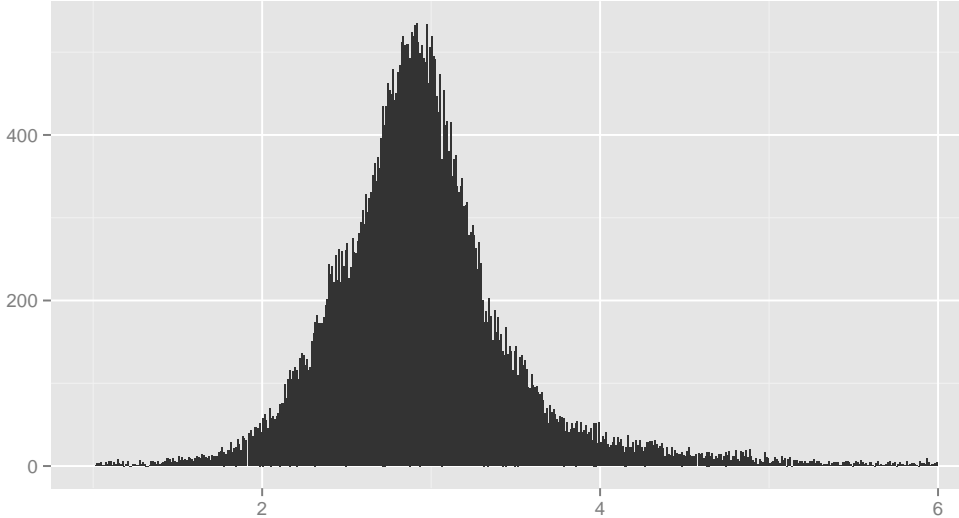

(a) PE

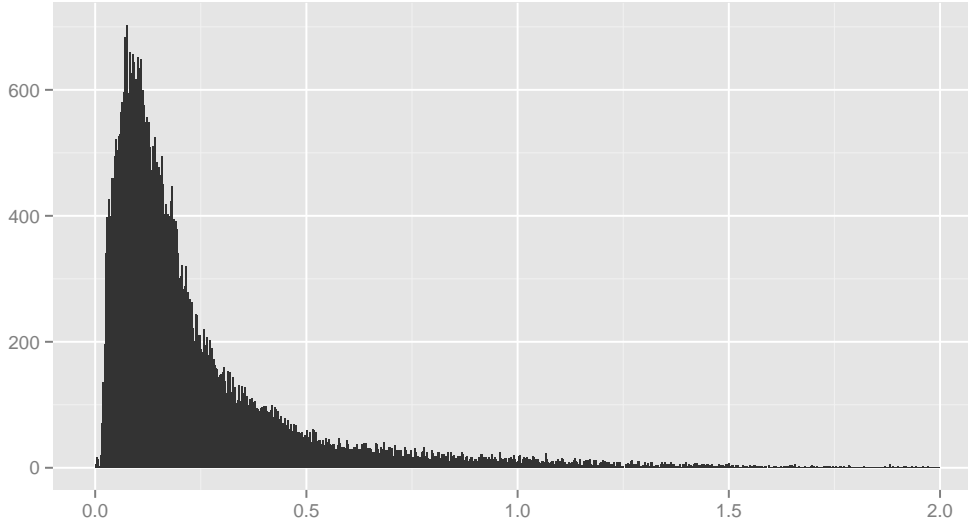

(c) SP

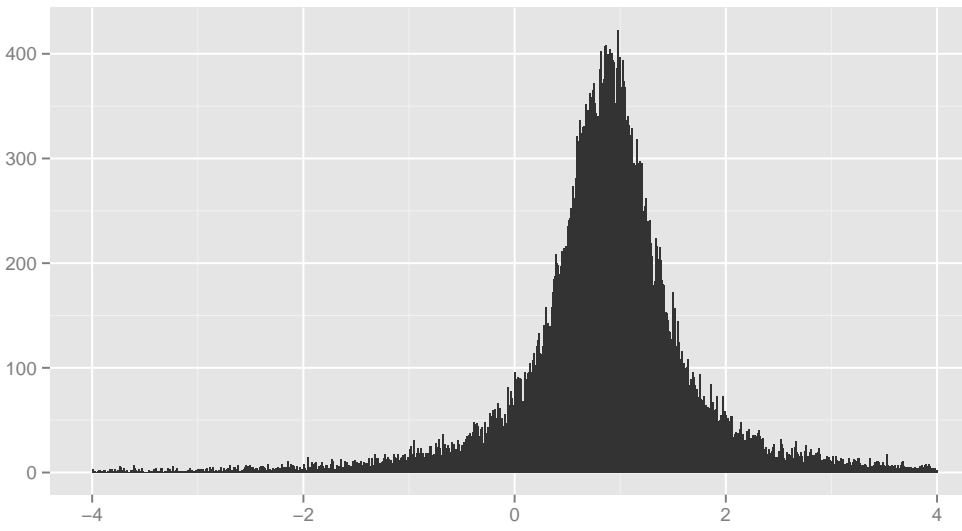

(e) RCFP

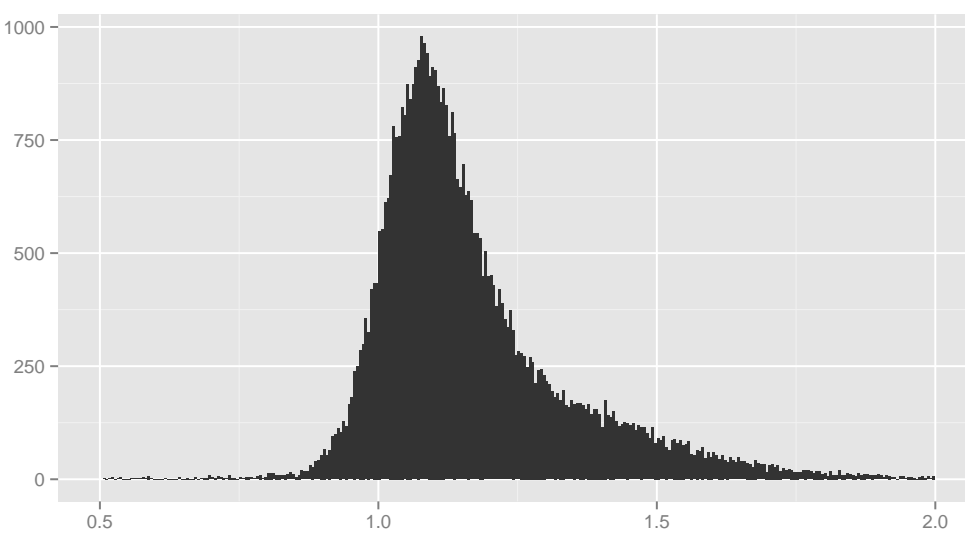

(g) $\mathrm{TP}$

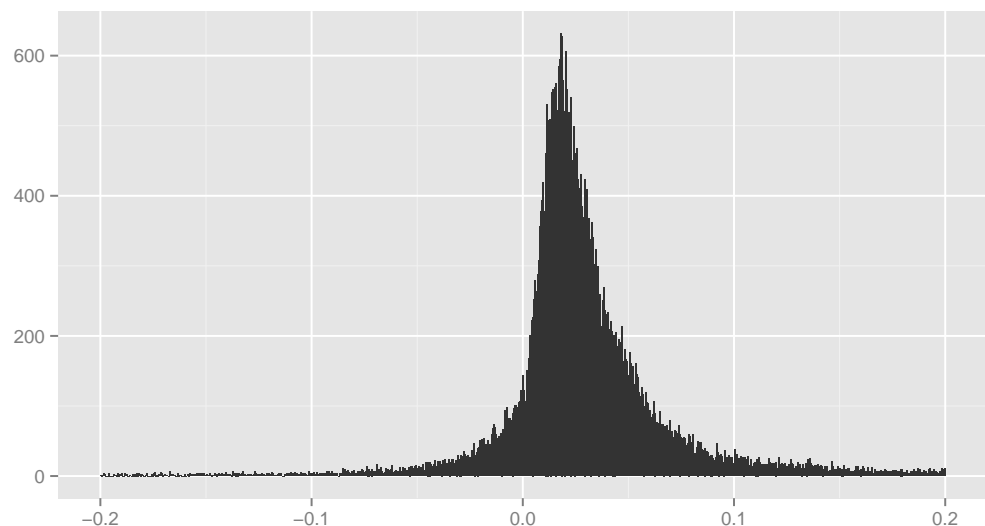

(b) CFP

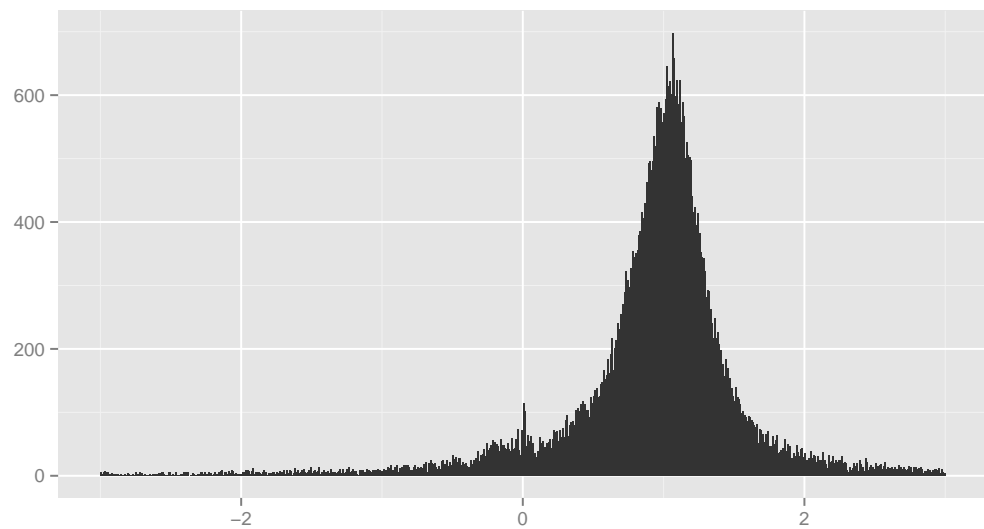

(d) RPE

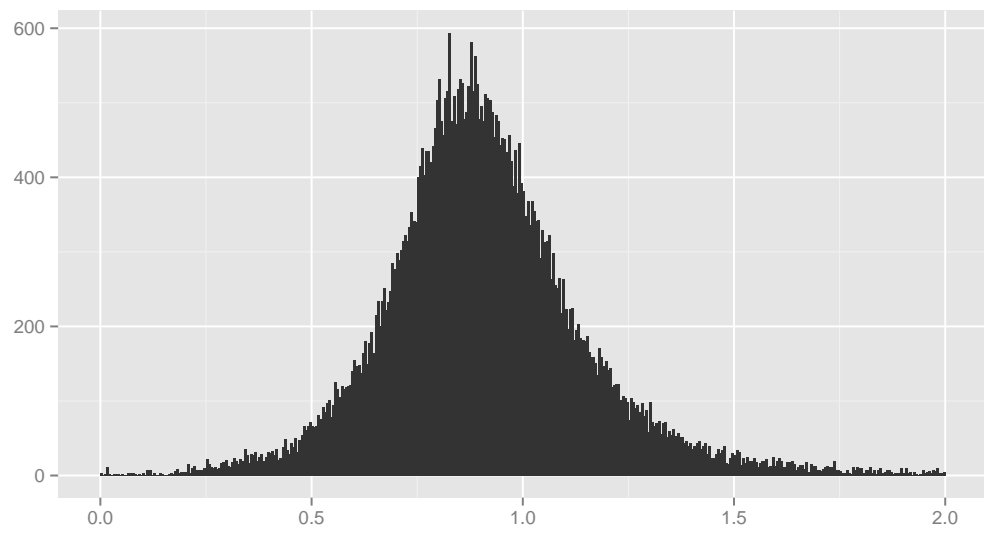

(f) RSP

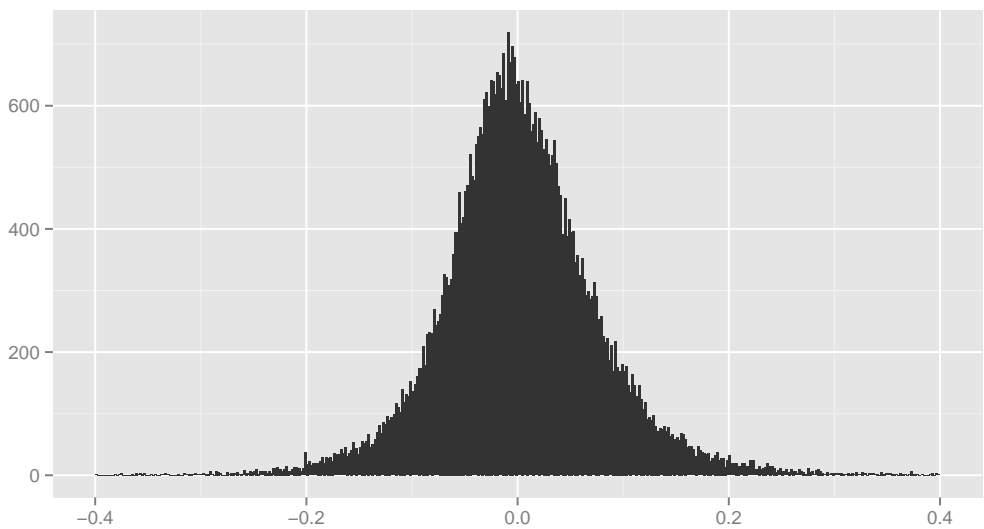

(h) TPR

Figure 1: Aggregate distributions of predictor across all companies over the entire sample period 
Table 2: Summary statistics of the predictor variables

\begin{tabular}{lcccc}
\hline Variable & Mean & Median & Std.dev & IC \\
\hline PE & 2.87 & 2.90 & 0.96 & -0.0209 \\
CFP & 0.03 & 0.02 & 0.12 & 0.0639 \\
SP & 0.25 & 0.16 & 0.30 & 0.0151 \\
RPE & 0.94 & 1.01 & 0.85 & -0.0133 \\
RCFP & 0.90 & 0.89 & 0.94 & 0.0740 \\
RSP & 0.91 & 0.89 & 0.43 & 0.0365 \\
TP & 1.18 & 1.12 & 0.57 & 0.0336 \\
TPR & 0.01 & -0.01 & 0.08 & 0.0448 \\
RRN & - & - & - & -0.0103 \\
\hline
\end{tabular}

Notes: This table shows common summary statistics of the predictor variables of interest. These are shown in aggregated form across all $N=896$ companies over the entire sample period from 2009:06 to 2015:07. Note that RRN, that is, negative rating revision, is a binary variable. Due to this, we do not report measures of central tendency or its standard deviation, but only its information coefficient (IC). The IC measures the Spearman correlation between the current value of the predictor variable with next periods equity return. 
Table 3: Average out-of-sample $R^{2}$ values

\begin{tabular}{lccccc}
\hline Equity Index & DMA & DMS & BMA & BMS & OLS \\
\hline All $(N=896)$ & $2.37 \%$ & $1.78 \%$ & $3.41 \%$ & $3.32 \%$ & $-117.27 \%$ \\
CAC $(N=52)$ & $-0.69 \%$ & $-0.55 \%$ & $0.79 \%$ & $0.33 \%$ & $-143.68 \%$ \\
DAX $(N=34)$ & $3.92 \%$ & $3.73 \%$ & $3.62 \%$ & $3.62 \%$ & $-196.37 \%$ \\
SMI $(N=27)$ & $-0.77 \%$ & $0.43 \%$ & $1.49 \%$ & $1.52 \%$ & $-210.16 \%$ \\
SPX $(N=643)$ & $2.75 \%$ & $1.96 \%$ & $3.66 \%$ & $3.59 \%$ & $-100.97 \%$ \\
FTSE $(N=140)$ & $2.03 \%$ & $1.62 \%$ & $3.57 \%$ & $3.43 \%$ & $-145.42 \%$ \\
\hline
\end{tabular}

Notes: This table reports the out-of-sample $R^{2}$ values $\left(R_{O O S}^{2}\right)$ of Campbell and Thompson (2008) for all models $\ell=\{$ DMA, DMS, BMA, BMS, OLS $\}$ that are considered, relative to the forecasts of the historic average (HA) benchmark. The out-of-sample evaluation period is from 2011:06 to 2015:07. The first column shows the equities belonging to a particular index that is analyzed, together with the number of individual equities included in the index. Columns two to six report the (average) $R_{O O S}^{2}$ of the 5 different forecasting models, relative to the HA benchmark. 
Table 4: Detailed CW - statistic results for every stock that is analysed in each equity index

\begin{tabular}{|c|c|c|c|c|c|c|}
\hline Index & Bloomberg Ticker & DMA & DMS & BMA & BMS & OLS \\
\hline \multirow[t]{52}{*}{ French CAC } & AC_FP_Equity & 1.0041 & 1.0061 & 1.0077 & 1.0076 & 2.1133 \\
\hline & AI_FP_Equity & $0.9073^{* * *}$ & $0.9310^{* * *}$ & $0.8894^{* * *}$ & $0.9182^{* * *}$ & 2.0709 \\
\hline & AF_FP_Equity & 1.0590 & 0.9950 & 0.9956 & 0.9953 & 2.0320 \\
\hline & AIR_FP_Equity & $0.9810^{*}$ & 1.0036 & 1.0205 & 1.0204 & 1.4643 \\
\hline & ALU_FP_Equity & 1.0832 & 1.0539 & 1.0315 & 1.0314 & 2.1990 \\
\hline & ALO_FP_Equity & 1.1869 & 1.3019 & 1.0569 & 1.2471 & 10.2000 \\
\hline & BN_FP_Equity & $0.9434^{* *}$ & $0.9360^{* *}$ & $0.9362^{* *}$ & $0.9362^{* *}$ & 1.1717 \\
\hline & BNP_FP_Equity & 1.0204 & 1.0095 & 1.0103 & 1.0102 & 3.2788 \\
\hline & CA_FP_Equity & 1.0391 & 1.0295 & 1.0308 & 1.0307 & 5.3177 \\
\hline & CAP_FP_Equity & 1.0449 & 1.0412 & 1.0416 & 1.0413 & 1.3002 \\
\hline & CS_FP_Equity & 1.1765 & 1.1546 & 1.1324 & 1.1324 & 4.3993 \\
\hline & CO_FP_Equity & $0.8998^{* *}$ & $0.9321^{* *}$ & $0.9310^{* *}$ & $0.9310^{* *}$ & 2.6617 \\
\hline & DG_FP_Equity & 1.0089 & 1.0174 & 1.0178 & 1.0179 & 1.8942 \\
\hline & DEXB_BB_Equity & 1.0884 & 1.0480 & 1.0255 & 1.0504 & 11.2376 \\
\hline & EDF_FP_Equity & 1.0590 & 1.0293 & 1.0307 & 1.0307 & 1.2077 \\
\hline & EI_FP_Equity & $0.9606^{*}$ & 0.9891 & 0.9827 & 0.9826 & 1.1114 \\
\hline & EN_FP_Equity & 0.9903 & 1.0317 & 1.0307 & 1.0318 & 2.4021 \\
\hline & DSY_FP_Equity & 1.0678 & 1.0139 & 1.0141 & 1.0141 & 1.7008 \\
\hline & ENGI_FP_Equity & 0.9948 & 0.9699 & 0.9701 & 0.9696 & 2.0754 \\
\hline & FP_FP_Equity & 1.0676 & 1.0231 & 1.0245 & 1.0245 & 1.4725 \\
\hline & HO_FP_Equity & 0.9809 & 0.9852 & 0.9872 & 0.9872 & 1.5540 \\
\hline & GTO_FP_Equity & 1.0385 & 1.0376 & 1.0339 & 1.0339 & 2.6115 \\
\hline & GTO_NA_Equity & 1.0487 & 1.0335 & 1.0336 & 1.0336 & 1.9111 \\
\hline & FR_FP_Equity & 1.0442 & 0.9959 & 0.9960 & 0.9958 & 2.5196 \\
\hline & KER_FP_Equity & $0.9236^{* *}$ & $0.9163^{* *}$ & $0.9336^{* *}$ & $0.9336^{* *}$ & 2.2830 \\
\hline & KN_FP_Equity & 1.0119 & 1.1119 & 1.0012 & 1.0019 & 1.4290 \\
\hline & MC_FP_Equity & $0.9210^{* * *}$ & $0.9322^{* *}$ & $0.9321^{* *}$ & $0.9321^{* *}$ & 1.7953 \\
\hline & LR_FP_Equity & $0.9471^{* *}$ & $0.9341^{* *}$ & $0.9288^{* *}$ & $0.9286^{* *}$ & 1.2838 \\
\hline & ML_FP_Equity & $0.9622^{*}$ & 0.9906 & 0.9940 & 0.9952 & 1.2127 \\
\hline & MT_NA_Equity & 0.9838 & $0.9223^{* *}$ & $0.9248^{* *}$ & $0.9237^{* *}$ & 5.1265 \\
\hline & MMB_FP_Equity & 1.0280 & 1.0270 & 1.0279 & 1.0279 & 1.3866 \\
\hline & OR_FP_Equity & 1.0381 & 1.0387 & 1.0163 & 1.0163 & 1.4285 \\
\hline & ORA_FP_Equity & 1.0916 & 1.0946 & 1.0306 & 1.0291 & 1.8984 \\
\hline & PUB_FP_Equity & 0.9852 & 1.0231 & 1.0051 & 1.0051 & 1.2396 \\
\hline & RI_FP_Equity & 1.0326 & 1.0081 & 1.0088 & 1.0088 & 1.5836 \\
\hline & RNO_FP_Equity & 1.0358 & 1.0316 & 1.0323 & 1.0322 & 1.4442 \\
\hline & SAN_FP_Equity & 1.0401 & 1.0402 & 1.0460 & 1.0460 & 1.6556 \\
\hline & SAF_FP_Equity & $0.8555^{* * *}$ & $0.8976^{* * *}$ & $0.8338^{* * *}$ & $0.8338^{* * *}$ & 1.2353 \\
\hline & SGO_FP_Equity & $0.9720^{*}$ & $0.9589^{*}$ & $0.9504^{*}$ & $0.9479^{*}$ & 1.8876 \\
\hline & STM_FP_Equity & 1.0359 & 1.0276 & 0.9968 & 0.9961 & 1.7477 \\
\hline & SEV_FP_Equity & $0.8345^{* * *}$ & $0.8121^{* * *}$ & $0.8052^{* * *}$ & $0.8049^{* * *}$ & 3.8019 \\
\hline & SU_FP_Equity & $0.8916^{* * *}$ & $0.8925^{* * *}$ & $0.8919^{* * *}$ & $0.8919^{* * *}$ & 5.2471 \\
\hline & SW_FP_Equity & 1.0040 & 1.0160 & 1.0166 & 1.0166 & 1.5358 \\
\hline & SOLB_BB_Equity & 0.9997 & 1.0188 & 1.0195 & 1.0194 & 1.4783 \\
\hline & UG_FP_Equity & 1.0253 & 1.0091 & 1.0099 & 1.0099 & 1.8445 \\
\hline & TEC_FP_Equity & $0.8633^{* * *}$ & $0.8226^{* * *}$ & $0.8225^{* * *}$ & $0.8217^{* * *}$ & 2.2858 \\
\hline & TFI_FP_Equity & 1.0257 & 1.0375 & 1.0098 & 1.0098 & 1.4891 \\
\hline & UL_FP_Equity & 1.0185 & 1.0222 & 1.0118 & 1.0118 & 1.9034 \\
\hline & VIE_FP_Equity & 0.9984 & 1.0613 & 1.0368 & 1.0368 & 1.5626 \\
\hline & UL_NA_Equity & 1.0815 & 1.0119 & 1.0087 & 1.0086 & 2.0808 \\
\hline & VIV_FP_Equity & 1.0520 & 1.0361 & 1.0364 & 1.0364 & 2.9684 \\
\hline & VK_FP_Equity & 1.0055 & 1.0218 & 1.0282 & 1.0258 & 1.9716 \\
\hline \multirow{15}{*}{$\begin{array}{r}------- \\
\text { German DAX }\end{array}$} & ------- & ---- & ---- & ---- & ----- & ---- \\
\hline & ADS_GY_Equity & 0.9729 & 0.9698 & 0.9724 & 0.9724 & 1.4767 \\
\hline & ALV_GY_Equity & 1.0360 & 1.0130 & 1.0011 & 1.0135 & 7.0482 \\
\hline & BAS_GY_Equity & $0.8483^{* * *}$ & $0.8675^{* * *}$ & $0.8692^{* * *}$ & $0.8691^{* * *}$ & 1.2973 \\
\hline & BAYN_GY_Equity & 1.0319 & 1.0456 & 1.0459 & 1.0458 & 2.2099 \\
\hline & BMW_GY_Equity & $0.9484^{* *}$ & $0.9512^{* *}$ & $0.9530^{* *}$ & $0.9522^{* *}$ & 1.5847 \\
\hline & BEI_GY_Equity & 1.0245 & 1.0177 & 1.0184 & 1.0184 & 1.7693 \\
\hline & DAI_GY_Equity & 1.0090 & 0.9985 & 0.9996 & 0.9988 & 2.7875 \\
\hline & CON_GY_Equity & $0.9198^{* *}$ & $0.9203^{* *}$ & $0.9250^{* *}$ & $0.9252^{* *}$ & 1.1976 \\
\hline & DBK_GY_Equity & 1.0301 & 1.0028 & 1.0035 & 1.0033 & 4.0074 \\
\hline & DB1_GY_Equity & 1.0458 & 1.0462 & 1.0420 & 1.0420 & 1.5788 \\
\hline & DPW_GY_Equity & 1.0598 & 1.0715 & 1.0522 & 1.0522 & 2.9374 \\
\hline & DTE_GY_Equity & 1.0450 & 1.0271 & 1.0283 & 1.0283 & 1.3287 \\
\hline & EOAN_GY_Equity & 1.0381 & 1.0279 & 1.0298 & 1.0298 & 15.1766 \\
\hline & FME_GY_Equity & $0.9489^{* *}$ & $0.9191^{* * *}$ & $0.9187^{* * *}$ & $0.9187^{* * *}$ & 1.7047 \\
\hline
\end{tabular}

(Continues on next page) 


\begin{tabular}{|c|c|c|c|c|c|c|}
\hline Index & Bloomberg Ticker & DMA & DMS & BMA & BMS & OLS \\
\hline & HEN3_GY_Equity & $0.9184^{* *}$ & $0.9247^{* *}$ & $0.9251^{* *}$ & $0.9251^{* *}$ & 1.4861 \\
\hline & FRE_GY_Equity & $0.9341^{* *}$ & 1.0347 & $0.9521^{* *}$ & $0.9371^{* *}$ & 1.4343 \\
\hline & HEI_GY_Equity & 1.0064 & 1.0047 & 1.0054 & 1.0054 & 1.2898 \\
\hline & IFX_GY_Equity & $0.7685^{* * *}$ & $0.7676^{* * *}$ & $0.7427^{* * *}$ & $0.7426^{* * *}$ & 12.0243 \\
\hline & HNR1_GY_Equity & 1.0483 & 1.0241 & 1.0259 & 1.0258 & 1.1875 \\
\hline & LHA_GY_Equity & $0.9742^{*}$ & 0.9700 & 0.9699 & 0.9699 & 1.4487 \\
\hline & LIN_GY_Equity & $0.9020^{* * *}$ & $0.8797^{* * *}$ & $0.8794^{* * *}$ & $0.8794^{* * *}$ & 1.7764 \\
\hline & MAN_GY_Equity & $0.8940^{* * *}$ & $0.8867^{* * *}$ & $0.8966^{* * *}$ & $0.8960^{* * *}$ & 2.1135 \\
\hline & MEO_GY_Equity & $0.9202^{* *}$ & $0.9321^{* *}$ & $0.9321^{* *}$ & $0.9321^{* *}$ & 7.1304 \\
\hline & MRK_GY_Equity & $0.9208^{* *}$ & 0.9720 & 0.9720 & 0.9720 & 1.2511 \\
\hline & LXS_GY_Equity & $0.7942^{* * *}$ & $0.7929^{* * *}$ & $0.7867^{* * *}$ & $0.7829^{* * *}$ & 2.1213 \\
\hline & MUV2_GY_Equity & 1.0285 & 1.0266 & 1.0272 & 1.0272 & 1.8273 \\
\hline & RWE_GY_Equity & 1.0469 & 1.0349 & 1.0363 & 1.0363 & 2.2335 \\
\hline & SAP_GY_Equity & 0.9939 & 1.0132 & 1.0138 & 1.0138 & 1.4834 \\
\hline & SDF_GY_Equity & 0.9945 & 1.0178 & 1.0181 & 1.0180 & 1.4396 \\
\hline & SIE_GY_Equity & $0.8655^{* * *}$ & $0.8601^{* * *}$ & $0.8599^{* * *}$ & $0.8598^{* * *}$ & 1.2829 \\
\hline & TKA_GY_Equity & $0.9615^{*}$ & $0.9420^{* *}$ & $0.9425^{* *}$ & $0.9424^{* *}$ & 2.9409 \\
\hline & SZG_GY_Equity & 0.9945 & 1.0180 & 1.0183 & 1.0183 & 3.3287 \\
\hline & VOW_GY_Equity & $0.8855^{* * *}$ & $0.8541^{* * *}$ & 1.0055 & 1.0144 & 3.2400 \\
\hline & VOW3_GY_Equity & $0.8556^{* * *}$ & $0.8972^{* * *}$ & $0.9011^{* * *}$ & $0.9011^{* * *}$ & 3.6218 \\
\hline \multirow{28}{*}{$\begin{array}{r}---------1 \\
\text { Swiss SMI }\end{array}$} & --------- & ---- & ---- & ---- & ---- & --- \\
\hline & ABBN_VX_Equity & $0.9391^{* *}$ & $0.9481^{*}$ & $0.9485^{*}$ & $0.9484^{*}$ & 1.3506 \\
\hline & ADEN_VX_Equity & 1.0200 & 1.0193 & 1.0304 & 1.0303 & 2.0219 \\
\hline & BALN_VX_Equity & 1.0293 & 1.0372 & 1.0393 & 1.0377 & 15.5434 \\
\hline & ATLN_VX_Equity & 1.0560 & 1.0076 & 0.9990 & 0.9988 & 10.6252 \\
\hline & CFR_VX_Equity & $0.8754^{* * *}$ & $0.8647^{* * *}$ & $0.8469^{* * *}$ & $0.8468^{* * *}$ & 1.4986 \\
\hline & CLN_VX_Equity & $0.8896^{* * *}$ & 1.0120 & $0.8983^{* * *}$ & $0.8982^{* * *}$ & 1.5422 \\
\hline & LHN_VX_Equity & 1.0061 & 0.9797 & 0.9807 & 0.9807 & 2.5284 \\
\hline & GIVN_VX_Equity & 1.0708 & 1.0510 & 1.0527 & 1.0527 & 1.7708 \\
\hline & GEBN_VX_Equity & $0.9654^{*}$ & $0.9682^{*}$ & $0.9632 *$ & $0.9624^{*}$ & 1.6025 \\
\hline & LONN_VX_Equity & 1.0032 & 1.0031 & 0.9965 & 0.9964 & 1.5449 \\
\hline & KUD_SW_Equity & 1.0579 & 1.0331 & 1.0405 & 1.0405 & 1.8137 \\
\hline & NESN_VX_Equity & $0.9368^{* *}$ & $0.9194^{* *}$ & $0.9198^{* *}$ & $0.9198^{* *}$ & 1.5011 \\
\hline & NOBN_SW_Equity & 1.0291 & 1.0298 & 1.0329 & 1.0329 & 1.4361 \\
\hline & NOVN_VX_Equity & 1.0668 & 1.0358 & 1.0369 & 1.0368 & 1.7942 \\
\hline & ROG_VX_Equity & 1.0079 & 0.9919 & 0.9902 & 0.9901 & 1.7955 \\
\hline & SCMN_VX_Equity & 1.0367 & 1.0137 & 1.0144 & 1.0144 & 4.2240 \\
\hline & SGSN_VX_Equity & 1.0418 & 0.9898 & 0.9905 & 0.9904 & 1.4151 \\
\hline & OERL_SW_Equity & 1.1409 & 1.1982 & 1.0554 & 1.0552 & 2.0519 \\
\hline & SLHN_VX_Equity & 1.0185 & 1.0011 & 1.0021 & 1.0021 & 3.5110 \\
\hline & SREN_VX_Equity & 1.1987 & 1.0255 & 1.0306 & 1.0271 & 5.0436 \\
\hline & SYNN_VX_Equity & 0.9569 & 1.0111 & 1.0110 & 1.0110 & 1.6802 \\
\hline & SYST_VX_Equity & 1.0499 & 1.0321 & 1.0358 & 1.0355 & 4.3681 \\
\hline & UBSN_SW_Equity & 1.0512 & 1.0349 & 1.0323 & 1.0321 & 4.2835 \\
\hline & UBSG_VX_Equity & 1.0430 & 1.0399 & 1.0327 & 1.0321 & 4.9011 \\
\hline & UHR_VX_Equity & $0.8636^{* * *}$ & $0.8281^{* * *}$ & $0.8089^{* * *}$ & $0.8086^{* * *}$ & 1.2752 \\
\hline & ZURN_VX_Equity & 1.0608 & 1.0356 & 1.0363 & 1.0363 & 1.4482 \\
\hline & SUN_SW_Equity & $0.7915^{* * *}$ & $0.7739^{* * *}$ & $0.7720^{* * *}$ & $0.7714^{* * *}$ & 1.1734 \\
\hline \multirow{22}{*}{$\begin{array}{r}------\overline{\text { U.S. SPX }}\end{array}$} & --------- & ---- & ----- & ----- & ---- & --- \\
\hline & X0111145D_UN_Equity & 0.8032 & $0.6152^{* * *}$ & $0.6197^{* * *}$ & $0.6128^{* * *}$ & 0.9658 \\
\hline & X0848680D_UN_Equity & 1.0338 & 1.0357 & 1.0377 & 1.0370 & 1.7901 \\
\hline & X1255459D_UW_Equity & 1.1896 & 1.3339 & 1.0291 & 1.0290 & 1.3563 \\
\hline & X1284849D_UN_Equity & 1.0563 & 1.0270 & 1.0274 & 1.0274 & 1.5218 \\
\hline & A_UN_Equity & $0.7962^{* * *}$ & $0.7914^{* * *}$ & $0.8018^{* * *}$ & $0.8018^{* * *}$ & 1.2608 \\
\hline & X0961514D_UN_Equity & 1.0496 & 1.0496 & 1.0518 & 1.0518 & 2.4972 \\
\hline & X1086832D_UN_Equity & 1.0692 & 1.0692 & 1.0692 & 1.0692 & 1.2140 \\
\hline & AA_UN_Equity & 1.0181 & 1.0291 & 1.0322 & 1.0322 & 4.9620 \\
\hline & X9876544D_UN_Equity & 1.1031 & 1.1258 & 1.0199 & 1.0198 & 1.4901 \\
\hline & AAPL_UW_Equity & $0.9769 *$ & $0.9371^{* *}$ & $0.9380^{* *}$ & $0.9380^{* *}$ & 1.3912 \\
\hline & ABC_UN_Equity & $0.9482^{* *}$ & $0.9388^{* *}$ & $0.9393^{* *}$ & $0.9393^{* *}$ & 1.5305 \\
\hline & ABT_UN_Equity & 1.0381 & 1.0689 & 1.0412 & 1.0412 & 2.7340 \\
\hline & ACE_UN_Equity & 0.9771 & 0.9991 & 1.0071 & 1.0071 & 1.9730 \\
\hline & X0948669D_UN_Equity & $0.9138^{* * *}$ & 1.2436 & $0.7782^{* * *}$ & $0.8042^{* * *}$ & 2.1929 \\
\hline & ACN_UN_Equity & $0.9192^{* * *}$ & $0.9794^{*}$ & $0.9435^{* *}$ & $0.9439^{* *}$ & 1.6723 \\
\hline & ADBE_UW_Equity & 1.1152 & 1.0405 & 1.0451 & 1.0396 & 2.5031 \\
\hline & ADP_UW_Equity & 1.0201 & 1.0287 & 1.0302 & 1.0302 & 2.4792 \\
\hline & ADS_UN_Equity & 0.9966 & $0.9691^{*}$ & 0.9774 & 0.9774 & 1.5836 \\
\hline & ADSK_UW_Equity & 0.9833 & $0.9441^{* *}$ & $0.9448^{* *}$ & $0.9443^{* *}$ & 1.6561 \\
\hline & ADI_UN_Equity & 0.9882 & 0.9856 & 0.9869 & 0.9871 & 1.0627 \\
\hline & AEE_UN_Equity & 1.0093 & 1.0310 & 1.0179 & 1.0179 & 1.5170 \\
\hline
\end{tabular}

(Continues on next page) 


\begin{tabular}{|c|c|c|c|c|c|c|}
\hline Index & Bloomberg Ticker & DMA & DMS & BMA & BMS & OLS \\
\hline & AEP_UN_Equity & 1.0045 & 1.0348 & 1.0046 & 1.0045 & 1.6034 \\
\hline & AES_UN_Equity & $0.8959^{* *}$ & $0.9099 * *$ & $0.9150^{* *}$ & $0.9151^{* *}$ & 4.4606 \\
\hline & ACAS_UW_Equity & $0.9440^{* *}$ & 0.9557 & 0.9646 & 0.9656 & 1.9152 \\
\hline & AET_UN_Equity & 1.0627 & 1.0864 & 1.0173 & 1.0176 & 1.5764 \\
\hline & AFL_UN_Equity & $0.9192^{* *}$ & $0.9051^{* *}$ & $0.8960^{* *}$ & $0.8960^{* *}$ & 4.3281 \\
\hline & AGN_UN_Equity & 1.0779 & 1.0273 & 1.0275 & 1.0275 & 3.1773 \\
\hline & AIV_UN_Equity & $0.6039^{* * *}$ & $0.6276^{* * *}$ & $0.5917^{* * *}$ & $0.6317^{* * *}$ & 2.5288 \\
\hline & AIZ_UN_Equity & 1.0190 & 1.0442 & 1.0057 & 1.0057 & 1.5349 \\
\hline & AKAM_UW_Equity & 1.0604 & 1.0506 & 1.0585 & 1.0585 & 1.1930 \\
\hline & ALL_UN_Equity & 1.0502 & 1.0525 & 1.0528 & 1.0528 & 2.4758 \\
\hline & ALTR_UW_Equity & $0.8747^{* * *}$ & $0.8386^{* * *}$ & $0.8389^{* * *}$ & $0.8389^{* * *}$ & 1.0483 \\
\hline & ALXN_UW_Equity & 0.9842 & 1.0050 & 0.9879 & 0.9879 & 1.2516 \\
\hline & AMAT_UW_Equity & 1.0285 & 1.0469 & 1.0249 & 1.0240 & 1.6489 \\
\hline & AKS_UN_Equity & 1.0049 & 1.0120 & 0.9909 & 0.9907 & 1.7842 \\
\hline & AME_UN_Equity & $0.9526^{* *}$ & $0.9620^{*}$ & $0.9625^{*}$ & $0.9624^{*}$ & 1.2706 \\
\hline & AMG_UN_Equity & 0.9880 & $0.9627^{*}$ & 0.9650 & 0.9649 & 3.1085 \\
\hline & AMGN_UW_Equity & 0.9868 & 1.0255 & 0.9995 & 0.9995 & 1.2164 \\
\hline & AMP_UN_Equity & $0.9317^{* *}$ & $0.9257^{* *}$ & $0.9246^{* *}$ & $0.9246^{* *}$ & 10.9721 \\
\hline & AMZN_UW_Equity & 0.9979 & $0.9637^{*}$ & 0.9682 & $0.9619^{*}$ & 2.8285 \\
\hline & AN_UN_Equity & $0.9532 *$ & 1.0277 & 0.9973 & 0.9967 & 0.9713 \\
\hline & ANF_UN_Equity & $0.8571^{* * *}$ & $0.8732^{* * *}$ & $0.8341^{* * *}$ & $0.8352^{* * *}$ & 1.7329 \\
\hline & ANTM_UN_Equity & 1.0402 & 1.0127 & 1.0145 & 1.0144 & 1.5530 \\
\hline & AAPL_UQ_Equity & $0.9769^{*}$ & $0.9371^{* *}$ & $0.9380^{* *}$ & $0.9380^{* *}$ & 1.3912 \\
\hline & ANRZQ_UN_Equity & $0.9381^{* *}$ & $0.7568^{* * *}$ & $0.7592^{* * *}$ & $0.7563^{* * *}$ & 4.2809 \\
\hline & AON_UN_Equity & 1.0291 & 1.0195 & 1.0211 & 1.0211 & 1.7470 \\
\hline & APA_UN_Equity & 1.0758 & 0.9942 & 0.9950 & 0.9950 & 2.3153 \\
\hline & APC_UN_Equity & 1.0322 & 1.0324 & $0.9467^{*}$ & $0.9467^{*}$ & 3.6867 \\
\hline & APD_UN_Equity & 0.9956 & 1.0049 & 1.0057 & 1.0056 & 1.1796 \\
\hline & APH_UN_Equity & 1.0282 & 1.0440 & 1.0194 & 1.0194 & 2.6970 \\
\hline & ADBE_UQ_Equity & 1.1152 & 1.0405 & 1.0451 & 1.0396 & 2.5031 \\
\hline & ARG_UN_Equity & 1.0083 & 0.9864 & 1.0234 & 1.0231 & 2.6244 \\
\hline & ALTR_UQ_Equity & $0.8747^{* * *}$ & $0.8386^{* * *}$ & $0.8389^{* * *}$ & $0.8389^{* * *}$ & 1.0483 \\
\hline & APOL_UW_Equity & 0.9859 & 1.0252 & 1.0253 & 1.0254 & 1.7027 \\
\hline & ATI_UN_Equity & $0.9739^{* * *}$ & $0.9030^{* * *}$ & $0.9040^{* * *}$ & $0.9026^{* * *}$ & 4.1861 \\
\hline & AVB_UN_Equity & $0.8767^{* * *}$ & $0.8279^{* * *}$ & $0.8475^{* * *}$ & $0.8470^{* * *}$ & 2.1797 \\
\hline & AVGO_UW_Equity & 1.0324 & 1.0312 & 1.0247 & 1.0247 & 3.8095 \\
\hline & AVP_UN_Equity & 1.0985 & 1.0580 & 1.1204 & 1.2175 & 2.0716 \\
\hline & AVY_UN_Equity & $0.9251^{* *}$ & $0.9093^{* *}$ & $0.9117^{* *}$ & $0.9118^{* *}$ & 1.7907 \\
\hline & ADSK_UQ_Equity & 0.9833 & $0.9441^{* *}$ & $0.9448^{* *}$ & $0.9443^{* *}$ & 1.6561 \\
\hline & AXP_UN_Equity & $0.8450^{* * *}$ & $0.8665^{* *}$ & $0.8986^{* * *}$ & $0.8992^{* * *}$ & 1.7049 \\
\hline & AZO_UN_Equity & 1.0772 & 1.0536 & 1.0531 & 1.0527 & 1.4217 \\
\hline & BA_UN_Equity & $0.9383^{* *}$ & $0.9348^{* *}$ & $0.9352^{* *}$ & $0.9352^{* *}$ & 1.3770 \\
\hline & BAC_UN_Equity & 1.0673 & 1.0492 & 1.0558 & 1.0555 & 1.4930 \\
\hline & BAX_UN_Equity & 1.0136 & 0.9987 & 1.0001 & 1.0001 & 1.6297 \\
\hline & BBBY_UW_Equity & $0.9607^{*}$ & $0.9208^{* *}$ & $0.9224^{* *}$ & $0.9224^{* *}$ & 1.7449 \\
\hline & BBT_UN_Equity & 1.0793 & 1.2000 & 1.0419 & 1.0418 & 1.8276 \\
\hline & ASH_UN_Equity & $0.8329^{* * *}$ & $0.8243^{* * *}$ & $0.8127^{* * *}$ & $0.8125^{* * *}$ & 3.9110 \\
\hline & BBY_UN_Equity & 1.0577 & 1.0519 & 1.0238 & 1.0221 & 2.7569 \\
\hline & BCR_UN_Equity & 1.0284 & 1.0226 & 1.0253 & 1.0234 & 1.9059 \\
\hline & BDX_UN_Equity & 1.0677 & 1.0541 & 1.0211 & 1.0163 & 1.6831 \\
\hline & BEN_UN_Equity & $0.8718^{* * *}$ & $0.8701^{* * *}$ & $0.8718^{* * *}$ & $0.8716^{* * *}$ & 1.3632 \\
\hline & AMAT_UQ_Equity & 1.0285 & 1.0469 & 1.0249 & 1.0240 & 1.6489 \\
\hline & BEAM_UN_Equity & 1.0099 & 1.0100 & 1.0151 & 1.0151 & 1.4316 \\
\hline & BF.B_UN_Equity & 1.0544 & 1.0299 & 1.0300 & 1.0300 & 1.5795 \\
\hline & BHI_UN_Equity & $0.9183^{* * *}$ & $0.8960^{* * *}$ & $0.8960^{* * *}$ & $0.8960^{* * *}$ & 1.6757 \\
\hline & AMGN_UQ_Equity & 0.9868 & 1.0255 & 0.9995 & 0.9995 & 1.2164 \\
\hline & BIIB_UW_Equity & 1.0548 & 1.0316 & 1.0323 & 1.0323 & 2.2464 \\
\hline & AMCC_UQ_Equity & $0.9715^{*}$ & 0.9911 & 0.9870 & 0.9870 & 1.4889 \\
\hline & BK_UN_Equity & 1.1095 & 1.0765 & 1.0773 & 1.0762 & 2.6928 \\
\hline & AMZN_UQ_Equity & 0.9979 & $0.9637^{*}$ & 0.9682 & $0.9619^{*}$ & 2.8285 \\
\hline & BLK_UN_Equity & 1.0578 & 1.2165 & 1.0598 & 1.0652 & 1.3028 \\
\hline & ABX_UN_Equity & $0.9196^{* *}$ & $0.9104^{* *}$ & $0.9105^{* *}$ & $0.9104^{* *}$ & 1.3739 \\
\hline & BIG_UN_Equity & 1.0922 & 1.1714 & 1.0145 & 1.0174 & 1.7160 \\
\hline & BLL_UN_Equity & $0.9447^{* *}$ & $0.9336^{* *}$ & $0.9368^{* *}$ & $0.9368^{* *}$ & 1.3957 \\
\hline & BMY_UN_Equity & 1.0319 & 1.0279 & 1.0287 & 1.0287 & 1.6110 \\
\hline & BMS_UN_Equity & 1.0388 & 1.0463 & 1.0246 & 1.0244 & 1.7091 \\
\hline & BRCM_UW_Equity & 1.0679 & 0.9939 & 1.0065 & 1.0066 & 1.4929 \\
\hline & BMC_UW_Equity & 1.0122 & 1.0002 & 1.0022 & 1.0021 & 2.6149 \\
\hline & BSX_UN_Equity & 0.9881 & 0.9971 & 0.9912 & 0.9911 & 1.6402 \\
\hline
\end{tabular}

(Continues on next page) 


\begin{tabular}{|c|c|c|c|c|c|c|}
\hline Index & Bloomberg Ticker & DMA & DMS & BMA & BMS & OLS \\
\hline & BWA_UN_Equity & $0.9076^{* * *}$ & $0.9122^{* * *}$ & $0.9153^{* * *}$ & $0.9153^{* * *}$ & 1.6306 \\
\hline & APOL_UQ_Equity & 0.9859 & 1.0252 & 1.0253 & 1.0254 & 1.7027 \\
\hline & BTU_UN_Equity & $0.7944^{* * *}$ & $0.7609^{* * *}$ & $0.7849^{* * *}$ & $0.7826^{* * *}$ & 1.4170 \\
\hline & BXP_UN_Equity & $0.7867^{* * *}$ & $0.7716^{* * *}$ & $0.7862^{* * *}$ & $0.7862^{* * *}$ & 1.1888 \\
\hline & C_UN_Equity & 1.0572 & 1.0255 & 1.0265 & 1.0257 & 1.6061 \\
\hline & CA_UW_Equity & 0.9996 & 0.9789 & 0.9796 & 0.9795 & 2.4267 \\
\hline & BC_UN_Equity & 1.0846 & 0.9962 & 1.0369 & 1.0326 & 2.3861 \\
\hline & CAG_UN_Equity & 1.0484 & 1.0230 & 1.0239 & 1.0239 & 1.8129 \\
\hline & CAH_UN_Equity & $0.9918^{*}$ & $0.9726^{*}$ & $0.9728^{*}$ & $0.9728^{*}$ & 2.1671 \\
\hline & ALTR_UA_Equity & 1.0644 & 1.0659 & 1.0697 & 1.0697 & 1.3265 \\
\hline & CAM_UN_Equity & 1.0487 & 1.1259 & $0.9196^{* *}$ & $0.9196^{* *}$ & 2.1438 \\
\hline & CAT_UN_Equity & $0.7547^{* * *}$ & $0.7534^{* * *}$ & $0.7509^{* * *}$ & $0.7509^{* * *}$ & 1.7386 \\
\hline & CB_UN_Equity & $0.9240^{* *}$ & $0.9675^{*}$ & $0.9352^{* *}$ & $0.9352^{* *}$ & 0.9715 \\
\hline & CBG_UN_Equity & $0.8508^{* * *}$ & $0.8524^{* * *}$ & $0.8541^{* * *}$ & $0.8541^{* * *}$ & 3.1455 \\
\hline & CBS_UN_Equity & $0.8541^{* * *}$ & $0.8346^{* * *}$ & $0.8347^{* * *}$ & $0.8342^{* * *}$ & 1.5518 \\
\hline & CCE_UN_Equity & $0.9733^{*}$ & $0.9381^{* *}$ & $0.9467^{* *}$ & $0.9460^{* *}$ & 7.7527 \\
\hline & BBBY_UQ_Equity & $0.9607^{*}$ & $0.9208^{* *}$ & $0.9224^{* *}$ & $0.9224^{* *}$ & 1.7449 \\
\hline & CCL_UN_Equity & 1.0622 & 1.0186 & 0.9928 & 0.9928 & 1.9258 \\
\hline & CELG_UW_Equity & 1.0293 & 1.0217 & 1.0203 & 1.0203 & 1.4678 \\
\hline & CBE_UN_Equity & 0.9948 & 0.9938 & 0.9938 & 0.9938 & 4.1634 \\
\hline & CERN_UW_Equity & $0.9431^{* *}$ & $0.9664^{*}$ & $0.9629^{*}$ & $0.9629^{*}$ & 2.2970 \\
\hline & CF_UN_Equity & 1.0121 & 1.1433 & 1.0075 & 1.0075 & 1.7703 \\
\hline & CHK_UN_Equity & $0.8966^{* * *}$ & $0.9160^{* *}$ & $0.9157^{* *}$ & $0.9157^{* *}$ & 1.6153 \\
\hline & CFN_UN_Equity & $0.8267^{* * *}$ & $0.8264^{* * *}$ & $0.8510^{* * *}$ & $0.8510^{* * *}$ & 6.6283 \\
\hline & CHRW_UW_Equity & $0.9254^{* *}$ & $0.9146^{* *}$ & $0.9174^{* *}$ & $0.9174^{* *}$ & 1.8355 \\
\hline & CI_UN_Equity & 1.0066 & 0.9902 & 0.9907 & 0.9906 & 1.3850 \\
\hline & CINF_UW_Equity & 1.0329 & 1.0289 & 1.0302 & 1.0301 & 1.1901 \\
\hline & CEG_UN_Equity & 1.0933 & $0.8317^{*}$ & $0.8291^{*}$ & $0.8303^{*}$ & 1.9258 \\
\hline & CL_UN_Equity & $0.9773^{*}$ & 1.0263 & 0.9946 & 0.9931 & 1.4745 \\
\hline & CLX_UN_Equity & 1.0460 & 1.0230 & 1.0248 & 1.0248 & 1.6029 \\
\hline & CMA_UN_Equity & 1.0736 & 1.0584 & 1.0595 & 1.0594 & 1.8133 \\
\hline & CMCSA_UW_Equity & 0.9944 & 0.9705 & 1.0185 & 1.0185 & 1.9715 \\
\hline & BIIB_UQ_Equity & 1.0548 & 1.0316 & 1.0323 & 1.0323 & 2.2464 \\
\hline & CME_UW_Equity & 1.0085 & 1.0017 & 0.9875 & 0.9875 & 1.9111 \\
\hline & CLF_UN_Equity & $0.7678^{* * *}$ & $0.7879^{* * *}$ & $0.7738^{* * *}$ & $0.7738^{* * *}$ & 1.3949 \\
\hline & CMG_UN_Equity & $0.8776^{* * *}$ & $0.9119^{* * *}$ & $0.9128^{* * *}$ & $0.9128^{* * *}$ & 1.8946 \\
\hline & ARB_UN_Equity & 1.0238 & 1.0174 & 1.0203 & 1.0182 & 1.8274 \\
\hline & CMI_UN_Equity & $0.7751^{* * *}$ & $0.8103^{* * *}$ & $0.8305^{* * *}$ & $0.8305^{* * *}$ & 1.3307 \\
\hline & CMS_UN_Equity & 0.9711 & $0.9683^{*}$ & $0.9673^{*}$ & $0.9673^{*}$ & 1.3978 \\
\hline & CNP_UN_Equity & $0.8492^{* * *}$ & $0.8513^{* * *}$ & $0.8456^{* * *}$ & $0.8456^{* * *}$ & 1.4112 \\
\hline & CNX_UN_Equity & $0.8855^{* * *}$ & $0.8819^{* * *}$ & $0.8817^{* * *}$ & $0.8817^{* * *}$ & 1.7931 \\
\hline & COF_UN_Equity & 1.0374 & 1.0228 & 1.0241 & 1.0240 & 1.7087 \\
\hline & COG_UN_Equity & 1.0589 & 1.0176 & 1.0194 & 1.0180 & 1.6996 \\
\hline & CIEN_UW_Equity & $0.9100^{* *}$ & $0.9395^{*}$ & $0.9417^{*}$ & $0.9497^{*}$ & 16.8298 \\
\hline & COH_UN_Equity & $0.8527^{* * *}$ & $0.8554^{* * *}$ & $0.8539^{* * *}$ & $0.8539^{* * *}$ & 1.0920 \\
\hline & COL_UN_Equity & $0.9331^{* *}$ & $0.9707^{*}$ & $0.9542^{*}$ & $0.9552^{*}$ & 1.6336 \\
\hline & BRCM_UQ_Equity & 1.0679 & 0.9939 & 1.0065 & 1.0066 & 1.4929 \\
\hline & COP_UN_Equity & $0.9045^{* *}$ & $0.8565^{* * *}$ & $0.8555^{* * *}$ & $0.8554^{* * *}$ & 4.0718 \\
\hline & COST_UW_Equity & $0.9604^{* *}$ & $0.9611^{*}$ & $0.9605^{*}$ & $0.9605^{*}$ & 1.1746 \\
\hline & CPB_UN_Equity & 1.0043 & 1.0173 & 1.0184 & 1.0184 & 1.3561 \\
\hline & CRM_UN_Equity & $0.9552^{*}$ & 1.1001 & $0.9280^{* *}$ & $0.9267^{* *}$ & 9.3821 \\
\hline & COV_UN_Equity & $0.9302^{*}$ & $0.9222^{* *}$ & $0.9206^{* *}$ & $0.9206^{* *}$ & 2.2838 \\
\hline & CSCO_UW_Equity & 1.0231 & 1.0334 & 1.0343 & 1.0343 & 1.6344 \\
\hline & CSX_UN_Equity & $0.7986^{* * *}$ & $0.7785^{* * *}$ & $0.7780^{* * *}$ & $0.7780^{* * *}$ & 1.1533 \\
\hline & CTAS_UW_Equity & 1.0460 & 0.9883 & 0.9884 & 0.9884 & 1.6088 \\
\hline & CTL_UN_Equity & $0.9528^{* *}$ & $0.9313^{* *}$ & $0.9308^{* *}$ & $0.9304^{* *}$ & 1.5015 \\
\hline & CTSH_UW_Equity & $0.7976^{* * *}$ & $0.8443^{* * *}$ & $0.8384^{* * *}$ & $0.8383^{* * *}$ & 0.9241 \\
\hline & CTXS_UW_Equity & $0.8900^{* * *}$ & $0.9368^{* *}$ & $0.8979^{* * *}$ & $0.8979^{* * *}$ & 1.4381 \\
\hline & CVC_UN_Equity & $0.9376^{* *}$ & $0.9263^{* *}$ & $0.9196^{* *}$ & $0.9195^{* *}$ & 1.6419 \\
\hline & CVS_UN_Equity & 1.0132 & $0.9601^{*}$ & $0.9612 *$ & $0.9611^{*}$ & 2.0014 \\
\hline & CVX_UN_Equity & $0.8386^{* * *}$ & $0.9584^{* *}$ & $0.8737^{* * *}$ & $0.8737^{* * *}$ & 1.0971 \\
\hline & CPWR_UW_Equity & 0.9932 & 0.9897 & 0.9902 & 0.9901 & 1.8936 \\
\hline & D_UN_Equity & $0.9432^{* *}$ & $0.9437^{* *}$ & $0.9364^{* *}$ & $0.9364^{* *}$ & 1.5019 \\
\hline & DAL_UN_Equity & $0.9843^{*}$ & 0.9732 & $0.9348^{* *}$ & $0.9320^{* *}$ & 1.4684 \\
\hline & BGG_UN_Equity & $0.8784^{* * *}$ & $0.9450^{* *}$ & $0.9456^{* *}$ & $0.9455^{* *}$ & 2.0363 \\
\hline & DD_UN_Equity & $0.9153^{* *}$ & $0.9134^{* *}$ & $0.9138^{* *}$ & $0.9136^{* *}$ & 1.5336 \\
\hline & DE_UN_Equity & $0.8538^{* * *}$ & $0.8341^{* * *}$ & $0.8324^{* * *}$ & $0.8324^{* * *}$ & 1.5809 \\
\hline & DFS_UN_Equity & $0.9209^{* *}$ & $0.9485^{*}$ & $0.9479^{*}$ & $0.9478^{*}$ & 1.7643 \\
\hline & DG_UN_Equity & 1.0429 & 1.0430 & 1.0393 & 1.0393 & 1.4973 \\
\hline
\end{tabular}

(Continues on next page) 


\begin{tabular}{|c|c|c|c|c|c|c|}
\hline Index & Bloomberg Ticker & DMA & DMS & BMA & BMS & OLS \\
\hline & DGX_UN_Equity & 1.0467 & 1.0307 & 1.0312 & 1.0312 & 1.4590 \\
\hline & CIEN_UQ_Equity & $0.9100^{* *}$ & $0.9395^{*}$ & $0.9417^{*}$ & $0.9497^{*}$ & 16.8298 \\
\hline & CVH_UN_Equity & 1.0186 & 0.9977 & 0.9991 & 0.9986 & 2.4747 \\
\hline & DHI_UN_Equity & 1.0172 & 1.1745 & 1.0598 & 1.2168 & 2.4254 \\
\hline & BMC_UQ_Equity & 1.0122 & 1.0002 & 1.0022 & 1.0021 & 2.6149 \\
\hline & CINF_UQ_Equity & 1.0329 & 1.0289 & 1.0302 & 1.0301 & 1.1901 \\
\hline & DHR_UN_Equity & $0.9106^{* * *}$ & $0.9182^{* *}$ & $0.9180^{* *}$ & $0.9180^{* *}$ & 1.4013 \\
\hline & DIS_UN_Equity & 1.0249 & 1.0150 & 1.0162 & 1.0162 & 2.1144 \\
\hline & DELL_UW_Equity & 1.0034 & 0.9988 & 0.9989 & 0.9989 & 1.6779 \\
\hline & DISCA_UW_Equity & 0.9640 & 0.9575 & 0.9626 & 0.9626 & 1.5845 \\
\hline & CVG_UN_Equity & 1.1012 & 1.0726 & 1.0368 & 1.0350 & 3.9194 \\
\hline & DISCK_UW_Equity & 0.9675 & 0.9847 & 0.9738 & 0.9738 & 1.6681 \\
\hline & CMCSA_UQ_Equity & 0.9944 & 0.9705 & 1.0185 & 1.0185 & 1.9715 \\
\hline & DLTR_UW_Equity & 1.0280 & 1.0030 & 1.0033 & 1.0033 & 1.1937 \\
\hline & DNB_UN_Equity & 1.0354 & 1.0152 & 1.0161 & 1.0161 & 1.5314 \\
\hline & DO_UN_Equity & 1.0173 & 1.1135 & 0.9769 & 0.9769 & 2.2971 \\
\hline & DOV_UN_Equity & $0.8881^{* * *}$ & $0.8991^{* * *}$ & $0.8973^{* * *}$ & $0.8973^{* * *}$ & 1.3389 \\
\hline & DNR_UN_Equity & 1.0187 & 0.9724 & 0.9725 & 0.9725 & 1.6825 \\
\hline & DOW_UN_Equity & $0.9583^{*}$ & $0.9438^{*}$ & $0.9463^{*}$ & $0.9462^{*}$ & 2.7549 \\
\hline & DPS_UN_Equity & 1.0076 & 1.0075 & 1.0084 & 1.0084 & 1.7692 \\
\hline & DRI_UN_Equity & 1.0355 & 1.0431 & 1.0374 & 1.0374 & 2.0131 \\
\hline & DDR_UN_Equity & 1.0305 & 1.2048 & 1.0541 & 1.0994 & 8.8731 \\
\hline & DTE_UN_Equity & $0.9299^{* *}$ & $0.9438^{* *}$ & $0.9174^{* *}$ & $0.9173^{* *}$ & 1.0375 \\
\hline & DTV_UW_Equity & 1.0660 & 1.0759 & 1.0763 & 1.0763 & 1.8363 \\
\hline & DUK_UN_Equity & 0.9970 & 1.0145 & 0.9956 & 0.9956 & 1.4158 \\
\hline & DVA_UN_Equity & 0.9762 & 0.9819 & 0.9830 & 0.9829 & 2.1278 \\
\hline & COST_UQ_Equity & $0.9604^{* *}$ & $0.9611^{*}$ & $0.9605^{*}$ & $0.9605^{*}$ & 1.1746 \\
\hline & DVN_UN_Equity & $0.9125^{* *}$ & $0.9013^{* * *}$ & $0.9016^{* * *}$ & $0.9016^{* * *}$ & 2.3793 \\
\hline & DDS_UN_Equity & $0.7518^{* * *}$ & $0.7842^{* * *}$ & $0.7803^{* * *}$ & $0.7802^{* * *}$ & 3.7063 \\
\hline & CPWR_UQ_Equity & 0.9932 & 0.9897 & 0.9902 & 0.9901 & 1.8936 \\
\hline & ECL_UN_Equity & 1.0300 & 1.0274 & 1.0347 & 1.0347 & 1.4387 \\
\hline & CSCO_UQ_Equity & 1.0231 & 1.0334 & 1.0343 & 1.0343 & 1.6344 \\
\hline & ED_UN_Equity & $0.9400^{* *}$ & $0.9420^{* *}$ & $0.9611^{*}$ & $0.9611^{*}$ & 1.2062 \\
\hline & CCK_UN_Equity & $0.9406^{* * *}$ & 1.0196 & 0.9744 & 0.9745 & 1.8712 \\
\hline & EFX_UN_Equity & 1.0310 & 1.0049 & 1.0063 & 1.0061 & 1.6687 \\
\hline & CMCSK_UQ_Equity & 1.0202 & 0.9988 & 1.0259 & 1.0246 & 2.1317 \\
\hline & CTAS_UQ_Equity & 1.0460 & 0.9883 & 0.9884 & 0.9884 & 1.6088 \\
\hline & EIX_UN_Equity & 1.0196 & 1.0451 & 1.0119 & 1.0119 & 1.2432 \\
\hline & CTB_UN_Equity & $0.9209^{* *}$ & $0.8840^{* * *}$ & $0.8891^{* *}$ & $0.8831^{* * *}$ & 2.3876 \\
\hline & EL_UN_Equity & $0.7601^{* * *}$ & $0.8808^{* * *}$ & $0.7995^{* * *}$ & $0.8380^{* * *}$ & 1.1922 \\
\hline & EMC_UN_Equity & $0.8807^{* * *}$ & $0.8707^{* * *}$ & $0.8720^{* * *}$ & $0.8719^{* * *}$ & 1.0858 \\
\hline & CTXS_UQ_Equity & $0.8900^{* * *}$ & $0.9368^{* *}$ & $0.8979^{* * *}$ & $0.8979^{* * *}$ & 1.4381 \\
\hline & DV_UN_Equity & 1.0222 & 0.9935 & 0.9944 & 0.9944 & 1.9036 \\
\hline & EMN_UN_Equity & $0.8761^{* * *}$ & $0.8609^{* * *}$ & $0.8966^{* *}$ & $0.8966^{* *}$ & 1.1444 \\
\hline & EMR_UN_Equity & $0.8776^{* * *}$ & $0.8932^{* * *}$ & $0.8931^{* * *}$ & $0.8931^{* * *}$ & 1.5137 \\
\hline & ENDP_UW_Equity & 1.0652 & $0.9560^{*}$ & $0.9590^{*}$ & $0.9590^{*}$ & 2.1688 \\
\hline & CR_UN_Equity & $0.8811^{* * *}$ & $0.9199^{* * *}$ & $0.9223^{* * *}$ & $0.9223^{* * *}$ & 1.3647 \\
\hline & EOG_UN_Equity & 1.0337 & 1.0107 & 1.0061 & 1.0061 & 1.6939 \\
\hline & EQIX_UW_Equity & 1.0359 & 1.0359 & 1.0366 & 1.0364 & 2.0986 \\
\hline & DYNIQ_UN_Equity & $0.8366^{*}$ & $0.8222^{* *}$ & $0.8188^{* *}$ & $0.8186^{* *}$ & 1.3108 \\
\hline & EQR_UN_Equity & $0.7823^{* * *}$ & $0.7932^{* * *}$ & $0.7913^{* * *}$ & $0.7913^{* * *}$ & 3.1112 \\
\hline & EQT_UN_Equity & 1.0192 & 1.0069 & 1.0078 & 1.0078 & 1.6225 \\
\hline & ES_UN_Equity & $0.9253^{* *}$ & $0.9240^{* * *}$ & $0.9147^{* *}$ & $0.9147^{* *}$ & 1.3723 \\
\hline & ESRX_UW_Equity & 0.9979 & 0.9968 & 0.9977 & 0.9977 & 3.0563 \\
\hline & DELL_UQ_Equity & 1.0034 & 0.9988 & 0.9989 & 0.9989 & 1.6779 \\
\hline & ESS_UN_Equity & $0.9081^{* * *}$ & $0.9152^{* * *}$ & $0.9252^{* *}$ & $0.9257^{* *}$ & 1.7815 \\
\hline & ESV_UN_Equity & $0.8852^{*}$ & 0.9684 & $0.8504^{* * *}$ & $0.8503^{* * *}$ & 1.3637 \\
\hline & ETFC_UW_Equity & 1.0596 & 1.0401 & 1.0382 & 1.0378 & 2.4840 \\
\hline & ETN_UN_Equity & $0.8591^{* * *}$ & $0.8945^{* * *}$ & $0.8646^{* * *}$ & $0.8648^{* * *}$ & 1.1515 \\
\hline & ETR_UN_Equity & 0.9839 & 1.0296 & 1.0308 & 1.0308 & 1.6038 \\
\hline & EW_UN_Equity & $0.9686^{* *}$ & 1.0158 & $0.9543^{* *}$ & $0.9544^{* *}$ & 1.5372 \\
\hline & EP_UN_Equity & 1.0421 & 1.0418 & 1.0427 & 1.0427 & 1.7987 \\
\hline & EXC_UN_Equity & 1.0752 & 1.0267 & 1.0268 & 1.0268 & 1.7441 \\
\hline & EXPD_UW_Equity & $0.9419^{* *}$ & $0.9532^{* *}$ & $0.9596^{*}$ & $0.9596^{*}$ & 1.3684 \\
\hline & EXPE_UW_Equity & 1.0784 & 1.0423 & 1.0427 & 1.0423 & 1.9096 \\
\hline & F_UN_Equity & $0.8200^{* * *}$ & $0.8326^{* * *}$ & $0.8197^{* * *}$ & $0.8198^{* * *}$ & 2.0882 \\
\hline & FAST_UW_Equity & $0.9744^{*}$ & 0.9943 & 0.9781 & 0.9782 & 1.4229 \\
\hline & FCX_UN_Equity & $0.8657^{* * *}$ & $0.9447^{* *}$ & $0.8458^{* * *}$ & $0.8458^{* * *}$ & 1.3057 \\
\hline & FDO_UN_Equity & 1.0247 & 1.0097 & 1.0072 & 1.0072 & 1.4599 \\
\hline
\end{tabular}

(Continues on next page) 


\begin{tabular}{|c|c|c|c|c|c|c|}
\hline Index & Bloomberg Ticker & DMA & DMS & BMA & BMS & OLS \\
\hline & FDX_UN_Equity & 1.0806 & 1.2252 & 1.0132 & 1.0049 & 1.4342 \\
\hline & FE_UN_Equity & 1.0413 & 1.1030 & 1.0257 & 1.0253 & 1.6464 \\
\hline & DLX_UN_Equity & 1.0361 & 1.0534 & 1.0232 & 1.0232 & 2.2531 \\
\hline & FFIV_UW_Equity & $0.8977^{* * *}$ & $0.8793^{* * *}$ & $0.8792^{* * *}$ & $0.8788^{* * *}$ & 1.7051 \\
\hline & FIS_UN_Equity & 0.9932 & 0.9867 & 0.9873 & 0.9873 & 1.4762 \\
\hline & FISV_UW_Equity & 1.0498 & 1.0403 & 1.0402 & 1.0402 & 1.5644 \\
\hline & FITB_UW_Equity & 1.0441 & 1.0572 & 1.0445 & 1.0444 & 1.8837 \\
\hline & FLIR_UW_Equity & $0.9568^{* *}$ & 0.9984 & $0.9590^{*}$ & $0.9591^{*}$ & 1.4282 \\
\hline & FLR_UN_Equity & $0.8796^{* * *}$ & $0.9530^{* *}$ & $0.9070^{* *}$ & $0.9066^{* *}$ & 1.2424 \\
\hline & FHN_UN_Equity & 1.0757 & 1.0426 & 1.0441 & 1.0427 & 3.2333 \\
\hline & FLS_UN_Equity & 0.9735 & 0.9618 & 0.9659 & 0.9658 & 1.2979 \\
\hline & FMC_UN_Equity & 0.9674 & $0.9382^{* *}$ & $0.9380^{* *}$ & $0.9381^{* *}$ & 1.8749 \\
\hline & FII_UN_Equity & 1.0571 & 1.0391 & 1.0403 & 1.0399 & 1.6479 \\
\hline & FOSL_UW_Equity & $0.8841^{* * *}$ & $0.8955^{* * *}$ & $0.8466^{* * *}$ & $0.8460^{* * *}$ & 1.3066 \\
\hline & FOXA_UW_Equity & 1.0134 & 1.0227 & 1.0252 & 1.0252 & 1.7520 \\
\hline & FSLR_UW_Equity & 1.0269 & 1.0583 & 1.0493 & 1.0493 & 4.6335 \\
\hline & FTI_UN_Equity & $0.8617^{* * *}$ & $0.8204^{* * *}$ & $0.8205^{* * *}$ & $0.8205^{* * *}$ & 1.4651 \\
\hline & GAS_UN_Equity & 0.9920 & 0.9794 & 0.9800 & 0.9800 & 1.4333 \\
\hline & ESRX_UQ_Equity & 0.9979 & 0.9968 & 0.9977 & 0.9977 & 3.0563 \\
\hline & GD_UN_Equity & 1.1045 & 1.2233 & 1.0263 & 1.0275 & 2.7521 \\
\hline & GGP_UN_Equity & 1.1189 & 1.1136 & 1.0855 & 1.0851 & 3.3878 \\
\hline & GILD_UW_Equity & $0.8528^{* * *}$ & $0.8337^{* * *}$ & $0.8304^{* * *}$ & $0.8292^{* * *}$ & 1.2702 \\
\hline & GIS_UN_Equity & $0.9616^{* *}$ & $0.9382^{* *}$ & $0.9397^{* *}$ & $0.9396^{* *}$ & 1.3645 \\
\hline & GHC_UN_Equity & 1.0235 & 0.9884 & 0.9763 & 0.9746 & 2.0776 \\
\hline & GLW_UN_Equity & 0.9751 & 0.9857 & 0.9885 & 0.9885 & 1.5389 \\
\hline & FTR_UN_Equity & 0.9744 & 0.9744 & 0.9707 & 0.9707 & 0.5072 \\
\hline & GM_UN_Equity & 0.9390 & 0.8042 & 0.8079 & 0.8038 & 3.5883 \\
\hline & GMCR_UW_Equity & $0.9447^{*}$ & 0.9711 & 0.9722 & 0.9722 & 1.0880 \\
\hline & GME_UN_Equity & 1.0242 & 0.9990 & 1.0020 & 0.9995 & 2.7012 \\
\hline & GNW_UN_Equity & $0.9887^{* *}$ & 1.5417 & $0.7957^{* * *}$ & $0.8002^{* * *}$ & 2.3371 \\
\hline & GOOGL_UW_Equity & 1.0732 & 1.0401 & 1.0424 & 1.0424 & 1.2411 \\
\hline & GPC_UN_Equity & 1.0226 & 1.0032 & 1.0050 & 1.0049 & 1.1328 \\
\hline & FISV_UQ_Equity & 1.0498 & 1.0403 & 1.0402 & 1.0402 & 1.5644 \\
\hline & GPS_UN_Equity & 1.0449 & 1.0236 & 1.0260 & 1.0260 & 1.7305 \\
\hline & FITB_UQ_Equity & 1.0441 & 1.0572 & 1.0445 & 1.0444 & 1.8837 \\
\hline & GRMN_UW_Equity & 1.0758 & 0.9941 & 0.9957 & 0.9957 & 1.8312 \\
\hline & GS_UN_Equity & 1.0704 & 1.0573 & 1.0585 & 1.0584 & 1.5452 \\
\hline & GWW_UN_Equity & $0.9451^{* *}$ & $0.9407^{* *}$ & $0.9427^{* *}$ & $0.9427^{* *}$ & 1.4893 \\
\hline & HAL_UN_Equity & $0.8827^{* * *}$ & $0.8800^{* * *}$ & $0.8879 * * *$ & $0.8812^{* * *}$ & 1.8815 \\
\hline & GR_UN_Equity & 1.0160 & 1.0218 & 1.0235 & 1.0239 & 2.0780 \\
\hline & HAR_UN_Equity & 0.9625 & 0.9800 & 0.9839 & 0.9830 & 1.6485 \\
\hline & HAS_UW_Equity & $0.8466^{* * *}$ & $0.8448^{* * *}$ & $0.8274^{* * *}$ & $0.8271^{* * *}$ & 6.3094 \\
\hline & GT_UN_Equity & 1.0340 & 0.9708 & 0.9724 & 0.9711 & 1.2587 \\
\hline & HBAN_UW_Equity & 1.0898 & 1.1507 & 1.0878 & 1.0935 & 1.7121 \\
\hline & HBI_UN_Equity & $0.7868^{* * *}$ & $0.7796^{* * *}$ & $0.7791^{* * *}$ & $0.7791^{* * *}$ & 1.3643 \\
\hline & HCBK_UW_Equity & 1.0096 & 1.0180 & 1.0239 & 1.0235 & 3.1773 \\
\hline & HCN_UN_Equity & 1.0257 & 1.0291 & 1.0299 & 1.0299 & 1.7596 \\
\hline & HAS_US_Equity & 1.0278 & 1.0027 & 1.0029 & 1.0029 & 2.1104 \\
\hline & HCP_UN_Equity & $0.8296^{* * *}$ & $0.8234^{* * *}$ & $0.8527^{* * *}$ & $0.8528^{* * *}$ & 1.7076 \\
\hline & HD_UN_Equity & 1.0523 & 1.0164 & 1.0171 & 1.0171 & 1.4111 \\
\hline & GILD_UQ_Equity & $0.8527^{* * *}$ & $0.8337^{* * *}$ & $0.8304^{* * *}$ & $0.8292^{* * *}$ & 1.2683 \\
\hline & HES_UN_Equity & 1.0205 & 0.9718 & 0.9724 & 0.9723 & 2.2847 \\
\hline & HIG_UN_Equity & $0.8994^{* * *}$ & $0.8809^{* * *}$ & $0.8612^{* * *}$ & $0.8587^{* * *}$ & 3.6072 \\
\hline & HOG_UN_Equity & $0.9765^{* *}$ & 1.0021 & $0.9517^{* *}$ & $0.9517^{* *}$ & 1.3814 \\
\hline & HON_UN_Equity & $0.9102^{* *}$ & $0.9178^{* *}$ & $0.9174^{* *}$ & $0.9174^{* *}$ & 1.7875 \\
\hline & GOOGL_UQ_Equity & 1.0732 & 1.0401 & 1.0424 & 1.0424 & 1.2411 \\
\hline & HOT_UN_Equity & $0.8015^{* * *}$ & $0.8124^{* * *}$ & $0.8410^{* * *}$ & $0.8410^{* * *}$ & 1.0679 \\
\hline & HNZ_UN_Equity & 0.9722 & 0.9954 & 0.9972 & 0.9973 & 2.0976 \\
\hline & HP_UN_Equity & $0.9603^{*}$ & $0.9651^{*}$ & $0.9653^{*}$ & $0.9653^{*}$ & 2.4257 \\
\hline & HPQ_UN_Equity & 1.0527 & 1.0277 & 1.0316 & 1.0316 & 2.2705 \\
\hline & HRB_UN_Equity & 1.0527 & 1.0396 & 1.0401 & 1.0401 & 1.7281 \\
\hline & HRL_UN_Equity & $0.9659^{*}$ & 0.9774 & 0.9715 & 0.9715 & 1.0826 \\
\hline & HRS_UN_Equity & $0.9698^{* *}$ & 1.0601 & 0.9805 & 0.9820 & 1.5676 \\
\hline & HSP_UN_Equity & 1.0328 & 1.0283 & 1.0382 & 1.0308 & 6.9019 \\
\hline & HST_UN_Equity & $0.8693^{* * *}$ & $0.8569^{* * *}$ & $0.8565^{* * *}$ & $0.8559^{* * *}$ & 2.0024 \\
\hline & HSIC_UW_Equity & $0.9705^{*}$ & 0.9748 & 0.9765 & 0.9765 & 1.2460 \\
\hline & FWLT_US_Equity & 1.0092 & 0.9991 & 0.9918 & 0.9918 & 1.9990 \\
\hline & HSY_UN_Equity & $0.9277^{* *}$ & $0.9395^{* *}$ & 0.9800 & 0.9827 & 1.5207 \\
\hline & HUM_UN_Equity & 0.9956 & 0.9792 & 0.9787 & 0.9787 & 1.3105 \\
\hline
\end{tabular}

(Continues on next page) 


\begin{tabular}{|c|c|c|c|c|c|c|}
\hline Index & Bloomberg Ticker & DMA & DMS & BMA & BMS & OLS \\
\hline & IBM_UN_Equity & $0.8856^{* *}$ & $0.8674^{* * *}$ & $0.8678^{* * *}$ & $0.8678^{* * *}$ & 1.3227 \\
\hline & HBAN_UQ_Equity & 1.0898 & 1.1507 & 1.0878 & 1.0935 & 1.7121 \\
\hline & HSH_UN_Equity & 0.9972 & 0.9884 & 0.9892 & 0.9892 & 2.4453 \\
\hline & ICE_UN_Equity & 1.0180 & 1.0586 & 1.0377 & 1.0352 & 1.3360 \\
\hline & HMA_UN_Equity & 1.0294 & 0.9872 & 0.9876 & 0.9873 & 2.7568 \\
\hline & IFF_UN_Equity & $0.9136^{* * *}$ & $0.9239^{* *}$ & $0.9236^{* *}$ & $0.9236^{* *}$ & 1.1266 \\
\hline & INTC_UW_Equity & 1.0258 & 0.9957 & 0.9965 & 0.9965 & 1.3077 \\
\hline & INTU_UW_Equity & $0.8413^{* * *}$ & $0.8329^{* * *}$ & $0.8358^{* * *}$ & $0.8358^{* * *}$ & 1.3151 \\
\hline & IP_UN_Equity & $0.8307^{* * *}$ & $0.8138^{* * *}$ & $0.8339^{* * *}$ & $0.8339^{* * *}$ & 1.4126 \\
\hline & IPG_UN_Equity & 1.0211 & 0.9723 & 0.9807 & 0.9795 & 2.4014 \\
\hline & IACI_UW_Equity & 0.9930 & $0.9649^{*}$ & $0.9653^{*}$ & $0.9653^{*}$ & 1.2444 \\
\hline & IR_UN_Equity & $0.9494^{* *}$ & $0.9456^{*}$ & $0.9462^{*}$ & $0.9461^{*}$ & 1.7668 \\
\hline & IRM_UN_Equity & 1.0155 & 1.0229 & 1.0257 & 1.0257 & 1.5449 \\
\hline & GRA_UN_Equity & $0.6714^{* * *}$ & $0.6969^{* * *}$ & $0.7035^{* * *}$ & $0.7035^{* * *}$ & 2.8123 \\
\hline & HBAN_UA_Equity & 1.0019 & 1.0067 & 0.9959 & 0.9960 & 1.9732 \\
\hline & ISRG_UW_Equity & $0.8638^{* * *}$ & $0.8678^{* * *}$ & $0.8679^{* * *}$ & $0.8679^{* * *}$ & 1.3729 \\
\hline & ITW_UN_Equity & $0.9603^{*}$ & $0.9501^{*}$ & $0.9520^{*}$ & $0.9520^{*}$ & 2.3051 \\
\hline & IVZ_UN_Equity & 1.2040 & 1.2081 & 1.1099 & 1.1099 & 2.2473 \\
\hline & HLS_UN_Equity & 1.0211 & 1.0245 & 1.0252 & 1.0252 & 2.5885 \\
\hline & JBL_UN_Equity & 1.0481 & 0.9953 & 1.0160 & 1.0150 & 1.7823 \\
\hline & JCI_UN_Equity & $0.8881^{* * *}$ & $0.9152^{* *}$ & $0.9139^{* *}$ & $0.9143^{* *}$ & 1.3396 \\
\hline & JCP_UN_Equity & 1.0439 & 1.1063 & 0.9734 & 0.9731 & 2.3895 \\
\hline & JEC_UN_Equity & 1.0182 & 1.0635 & 0.9940 & 0.9940 & 0.9263 \\
\hline & JBHT_UW_Equity & 0.9822 & 1.0010 & 1.0087 & 1.0087 & 1.4640 \\
\hline & ITT_UN_Equity & 1.0469 & 1.0418 & 1.0415 & 1.0415 & 3.2170 \\
\hline & JNJ_UN_Equity & 1.0305 & 1.0250 & 1.0256 & 1.0256 & 1.5478 \\
\hline & JNPR_UN_Equity & 1.0966 & 1.0979 & 1.0986 & 1.0986 & 2.3916 \\
\hline & JPM_UN_Equity & 1.0484 & 1.0450 & 1.0452 & 1.0452 & 1.7221 \\
\hline & JWN_UN_Equity & $0.8822^{* * *}$ & $0.9859^{* * *}$ & $0.8573^{* * *}$ & $0.8574^{* * *}$ & 1.5716 \\
\hline & K_UN_Equity & $0.9658^{*}$ & 0.9875 & $0.9732^{*}$ & $0.9732^{*}$ & 1.1935 \\
\hline & INTC_UQ_Equity & 1.0258 & 0.9957 & 0.9965 & 0.9965 & 1.3077 \\
\hline & KEY_UN_Equity & 1.0687 & 1.0713 & 1.0388 & 1.0388 & 1.5958 \\
\hline & INTU_UQ_Equity & $0.8413^{* * *}$ & $0.8329^{* * *}$ & $0.8358^{* * *}$ & $0.8358^{* * *}$ & 1.3151 \\
\hline & KIM_UN_Equity & 1.0293 & 1.0269 & 1.0273 & 1.0273 & 1.8359 \\
\hline & KLAC_UW_Equity & 0.9926 & 0.9889 & 0.9889 & 0.9889 & 2.0670 \\
\hline & JNS_UN_Equity & $0.8586^{* * *}$ & $0.8335^{* * *}$ & $0.8345^{* * *}$ & $0.8344^{* * *}$ & 1.4812 \\
\hline & KMB_UN_Equity & 1.0168 & 1.0263 & 1.0269 & 1.0269 & 1.6659 \\
\hline & JNY_UN_Equity & 1.0016 & 1.0082 & 1.0100 & 1.0099 & 1.2439 \\
\hline & KMX_UN_Equity & $0.9290^{* *}$ & $0.9492^{*}$ & $0.9485^{*}$ & $0.9483^{*}$ & 3.4278 \\
\hline & JOY_UW_Equity & 1.0460 & 1.0076 & 1.0010 & 0.9994 & 2.5214 \\
\hline & KO_UN_Equity & $0.9259^{* *}$ & $0.9236^{* *}$ & $0.9237^{* *}$ & $0.9237^{* *}$ & 1.1541 \\
\hline & KR_UN_Equity & 0.9802 & $0.9485^{* *}$ & $0.9494^{* *}$ & $0.9493^{* *}$ & 1.4572 \\
\hline & KBH_UN_Equity & 1.0135 & 1.0413 & 1.0033 & 1.0050 & 1.8796 \\
\hline & KSS_UN_Equity & 1.0036 & 1.1320 & 1.0272 & 1.0272 & 0.9677 \\
\hline & KSU_UN_Equity & $0.7068^{* * *}$ & $0.7056^{* * *}$ & $0.7324^{* * *}$ & $0.7368^{* * *}$ & 1.1123 \\
\hline & L_UN_Equity & $0.7649^{* * *}$ & $0.7765^{* * *}$ & $0.7679^{* * *}$ & $0.7679^{* * *}$ & 0.9498 \\
\hline & LB_UN_Equity & $0.8206^{* * *}$ & $0.8966^{* * *}$ & $0.7733^{* * *}$ & $0.7764^{* * *}$ & 0.9513 \\
\hline & LEG_UN_Equity & $0.9765^{* *}$ & $0.9912^{* *}$ & $0.9707^{*}$ & $0.9706^{*}$ & 1.5856 \\
\hline & LDOS_UN_Equity & 1.0566 & 1.0195 & 1.0022 & 1.0005 & 4.7448 \\
\hline & LEN_UN_Equity & 0.9974 & 1.0629 & 1.0117 & 1.0159 & 3.7442 \\
\hline & LH_UN_Equity & 1.0045 & 0.9881 & 0.9890 & 0.9890 & 1.3362 \\
\hline & LLL_UN_Equity & 1.0585 & 1.0304 & 1.0308 & 1.0308 & 1.7209 \\
\hline & LLTC_UW_Equity & $0.9684^{*}$ & 0.9665 & 0.9670 & 0.9670 & 1.8858 \\
\hline & LLY_UN_Equity & 0.9766 & $0.9604^{*}$ & $0.9608^{*}$ & $0.9608^{*}$ & 1.4826 \\
\hline & LM_UN_Equity & 1.0217 & 1.0118 & 1.0101 & 1.0084 & 2.1247 \\
\hline & LMT_UN_Equity & $0.9379^{* *}$ & $0.9459^{* *}$ & $0.9166^{* * *}$ & $0.9077^{* * *}$ & 1.6905 \\
\hline & KLAC_UQ_Equity & 0.9926 & 0.9889 & 0.9889 & 0.9889 & 2.0670 \\
\hline & LNC_UN_Equity & $0.9729^{* *}$ & $0.9516^{* *}$ & $0.9494^{* *}$ & $0.9494^{* *}$ & 1.3684 \\
\hline & LO_UN_Equity & 0.9534 & 0.9600 & 0.9624 & 0.9628 & 2.1162 \\
\hline & LOW_UN_Equity & 1.0136 & 1.0154 & 1.0163 & 1.0162 & 1.5192 \\
\hline & LRCX_UW_Equity & 0.9797 & 0.9768 & 0.9777 & 0.9777 & 1.4741 \\
\hline & LUV_UN_Equity & $0.9523^{*}$ & 0.9918 & 1.0252 & 1.0252 & 1.8074 \\
\hline & LSI_UN_Equity & 1.0122 & 0.9944 & 0.9975 & 0.9958 & 1.6641 \\
\hline & M_UN_Equity & 1.0063 & 1.2122 & 1.0237 & 1.0252 & 1.2499 \\
\hline & MA_UN_Equity & 1.0059 & 1.0423 & 1.0290 & 1.0289 & 1.2785 \\
\hline & LXK_UN_Equity & 1.0955 & 1.0906 & 1.0488 & 1.0486 & 1.2930 \\
\hline & MAC_UN_Equity & $0.7164^{* * *}$ & $0.8458^{* * *}$ & $0.8655^{* * *}$ & $0.8823^{* * *}$ & 2.0892 \\
\hline & MAR_UN_Equity & 1.0370 & 1.0286 & 1.0269 & 1.0267 & 1.6484 \\
\hline & MAS_UN_Equity & $0.8581^{* * *}$ & $0.8579^{* * *}$ & $0.8717^{* * *}$ & $0.8715^{* * *}$ & 1.9255 \\
\hline
\end{tabular}

(Continues on next page) 


\begin{tabular}{|c|c|c|c|c|c|c|}
\hline Index & Bloomberg Ticker & DMA & DMS & BMA & BMS & OLS \\
\hline & MAT_UW_Equity & $0.7986^{*}$ & $0.6937^{* *}$ & $0.8393^{* *}$ & $0.8964^{*}$ & 1.2941 \\
\hline & LLTC_UQ_Equity & $0.9684^{*}$ & 0.9665 & 0.9670 & 0.9670 & 1.8858 \\
\hline & MCD_UN_Equity & $0.9105^{* * *}$ & $0.9187^{* * *}$ & $0.9144^{* * *}$ & $0.9143^{* * *}$ & 1.1667 \\
\hline & MCHP_UW_Equity & $0.8841^{* * *}$ & $0.8618^{* * *}$ & $0.9349^{* *}$ & $0.9349^{* *}$ & 1.2394 \\
\hline & LPX_UN_Equity & $0.9737^{*}$ & 1.0985 & 0.9848 & 1.0086 & 2.6528 \\
\hline & MCK_UN_Equity & $0.9459^{* *}$ & $0.9380^{* *}$ & $0.9388^{* *}$ & $0.9388^{* *}$ & 1.3332 \\
\hline & MCO_UN_Equity & 1.0744 & 1.0374 & 1.0357 & 1.0351 & 2.5244 \\
\hline & MBI_UN_Equity & $0.8849^{* *}$ & $0.9441^{*}$ & $0.8751^{* * *}$ & $0.8751^{* * *}$ & 1.4129 \\
\hline & MDT_UN_Equity & 1.0625 & 1.0337 & 1.0352 & 1.0350 & 2.0505 \\
\hline & MDLZ_UN_Equity & 1.0396 & 1.0392 & 1.0407 & 1.0407 & 4.0393 \\
\hline & MET_UN_Equity & 1.0188 & 1.0087 & 1.0093 & 1.0091 & 1.5013 \\
\hline & MDP_UN_Equity & 1.0194 & 1.0357 & 1.0365 & 1.0364 & 1.7694 \\
\hline & MHFI_UN_Equity & 1.0118 & 1.0557 & 1.0353 & 1.0367 & 2.2207 \\
\hline & MJN_UN_Equity & 1.0811 & 1.0767 & 1.0589 & 1.0589 & 2.6459 \\
\hline & MHK_UN_Equity & $0.9660^{*}$ & 1.0203 & 1.0291 & 1.0290 & 2.0876 \\
\hline & MKC_UN_Equity & $0.9661^{*}$ & $0.9648^{*}$ & $0.9660^{*}$ & $0.9660^{*}$ & 1.3438 \\
\hline & MMC_UN_Equity & 0.9974 & 1.0443 & 1.0435 & 1.0435 & 1.7533 \\
\hline & MMM_UN_Equity & $0.9543^{*}$ & $0.9747^{*}$ & 0.9771 & 0.9776 & 1.5825 \\
\hline & MLM_UN_Equity & 1.0411 & 1.1045 & 1.0341 & 1.0341 & 1.1970 \\
\hline & MO_UN_Equity & 1.0060 & 0.9980 & 0.9997 & 0.9997 & 1.6047 \\
\hline & MHS_UN_Equity & 1.0484 & 1.0417 & 1.0432 & 1.0430 & 1.3844 \\
\hline & MOLX_UW_Equity & 1.0211 & 1.0162 & 1.0167 & 1.0167 & 1.5945 \\
\hline & MON_UN_Equity & $0.9946^{* *}$ & 1.0468 & 1.0045 & 1.0046 & 1.4290 \\
\hline & MOS_UN_Equity & $0.9111^{* * *}$ & $0.8993^{* * *}$ & $0.8996^{* * *}$ & $0.8995^{* * *}$ & 2.1287 \\
\hline & MNST_UW_Equity & 1.0834 & 1.0152 & 1.0157 & 1.0156 & 1.3722 \\
\hline & MRK_UN_Equity & 0.9975 & 0.9972 & 0.9979 & 0.9979 & 1.5811 \\
\hline & MRO_UN_Equity & 0.9759 & $0.9423^{* *}$ & $0.9447^{* *}$ & $0.9447^{* *}$ & 1.4781 \\
\hline & MS_UN_Equity & $0.8860^{* * *}$ & $0.8831^{* * *}$ & $0.8806^{* * *}$ & $0.8806^{* * *}$ & 1.3322 \\
\hline & MSFT_UW_Equity & 1.0700 & 1.0986 & 1.0519 & 1.0519 & 1.1066 \\
\hline & MSI_UN_Equity & 1.1289 & 2.4973 & $0.8079^{* * *}$ & $0.8069^{* * *}$ & 1.6769 \\
\hline & MTB_UN_Equity & $0.9467^{*}$ & $0.9436^{* *}$ & $0.9425^{* *}$ & $0.9424^{* *}$ & 1.5558 \\
\hline & MDR_UN_Equity & $0.9314^{* * *}$ & 1.1186 & $0.8692^{* * *}$ & $0.8693^{* * *}$ & 2.8299 \\
\hline & MU_UW_Equity & $0.9627^{*}$ & 0.9616 & 0.9803 & 0.9801 & 1.2460 \\
\hline & MUR_UN_Equity & $0.9263^{* *}$ & $0.9269^{* *}$ & $0.9278^{* *}$ & $0.9278^{* *}$ & 1.3526 \\
\hline & MWV_UN_Equity & $0.9275^{* *}$ & $0.9048^{* * *}$ & $0.9037^{* * *}$ & $0.9037^{* * *}$ & 1.6343 \\
\hline & MYL_UW_Equity & 0.9649 & 0.9621 & 0.9616 & 0.9616 & 1.1164 \\
\hline & NBL_UN_Equity & $0.9489^{*}$ & $0.9404^{* *}$ & $0.9416^{* *}$ & $0.9416^{* *}$ & 1.4849 \\
\hline & NBR_UN_Equity & $0.9586^{*}$ & $0.9461^{*}$ & 0.9671 & 0.9672 & 3.0251 \\
\hline & NDAQ_UW_Equity & 1.0495 & 1.0235 & 1.0236 & 1.0236 & 1.7380 \\
\hline & MTW_UN_Equity & $0.9879^{*}$ & 1.0518 & 1.0225 & 1.0227 & 1.1122 \\
\hline & NE_UN_Equity & $0.9480^{*}$ & $0.8994^{* *}$ & $0.9001^{* *}$ & $0.9001^{* *}$ & 1.6479 \\
\hline & NEE_UN_Equity & 1.0286 & 1.0018 & 0.9988 & 0.9988 & 1.4054 \\
\hline & MOLX_UQ_Equity & 1.0211 & 1.0162 & 1.0167 & 1.0167 & 1.5945 \\
\hline & MTG_UN_Equity & 1.0606 & 1.0552 & $0.9819^{* *}$ & 1.0082 & 14.0578 \\
\hline & NEM_UN_Equity & $0.9379^{*}$ & $0.9613^{*}$ & $0.9352^{* *}$ & $0.9361^{* *}$ & 1.5580 \\
\hline & NFLX_UW_Equity & 1.1568 & 1.3833 & 1.1867 & 1.1912 & 2.5890 \\
\hline & NFX_UN_Equity & $0.9103^{* * *}$ & $0.8953^{* * *}$ & $0.8953^{* * *}$ & $0.8953^{* * *}$ & 1.4166 \\
\hline & NI_UN_Equity & $0.9552^{*}$ & 0.9890 & 0.9905 & 0.9905 & 1.1331 \\
\hline & NKE_UN_Equity & 1.0575 & 1.0349 & 1.0352 & 1.0352 & 1.8815 \\
\hline & MSFT_UQ_Equity & 1.0700 & 1.0986 & 1.0519 & 1.0519 & 1.1066 \\
\hline & NOC_UN_Equity & 1.0382 & 1.0254 & 1.0273 & 1.0270 & 1.5343 \\
\hline & NOV_UN_Equity & $0.8450^{* * *}$ & $0.8097^{* * *}$ & $0.8105^{* * *}$ & $0.8101^{* * *}$ & 1.8206 \\
\hline & MXIM_UW_Equity & $0.8732^{* * *}$ & $0.8782^{* * *}$ & $0.8550^{* * *}$ & $0.8550^{* * *}$ & 1.1489 \\
\hline & NRG_UN_Equity & 1.0271 & 0.9954 & 0.9969 & 0.9959 & 2.6253 \\
\hline & NSC_UN_Equity & $0.8391^{* * *}$ & $0.8691^{* * *}$ & $0.8850^{* * *}$ & $0.8849^{* * *}$ & 1.5667 \\
\hline & NTAP_UW_Equity & $0.8164^{* * *}$ & $0.7988^{* * *}$ & $0.7971^{* * *}$ & $0.7968^{* * *}$ & 1.1477 \\
\hline & NTRS_UW_Equity & 1.0009 & 1.0243 & 1.0175 & 1.0175 & 1.8920 \\
\hline & NAV_UN_Equity & 0.9832 & 0.9908 & $0.9598^{*}$ & $0.9558^{*}$ & 1.5042 \\
\hline & NCR_UN_Equity & 1.0553 & 1.1144 & 0.9974 & $0.9711^{*}$ & 1.5354 \\
\hline & NUE_UN_Equity & 0.9833 & $0.9652^{*}$ & 0.9651 & 0.9649 & 2.1720 \\
\hline & NVDA_UW_Equity & 0.9738 & $0.9704^{*}$ & 1.0688 & 1.0689 & 1.5151 \\
\hline & MXIM_UQ_Equity & $0.8732^{* * *}$ & $0.8782^{* * *}$ & $0.8550^{* * *}$ & $0.8550^{* * *}$ & 1.1489 \\
\hline & NWL_UN_Equity & 1.0450 & 1.0270 & 1.0274 & 1.0272 & 2.3109 \\
\hline & NYX_UN_Equity & 1.0011 & 0.9928 & 0.9950 & 0.9950 & 1.4677 \\
\hline & OI_UN_Equity & 1.0300 & 1.0177 & 1.0149 & 1.0148 & 1.7196 \\
\hline & NC_UN_Equity & 0.9748 & 1.0124 & 1.0189 & 1.0174 & 1.7391 \\
\hline & NYT_UN_Equity & 1.0609 & 1.0436 & 1.0439 & 1.0437 & 2.0713 \\
\hline & OKE_UN_Equity & $0.8579^{* * *}$ & $0.8219^{* * *}$ & $0.8218^{* * *}$ & $0.8211^{* * *}$ & 1.3025 \\
\hline & OMC_UN_Equity & 0.9748 & 0.9849 & 0.9867 & 0.9866 & 1.9626 \\
\hline
\end{tabular}

(Continues on next page) 


\begin{tabular}{|c|c|c|c|c|c|c|}
\hline Index & Bloomberg Ticker & DMA & DMS & BMA & BMS & OLS \\
\hline & O_UN_Equity & $0.9392^{* *}$ & 0.9690 & 0.9813 & 0.9812 & 1.3659 \\
\hline & ORLY_UW_Equity & 0.9895 & 1.0125 & 1.0019 & 1.0019 & 1.1983 \\
\hline & ORCL_UW_Equity & 0.9495 & 0.9505 & 0.9512 & 0.9512 & 1.7952 \\
\hline & OXY_UN_Equity & $0.8700^{* * *}$ & $0.8495^{* * *}$ & $0.8503^{* * *}$ & $0.8502^{* * *}$ & 1.4065 \\
\hline & PAYX_UW_Equity & 1.0523 & 1.0316 & 1.0322 & 1.0322 & 1.5599 \\
\hline & PBCT_UW_Equity & 1.0042 & 1.0159 & 1.0132 & 1.0132 & 2.3684 \\
\hline & PBI_UN_Equity & 1.0469 & 1.0271 & 1.0283 & 1.0282 & 2.5303 \\
\hline & PCAR_UW_Equity & $0.9375^{* *}$ & 1.0307 & 1.0375 & 1.0375 & 1.3584 \\
\hline & PCG_UN_Equity & 1.0033 & 1.0090 & 1.0061 & 1.0061 & 1.7362 \\
\hline & PCL_UN_Equity & 1.0161 & 1.0432 & 1.0060 & 1.0064 & 2.0997 \\
\hline & OMX_UN_Equity & 1.0628 & 1.0454 & 1.0457 & 1.0455 & 2.5854 \\
\hline & PCLN_UW_Equity & $0.7477^{* * *}$ & $0.7390^{* * *}$ & $0.7501^{* * *}$ & $0.7501^{* * *}$ & 1.0984 \\
\hline & NTAP_UQ_Equity & $0.8164^{* * *}$ & $0.7988^{* * *}$ & $0.7971^{* * *}$ & $0.7968^{* * *}$ & 1.1477 \\
\hline & PCP_UN_Equity & $0.8876^{* *}$ & $0.9973^{*}$ & $0.8373^{* * *}$ & $0.8300^{* * *}$ & 1.6305 \\
\hline & NTRS_UQ_Equity & 1.0009 & 1.0243 & 1.0175 & 1.0175 & 1.8920 \\
\hline & PDCO_UW_Equity & $0.9005^{* *}$ & $0.8986^{* *}$ & $0.8995^{* *}$ & $0.8995^{* *}$ & 1.3164 \\
\hline & PEG_UN_Equity & 1.0327 & 1.0551 & 1.0265 & 1.0264 & 1.4044 \\
\hline & NVDA_UQ_Equity & 0.9738 & $0.9704^{*}$ & 1.0688 & 1.0689 & 1.5151 \\
\hline & PEP_UN_Equity & 0.9914 & 0.9794 & 0.9811 & 0.9810 & 1.3916 \\
\hline & PETM_UW_Equity & 1.0300 & 1.0149 & 1.0158 & 1.0158 & 1.3688 \\
\hline & NVDA_UA_Equity & 1.0275 & 1.0969 & 1.0266 & 1.0266 & 1.5229 \\
\hline & PFE_UN_Equity & 0.9772 & 0.9834 & 0.9847 & 0.9846 & 1.3168 \\
\hline & PFG_UN_Equity & $0.9089^{* *}$ & $0.9092^{* *}$ & $0.8970^{* * *}$ & $0.8968^{* * *}$ & 4.0193 \\
\hline & PG_UN_Equity & 0.9850 & 1.0088 & 0.9860 & 0.9860 & 1.4176 \\
\hline & PGR_UN_Equity & 1.0107 & 1.0002 & 1.0007 & 1.0007 & 1.2131 \\
\hline & ORCL_UQ_Equity & 0.9495 & 0.9505 & 0.9512 & 0.9512 & 1.7952 \\
\hline & PH_UN_Equity & $0.9692^{*}$ & $0.9352^{* *}$ & $0.9385^{* *}$ & $0.9339^{* *}$ & 1.7702 \\
\hline & PHM_UN_Equity & $0.7053^{* * *}$ & $0.8447^{* * *}$ & $0.7643^{* * *}$ & $0.7986^{* * *}$ & 1.9281 \\
\hline & PAYX_UQ_Equity & 1.0523 & 1.0316 & 1.0322 & 1.0322 & 1.5599 \\
\hline & PLL_UN_Equity & $0.9397^{* *}$ & $0.9396^{* *}$ & 0.9788 & 0.9788 & 1.3697 \\
\hline & PCAR_UQ_Equity & $0.9375^{* *}$ & 1.0307 & 1.0375 & 1.0375 & 1.3584 \\
\hline & PM_UN_Equity & $0.7689^{* * *}$ & $0.8294^{* * *}$ & $0.8140^{* * *}$ & $0.8140^{* * *}$ & 0.8858 \\
\hline & PNC_UN_Equity & 1.0263 & 0.9824 & 0.9796 & 0.9796 & 1.8772 \\
\hline & PNW_UN_Equity & $0.9401^{* *}$ & $0.9546^{*}$ & $0.9446^{* *}$ & $0.9445^{* *}$ & 1.1904 \\
\hline & PDCO_UQ_Equity & $0.9005^{* *}$ & $0.8986^{* *}$ & $0.8995^{* *}$ & $0.8995^{* *}$ & 1.3164 \\
\hline & POM_UN_Equity & $0.8517^{* * *}$ & $0.8397^{* * *}$ & $0.8384^{* * *}$ & $0.8384^{* * *}$ & 1.2668 \\
\hline & PBY_UN_Equity & $0.9599 * *$ & 0.9850 & 0.9938 & 0.9937 & 1.4607 \\
\hline & PPG_UN_Equity & 0.9948 & 0.9909 & 0.9915 & 0.9915 & 1.7182 \\
\hline & PPL_UN_Equity & 1.0548 & 1.0201 & 1.0188 & 1.0187 & 1.3606 \\
\hline & PMCS_UW_Equity & 1.0262 & 1.0309 & 1.0311 & 1.0311 & 2.2310 \\
\hline & PRU_UN_Equity & $0.9087^{* * *}$ & $0.9044^{* *}$ & $0.9046^{* *}$ & $0.9046^{* *}$ & 2.0017 \\
\hline & PRGO_UW_Equity & $0.8398^{* *}$ & $0.8616^{* * *}$ & $0.8430^{* * *}$ & $0.8430^{* * *}$ & 2.0997 \\
\hline & PSA_UN_Equity & $0.9119^{* * *}$ & 0.9922 & 0.9705 & 0.9705 & 1.0557 \\
\hline & PWR_UN_Equity & 1.1146 & 1.0381 & 1.0271 & 1.0271 & 2.8584 \\
\hline & PVH_UN_Equity & 1.1117 & 0.9728 & $0.9371^{* *}$ & $0.9680^{*}$ & 1.6879 \\
\hline & PX_UN_Equity & $0.8870^{* * *}$ & 1.0020 & $0.9405^{* *}$ & $0.9441^{* *}$ & 1.6404 \\
\hline & PXD_UN_Equity & $0.9345^{* *}$ & $0.9502^{* *}$ & $0.9503^{* *}$ & $0.9503^{* *}$ & 1.4499 \\
\hline & QCOM_UW_Equity & $0.9635^{*}$ & 1.0099 & 0.9861 & 0.9861 & 1.4925 \\
\hline & QLGC_UW_Equity & $0.9459^{* *}$ & 1.0091 & 1.0127 & 1.0125 & 1.8708 \\
\hline & PMCS_UQ_Equity & 1.0262 & 1.0309 & 1.0311 & 1.0311 & 2.2310 \\
\hline & R_UN_Equity & $0.9497^{* * *}$ & 1.0307 & 0.9773 & 0.9789 & 1.5829 \\
\hline & QEP_UN_Equity & 1.0184 & 1.0235 & 1.0244 & 1.0249 & 4.0792 \\
\hline & PTC_UW_Equity & $0.9728^{*}$ & $0.9813^{*}$ & 0.9732 & 0.9753 & 1.4084 \\
\hline & RAI_UN_Equity & $0.9421^{* *}$ & $0.9475^{* *}$ & $0.9534^{* *}$ & $0.9533^{* *}$ & 1.3902 \\
\hline & RDC_UN_Equity & $0.7476^{* * *}$ & $0.8068^{* * *}$ & $0.7357^{* * *}$ & $0.7354^{* * *}$ & 0.9864 \\
\hline & RHI_UN_Equity & 1.0560 & 1.0853 & 1.0317 & 1.0315 & 2.4892 \\
\hline & REGN_UW_Equity & 1.0132 & 1.0112 & 1.0024 & 1.0023 & 1.8908 \\
\hline & RCL_UN_Equity & $0.9885^{* *}$ & $0.9317^{* *}$ & $0.9347^{* *}$ & $0.9340^{* *}$ & 4.4927 \\
\hline & RIG_UN_Equity & 1.0313 & 0.9556 & $0.9485^{*}$ & $0.9485^{*}$ & 1.7294 \\
\hline & RHT_UN_Equity & $0.9053^{* *}$ & $0.9326^{* *}$ & $0.9133^{* *}$ & $0.9164^{* *}$ & 1.6457 \\
\hline & PTC_UQ_Equity & $0.9728^{*}$ & $0.9813^{*}$ & 0.9732 & 0.9753 & 1.4084 \\
\hline & RL_UN_Equity & $0.8263^{* * *}$ & $0.8515^{* * *}$ & $0.8362^{* * *}$ & $0.8362^{* * *}$ & 1.1228 \\
\hline & ROK_UN_Equity & $0.8625^{* * *}$ & $0.8541^{* * *}$ & $0.8542^{* * *}$ & $0.8542^{* * *}$ & 1.5530 \\
\hline & ROP_UN_Equity & 0.9680 & 0.9677 & 0.9699 & 0.9698 & 1.3812 \\
\hline & PWER_UQ_Equity & $0.7596^{* * *}$ & $0.9016^{* * *}$ & 1.0801 & 1.1610 & 2.0253 \\
\hline & RRC_UN_Equity & 1.0614 & 0.9956 & 0.9962 & 0.9962 & 1.2223 \\
\hline & ROST_UW_Equity & 1.0288 & 1.0345 & 1.0108 & 1.0112 & 1.3786 \\
\hline & QCOM_UQ_Equity & $0.9635^{*}$ & 1.0099 & 0.9861 & 0.9861 & 1.4925 \\
\hline & RRD_UW_Equity & 1.1211 & 1.1235 & 1.1238 & 1.1241 & 3.0239 \\
\hline
\end{tabular}

(Continues on next page) 


\begin{tabular}{|c|c|c|c|c|c|c|}
\hline Index & Bloomberg Ticker & DMA & DMS & BMA & BMS & OLS \\
\hline & QLGC_UQ_Equity & $0.9459^{* *}$ & 1.0091 & 1.0127 & 1.0125 & 1.8708 \\
\hline & RTN_UN_Equity & 1.0015 & 0.9988 & 1.0005 & 1.0005 & 1.4673 \\
\hline & RSG_UN_Equity & $0.9515^{* *}$ & $0.9308^{* *}$ & $0.9317^{* *}$ & $0.9317^{* *}$ & 1.6040 \\
\hline & SBUX_UW_Equity & $0.9887^{* *}$ & $0.9579 *$ & $0.9581^{*}$ & $0.9581^{*}$ & 3.8363 \\
\hline & RAD_UN_Equity & 1.0901 & 1.1845 & 1.0177 & 1.0175 & 2.7023 \\
\hline & SANM_UW_Equity & $0.9734^{* *}$ & $0.9706^{* *}$ & $0.9438^{* *}$ & $0.9438^{* *}$ & 1.4517 \\
\hline & SE_UN_Equity & 1.0177 & 0.9990 & 0.9989 & 0.9989 & 1.7644 \\
\hline & SCG_UN_Equity & 0.9911 & 0.9761 & 0.9767 & 0.9767 & 1.4333 \\
\hline & SEE_UN_Equity & 1.0631 & 1.0322 & 1.0337 & 1.0337 & 5.3094 \\
\hline & SCHW_UN_Equity & $0.9171^{* * *}$ & $0.9022^{* * *}$ & $0.8978^{* * *}$ & $0.8978^{* * *}$ & 1.7515 \\
\hline & SHLD_UW_Equity & $0.9202^{* *}$ & $0.9096^{* *}$ & 1.0434 & 1.0263 & 14.1374 \\
\hline & SHW_UN_Equity & 1.0185 & 1.0024 & 1.0042 & 1.0037 & 2.2915 \\
\hline & SIAL_UW_Equity & 1.0226 & 0.9742 & 0.9774 & 0.9774 & 2.1350 \\
\hline & SLB_UN_Equity & 1.0005 & $0.9430^{* *}$ & $0.9313^{* *}$ & $0.9313^{* *}$ & 3.4997 \\
\hline & SJM_UN_Equity & $0.8651^{* * *}$ & $0.8893^{* * *}$ & $0.8895^{* * *}$ & $0.8894^{* * *}$ & 1.2695 \\
\hline & SANM_UQ_Equity & $0.9734^{* *}$ & $0.9706^{* *}$ & $0.9438^{* *}$ & $0.9438^{* *}$ & 1.4517 \\
\hline & SNA_UN_Equity & 1.0754 & 1.0802 & 1.0397 & 1.0388 & 1.5295 \\
\hline & SBUX_UQ_Equity & $0.9887^{* *}$ & $0.9579^{*}$ & $0.9581^{*}$ & $0.9581^{*}$ & 3.8363 \\
\hline & SNDK_UW_Equity & $0.9202^{* * *}$ & $0.9201^{* * *}$ & $0.8941^{* * *}$ & $0.8942^{* * *}$ & 1.4768 \\
\hline & SLG_UN_Equity & $0.7313^{* * *}$ & $0.7529^{* * *}$ & $0.6712^{* * *}$ & $0.6692^{* * *}$ & 5.0845 \\
\hline & SNV_UN_Equity & 1.1323 & 1.0639 & 1.0894 & 1.0743 & 8.4839 \\
\hline & SO_UN_Equity & $0.9672^{*}$ & $0.9701^{*}$ & $0.9704^{*}$ & $0.9703^{*}$ & 1.3091 \\
\hline & SNI_UN_Equity & 1.0513 & 1.0514 & 1.0573 & 1.0574 & 0.9497 \\
\hline & SAPE_UQ_Equity & $0.9480^{*}$ & 0.9972 & 0.9726 & 0.9735 & 1.2380 \\
\hline & SHLD_UQ_Equity & $0.9202^{* *}$ & $0.9096^{* *}$ & 1.0434 & 1.0263 & 14.1374 \\
\hline & SPG_UN_Equity & $0.8033^{* * *}$ & $0.8354^{* * *}$ & $0.8370^{* * *}$ & $0.8370^{* * *}$ & 1.5916 \\
\hline & SPLS_UW_Equity & 1.2883 & 1.2240 & 1.0897 & 1.0234 & 3.4213 \\
\hline & SIAL_UQ_Equity & 1.0226 & 0.9742 & 0.9774 & 0.9774 & 2.1350 \\
\hline & SRE_UN_Equity & 1.0490 & 1.0285 & 1.0282 & 1.0282 & 1.9897 \\
\hline & SRCL_UW_Equity & $0.8132^{* * *}$ & $0.8970^{* * *}$ & $0.8707^{* * *}$ & $0.8710^{* * *}$ & 0.9118 \\
\hline & SCI_UN_Equity & $0.8173^{* * *}$ & $0.7822^{* * *}$ & $0.8149^{* * *}$ & $0.8149^{* * *}$ & 1.7421 \\
\hline & SSP_UN_Equity & 1.0069 & 1.0825 & 1.0331 & 1.0334 & 1.3914 \\
\hline & STI_UN_Equity & 1.0509 & 1.0176 & 1.0170 & 1.0170 & 2.2641 \\
\hline & STJ_UN_Equity & 1.0257 & 1.0032 & 1.0043 & 1.0043 & 1.4214 \\
\hline & SNDK_UQ_Equity & $0.9202^{* * *}$ & $0.9201^{* * *}$ & $0.8941^{* * *}$ & $0.8942^{* * *}$ & 1.4768 \\
\hline & STR_UN_Equity & $0.8556^{* * *}$ & $0.8682^{* * *}$ & $0.8430^{* * *}$ & $0.8430^{* * *}$ & 1.0758 \\
\hline & STT_UN_Equity & 1.0819 & 1.0773 & 1.0649 & 1.0648 & 2.7357 \\
\hline & STZ_UN_Equity & 1.0538 & 1.0561 & 1.0376 & 1.0372 & 1.2844 \\
\hline & SUNE_UN_Equity & 1.0199 & 1.0316 & 1.0278 & 1.0278 & 2.3058 \\
\hline & SVU_UN_Equity & 1.0430 & 1.0244 & 1.0246 & 1.0245 & 1.7750 \\
\hline & SWK_UN_Equity & $0.9870^{* *}$ & $0.9600^{*}$ & $0.9603^{*}$ & $0.9603^{*}$ & 1.2792 \\
\hline & SWN_UN_Equity & 1.0163 & 0.9851 & 0.9855 & 0.9853 & 1.6511 \\
\hline & SPLS_UQ_Equity & 1.2883 & 1.2240 & 1.0897 & 1.0234 & 3.4213 \\
\hline & SWY_UN_Equity & 1.0496 & 1.0264 & 1.0277 & 1.0276 & 1.4358 \\
\hline & SWKS_UW_Equity & $0.9953^{*}$ & $0.9753^{*}$ & $0.9755^{*}$ & $0.9755^{*}$ & 2.9398 \\
\hline & SPLS_UA_Equity & 0.9849 & 0.9751 & 0.9802 & 0.9749 & 1.5761 \\
\hline & SYK_UN_Equity & 1.0317 & 0.9998 & 0.9993 & 0.9993 & 1.4123 \\
\hline & SYMC_UW_Equity & 1.0014 & 1.1579 & 1.0231 & 1.0254 & 1.2715 \\
\hline & SYY_UN_Equity & 0.9890 & 1.0073 & 1.0132 & 1.0132 & 2.0510 \\
\hline & T_UN_Equity & 1.0086 & 1.0390 & 1.0155 & 1.0154 & 1.4429 \\
\hline & TAP_UN_Equity & 1.0493 & 1.0348 & 1.0346 & 1.0345 & 1.4759 \\
\hline & TDC_UN_Equity & $0.8061^{* * *}$ & $0.8231^{* * *}$ & $0.8191^{* * *}$ & $0.8191^{* * *}$ & 1.5245 \\
\hline & TE_UN_Equity & $0.7698^{* * *}$ & $0.7809^{* * *}$ & $0.7793^{* * *}$ & $0.7792^{* * *}$ & 1.0675 \\
\hline & TEG_UN_Equity & $0.8662^{* *}$ & $0.9462^{* * *}$ & $0.8736^{* * *}$ & $0.8736^{* * *}$ & 1.0850 \\
\hline & TEL_UN_Equity & 1.0420 & 1.0402 & 1.0423 & 1.0422 & 1.5976 \\
\hline & SYMC_UQ_Equity & 1.0014 & 1.1579 & 1.0231 & 1.0254 & 1.2715 \\
\hline & TER_UN_Equity & $0.8689^{* * *}$ & $0.8611^{* * *}$ & $0.8612^{* * *}$ & $0.8612^{* * *}$ & 1.0829 \\
\hline & TGT_UN_Equity & 1.0612 & 1.0240 & 1.0300 & 1.0300 & 1.3221 \\
\hline & TEX_UN_Equity & 1.1476 & 1.0222 & 1.0221 & 1.0224 & 1.5322 \\
\hline & THC_UN_Equity & $0.9222^{* * *}$ & $0.8919^{* * *}$ & $0.8638^{* * *}$ & $0.8602^{* * *}$ & 1.3818 \\
\hline & TIE_UN_Equity & 0.9617 & 0.9535 & 0.9501 & 0.9497 & 2.4641 \\
\hline & TIF_UN_Equity & $0.9196^{* *}$ & $0.9235^{* *}$ & $0.9215^{* *}$ & $0.9237^{* *}$ & 1.7619 \\
\hline & TJX_UN_Equity & 0.9974 & 0.9851 & 0.9858 & 0.9858 & 1.5249 \\
\hline & TMK_UN_Equity & $0.8780^{* * *}$ & $0.9025^{* *}$ & $0.9029^{* *}$ & $0.9028^{* *}$ & 1.2235 \\
\hline & TMO_UN_Equity & 0.9917 & 1.0052 & 0.9959 & 0.9957 & 1.5335 \\
\hline & TIN_UN_Equity & 1.0626 & 1.0597 & 1.0614 & 1.0612 & 2.1024 \\
\hline & TLAB_UW_Equity & 1.0225 & 0.9920 & 0.9947 & 0.9942 & 4.6413 \\
\hline & TROW_UW_Equity & $0.9279^{* *}$ & $0.9127^{* *}$ & $0.9136^{* *}$ & $0.9135^{* *}$ & 1.5424 \\
\hline & TRV_UN_Equity & 0.9602 & 1.0081 & 1.0079 & 1.0079 & 1.7425 \\
\hline
\end{tabular}

(Continues on next page) 


\begin{tabular}{|c|c|c|c|c|c|c|}
\hline Index & Bloomberg Ticker & DMA & DMS & BMA & BMS & OLS \\
\hline & TKR_UN_Equity & $0.8188^{* * *}$ & $0.8270^{* * *}$ & $0.8270^{* * *}$ & $0.8270^{* * *}$ & 1.4560 \\
\hline & TSN_UN_Equity & 1.0523 & 1.0418 & 1.0413 & 1.0413 & 1.5908 \\
\hline & TSCO_UW_Equity & $0.9168^{* * *}$ & $0.9188^{* *}$ & $0.9224^{* *}$ & $0.9224^{* *}$ & 1.2617 \\
\hline & TLAB_UQ_Equity & 1.0225 & 0.9920 & 0.9947 & 0.9942 & 4.6413 \\
\hline & TSO_UN_Equity & 1.0129 & 1.0257 & 1.0261 & 1.0260 & 1.1122 \\
\hline & TSS_UN_Equity & 1.0753 & 1.1897 & 1.0428 & 1.0428 & 1.4988 \\
\hline & TWC_UN_Equity & 0.9985 & 1.0305 & 1.0308 & 1.0308 & 1.0696 \\
\hline & TNB_UN_Equity & 1.0353 & 1.0346 & 1.0376 & 1.0376 & 1.3763 \\
\hline & TWX_UN_Equity & 1.0370 & 1.0145 & 1.0152 & 1.0152 & 3.0163 \\
\hline & TXT_UN_Equity & 1.0154 & 1.1685 & 1.0423 & 1.0577 & 1.8119 \\
\hline & TROW_UQ_Equity & $0.9279 * *$ & $0.9127^{* *}$ & $0.9136^{* *}$ & $0.9135^{* *}$ & 1.5424 \\
\hline & TYC_UN_Equity & $0.8954^{* * *}$ & $0.8706^{* * *}$ & $0.8724^{* * *}$ & $0.8710^{* * *}$ & 2.0678 \\
\hline & TXN_UN_Equity & 0.8976 & 0.8975 & 0.9039 & 0.9039 & 1.6848 \\
\hline & UNH_UN_Equity & 1.0220 & 0.9796 & 0.9801 & 0.9801 & 1.9142 \\
\hline & UA_UN_Equity & 1.0278 & 1.0237 & 1.0241 & 1.0241 & 1.5542 \\
\hline & TUP_UN_Equity & $0.8111^{* * *}$ & $0.8051^{* * *}$ & $0.8055^{* * *}$ & $0.8055^{* * *}$ & 1.1959 \\
\hline & UNP_UN_Equity & $0.8898^{* *}$ & $0.9162^{* *}$ & $0.9176^{* *}$ & $0.9175^{* *}$ & 1.3537 \\
\hline & UHS_UN_Equity & 1.0447 & 1.0105 & 1.0109 & 1.0109 & 1.5655 \\
\hline & UPS_UN_Equity & 0.9964 & 0.9921 & 0.9905 & 0.9923 & 1.3574 \\
\hline & URBN_UW_Equity & $0.9608^{*}$ & 0.9851 & 0.9852 & 0.9852 & 2.1501 \\
\hline & UIS_UN_Equity & 1.0153 & 1.0186 & $0.9538^{* *}$ & $0.9537^{* *}$ & 2.2892 \\
\hline & USB_UN_Equity & 1.1282 & 1.4814 & 1.0173 & 1.0173 & 1.9989 \\
\hline & UTX_UN_Equity & $0.8607^{* * *}$ & $0.8812^{* * *}$ & $0.8810^{* * *}$ & $0.8810^{* * *}$ & 0.8575 \\
\hline & V_UN_Equity & 0.9716 & 0.9722 & 0.9730 & 0.9729 & 1.5849 \\
\hline & VAR_UN_Equity & $0.8106^{* * *}$ & $0.9500^{* * *}$ & $0.8630^{* * *}$ & $0.8765^{* * *}$ & 1.1895 \\
\hline & URI_UN_Equity & $0.7831^{* * *}$ & $0.7576^{* * *}$ & $0.7579^{* * *}$ & $0.7578^{* * *}$ & 1.1562 \\
\hline & VFC_UN_Equity & 1.0173 & 0.9899 & 1.0311 & 1.0308 & 1.3811 \\
\hline & VIAV_UW_Equity & $0.6952^{* * *}$ & $0.7251^{* * *}$ & $0.7480^{* * *}$ & $0.7480^{* * *}$ & 1.2003 \\
\hline & VIAB_UN_Equity & 0.9789 & 0.9789 & 0.9781 & 0.9781 & 1.7582 \\
\hline & VLO_UN_Equity & $0.9487^{*}$ & 1.0365 & 0.9905 & 0.9910 & 1.3742 \\
\hline & VMC_UN_Equity & 0.9758 & $0.9520^{* *}$ & $0.9509^{* *}$ & $0.9503^{* *}$ & 2.2653 \\
\hline & VNO_UN_Equity & 1.0200 & 1.0375 & 1.0373 & 1.0376 & 3.6746 \\
\hline & VRSN_UW_Equity & $0.9664^{*}$ & 0.9761 & 1.0048 & 1.0049 & 1.8034 \\
\hline & VTR_UN_Equity & $0.8925^{* * *}$ & $0.8712^{* * *}$ & $0.8719^{* * *}$ & $0.8713^{* * *}$ & 1.7227 \\
\hline & VIAV_UQ_Equity & $0.6952^{* * *}$ & $0.7251^{* * *}$ & $0.7480^{* * *}$ & $0.7480^{* * *}$ & 1.2003 \\
\hline & VZ_UN_Equity & 0.9983 & 1.0020 & 1.0042 & 1.0042 & 1.5998 \\
\hline & WAT_UN_Equity & $0.8106^{* * *}$ & $0.9634^{* * *}$ & $0.8401^{* * *}$ & $0.8398^{* * *}$ & 0.6987 \\
\hline & WBA_UN_Equity & 1.0482 & 1.0239 & 1.0248 & 1.0248 & 1.7872 \\
\hline & VRSN_UQ_Equity & $0.9664^{*}$ & 0.9761 & 1.0048 & 1.0049 & 1.8034 \\
\hline & WEC_UN_Equity & 0.9667 & $0.9696^{*}$ & $0.9695^{*}$ & $0.9695^{*}$ & 1.0851 \\
\hline & WDC_UN_Equity & 1.0032 & 0.9985 & 0.9989 & 0.9993 & 2.8866 \\
\hline & WFC_UN_Equity & 1.1264 & 1.2204 & 1.0210 & 1.0210 & 2.1713 \\
\hline & WFM_UW_Equity & $0.8210^{* * *}$ & $0.8185^{* * *}$ & $0.7909^{* * *}$ & $0.8046^{* * *}$ & 1.2142 \\
\hline & WFT_UN_Equity & 0.9780 & 0.9997 & 0.9911 & 0.9947 & 1.6255 \\
\hline & WHR_UN_Equity & 1.0141 & 1.0140 & 1.0143 & 1.0143 & 1.4857 \\
\hline & WIN_UW_Equity & 1.0020 & 1.0015 & 1.0123 & 1.0123 & 3.7023 \\
\hline & WM_UN_Equity & $0.9730^{*}$ & $0.9677^{*}$ & $0.9676^{*}$ & $0.9676^{*}$ & 1.7406 \\
\hline & WFM_UQ_Equity & $0.8210^{* * *}$ & $0.8185^{* * *}$ & $0.7909^{* * *}$ & $0.8046^{* * *}$ & 1.2142 \\
\hline & WMB_UN_Equity & 1.0094 & $0.9670^{*}$ & $0.9679 *$ & $0.9679^{*}$ & 1.7414 \\
\hline & WMT_UN_Equity & 0.9885 & 1.0285 & 1.0293 & 1.0293 & 1.1591 \\
\hline & WU_UN_Equity & 1.0122 & 1.0293 & 1.0283 & 1.0283 & 3.3790 \\
\hline & WY_UN_Equity & 1.0110 & 0.9830 & 1.0053 & 1.0012 & 3.9521 \\
\hline & WYN_UN_Equity & 0.9889 & 1.0691 & 0.9781 & 0.9781 & 1.5464 \\
\hline & WOR_UN_Equity & 0.9887 & 1.1152 & 1.0084 & 1.0142 & 1.1014 \\
\hline & WYNN_UW_Equity & $0.6770^{* * *}$ & $0.6737^{* * *}$ & $0.7218^{* * *}$ & $0.7219^{* * *}$ & 0.7444 \\
\hline & X_UN_Equity & $0.8967^{* * *}$ & $0.9146^{* *}$ & $0.9015^{* * *}$ & $0.9015^{* * *}$ & 2.1373 \\
\hline & XEL_UN_Equity & 1.0089 & 1.0066 & 1.0071 & 1.0070 & 1.4245 \\
\hline & XEC_UN_Equity & $0.8349^{* * *}$ & $0.8230^{* * *}$ & $0.8230^{* * *}$ & $0.8229^{* * *}$ & 1.3143 \\
\hline & XL_UN_Equity & $0.7226^{* * *}$ & $0.7522^{* * *}$ & $0.7339 * * *$ & $0.7339^{* * *}$ & 1.7902 \\
\hline & XLNX_UW_Equity & 0.9884 & 0.9805 & 0.9820 & 0.9820 & 1.3624 \\
\hline & XOM_UN_Equity & $0.9308^{* *}$ & $0.9526^{*}$ & $0.9560^{*}$ & $0.9560^{*}$ & 1.7158 \\
\hline & XLNX_UQ_Equity & 0.9884 & 0.9805 & 0.9820 & 0.9820 & 1.3624 \\
\hline & XRAY_UW_Equity & 1.0121 & 1.0094 & 1.0112 & 1.0112 & 1.4703 \\
\hline & XRX_UN_Equity & $0.9607^{* *}$ & $0.9481^{*}$ & $0.9470^{*}$ & $0.9456^{*}$ & 1.3749 \\
\hline & YHOO_UW_Equity & 1.0355 & 1.0196 & 1.0211 & 1.0211 & 3.9435 \\
\hline & YHOO_UQ_Equity & 1.0355 & 1.0196 & 1.0211 & 1.0211 & 3.9435 \\
\hline & YUM_UN_Equity & 1.0531 & 1.0198 & 1.0204 & 1.0204 & 1.5143 \\
\hline & ZBH_UN_Equity & 1.0170 & 1.0094 & 1.0098 & 1.0098 & 1.6807 \\
\hline & ZION_UW_Equity & 1.0921 & 1.0514 & 1.0402 & 1.0387 & 2.4751 \\
\hline
\end{tabular}

(Continues on next page) 


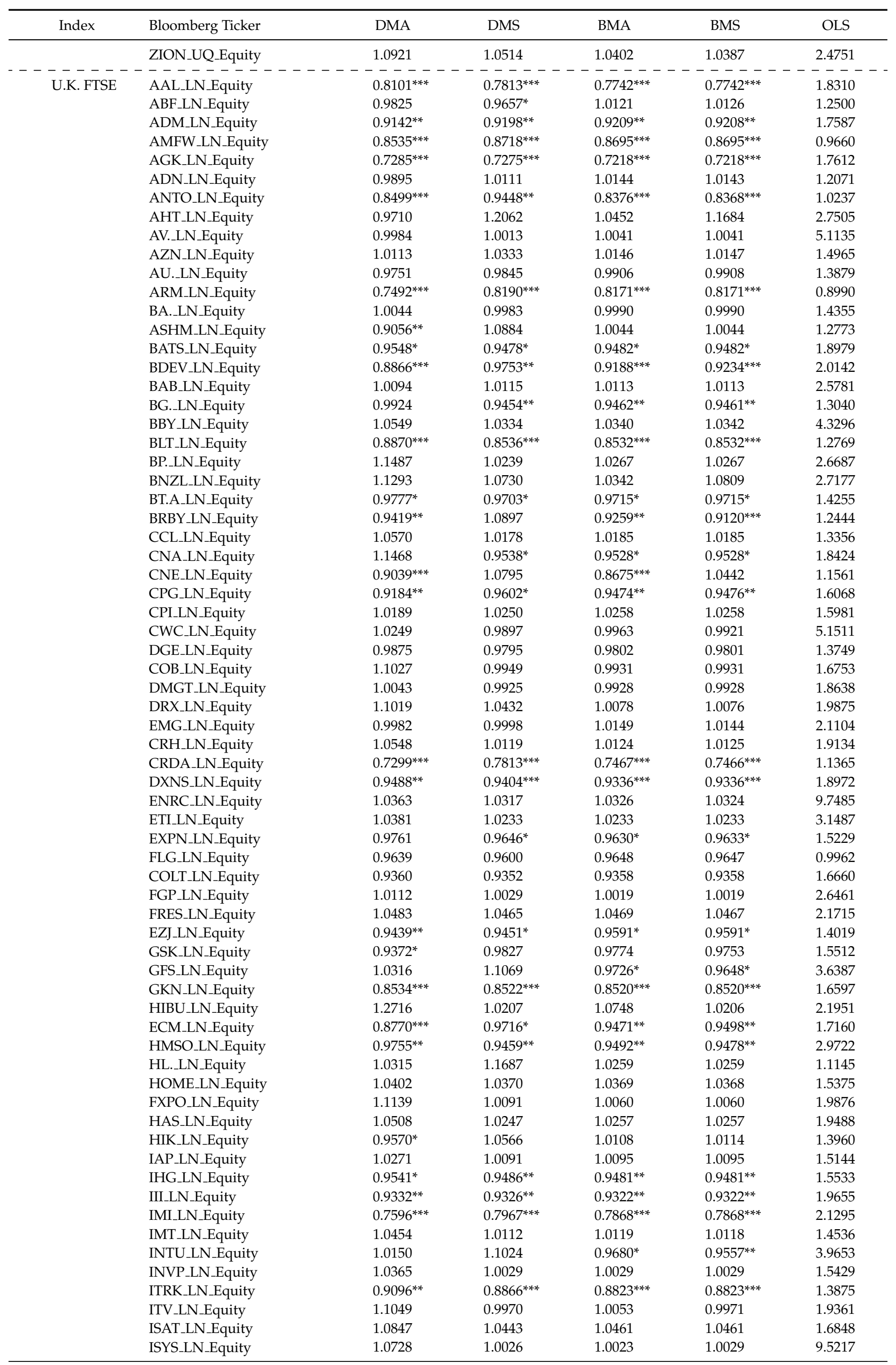

(Continues on next page) 


\begin{tabular}{|c|c|c|c|c|c|c|}
\hline Index & Bloomberg Ticker & DMA & DMS & BMA & BMS & OLS \\
\hline & JMAT_LN_Equity & 0.9934 & 0.9874 & 0.9879 & 0.9879 & 1.7822 \\
\hline & KGF_LN_Equity & 1.0229 & 0.9991 & 0.9996 & 0.9996 & 1.9193 \\
\hline & KAZ_LN_Equity & $0.8912^{* *}$ & $0.8444^{* * *}$ & $0.8451^{* * *}$ & $0.8443^{* * *}$ & 2.0044 \\
\hline & LAND_LN_Equity & 1.0250 & 1.0224 & 1.0229 & 1.0228 & 4.6767 \\
\hline & LSE_LN_Equity & $0.9402^{* *}$ & $0.9378^{* *}$ & $0.9350^{* *}$ & $0.9350^{* *}$ & 1.6430 \\
\hline & LAD_LN_Equity & 1.0487 & 1.0186 & 1.0196 & 1.0196 & 1.4821 \\
\hline & MGGT_LN_Equity & $0.8923^{* * *}$ & $0.8972^{* * *}$ & $0.8959^{* * *}$ & $0.8959^{* * *}$ & 1.3837 \\
\hline & LMI_LN_Equity & 1.0024 & 1.0337 & 0.9783 & 0.9774 & 15.7393 \\
\hline & MKS_LN_Equity & 1.0408 & 1.0252 & 1.0259 & 1.0259 & 1.2731 \\
\hline & MAB_LN_Equity & 1.1031 & 1.0302 & 1.0318 & 1.0311 & 2.6103 \\
\hline & MRO_LN_Equity & $0.6888^{* * *}$ & $0.6982^{* * *}$ & $0.6887^{* * *}$ & $0.6887^{* * *}$ & 15.0548 \\
\hline & MNDI_LN_Equity & 1.0350 & 1.0304 & 1.0306 & 1.0304 & 1.6577 \\
\hline & MRW_LN_Equity & 0.9516 & $0.9485^{*}$ & $0.9489^{*}$ & $0.9490^{*}$ & 2.7551 \\
\hline & NG._LN_Equity & 0.9568 & 1.0243 & 1.0248 & 1.0248 & 1.5096 \\
\hline & NXT_LN_Equity & 1.0411 & 1.0005 & 1.0012 & 1.0011 & 2.1356 \\
\hline & OML_LN_Equity & $0.8993^{* *}$ & $0.9091^{* *}$ & $0.9204^{* *}$ & $0.9205^{* *}$ & 1.6212 \\
\hline & LOG_LN_Equity & 1.0012 & 1.0009 & 1.0013 & 1.0013 & 7.1671 \\
\hline & PFC_LN_Equity & $0.8133^{* * *}$ & $0.7870^{* * *}$ & $0.7819^{* * *}$ & $0.7818^{* * *}$ & 1.6968 \\
\hline & PRU_LN_Equity & 0.9666 & 0.9791 & 0.9790 & 0.9790 & 4.6151 \\
\hline & PNN_LN_Equity & 1.0272 & 0.9790 & 0.9791 & 0.9791 & 11.8315 \\
\hline & PSN_LN_Equity & $0.9398^{* *}$ & $0.9632^{*}$ & $0.9545^{*}$ & $0.9589^{*}$ & 1.6396 \\
\hline & PSON_LN_Equity & 0.9922 & $0.9381^{* *}$ & $0.9387^{* *}$ & $0.9376^{* *}$ & 1.3985 \\
\hline & MSY_LN_Equity & 1.0424 & 1.0368 & 1.0163 & 1.0154 & 2.2560 \\
\hline & RB._LN_Equity & 1.0594 & 1.0278 & 1.0291 & 1.0291 & 1.6347 \\
\hline & PFG_LN_Equity & 1.0071 & 0.9865 & 0.9867 & 0.9867 & 1.2147 \\
\hline & PUB_LN_Equity & 1.1290 & 1.0951 & 1.0637 & 1.0291 & 4.1433 \\
\hline & RBS_LN_Equity & $0.8809^{* *}$ & $0.9485^{* *}$ & 1.0195 & 1.0280 & 1.3602 \\
\hline & RDSA_LN_Equity & $0.8812^{* * *}$ & $0.8965^{* * *}$ & $0.8600^{* * *}$ & $0.8597^{* * *}$ & 1.0689 \\
\hline & RDSB_LN_Equity & $0.8355^{* * *}$ & $0.9137^{* * *}$ & $0.8654^{* * *}$ & $0.8654^{* * *}$ & 1.1708 \\
\hline & REL_LN_Equity & 0.9884 & 1.0011 & 0.9870 & 0.9870 & 1.5640 \\
\hline & REX_LN_Equity & 0.9991 & 0.9883 & 1.0064 & 1.0065 & 1.5114 \\
\hline & RIO_LN_Equity & 1.0401 & 1.0365 & 1.0365 & 1.0368 & 2.8700 \\
\hline & RR._LN_Equity & $0.9459^{*}$ & $0.9319^{* *}$ & $0.9311^{* *}$ & $0.9309^{* *}$ & 1.5923 \\
\hline & RRS_LN_Equity & 1.0182 & 0.9899 & 0.9866 & 0.9866 & 2.3049 \\
\hline & RSA_LN_Equity & 1.0680 & 1.5355 & 1.0096 & 1.0097 & 6.7081 \\
\hline & RTO_LN_Equity & 0.9871 & $0.9669^{*}$ & $0.9680^{*}$ & $0.9679^{*}$ & 1.9008 \\
\hline & SAB_LN_Equity & $0.8626^{* * *}$ & $0.8668^{* * *}$ & $0.8661^{* * *}$ & $0.8665^{* * *}$ & 1.2813 \\
\hline & SBRY_LN_Equity & 1.0425 & 1.0313 & 1.0139 & 1.0139 & 2.1089 \\
\hline & SDR_LN_Equity & 1.0358 & 1.0083 & 1.0095 & 1.0089 & 2.3162 \\
\hline & SGE_LN_Equity & 1.0460 & 1.0281 & 1.0173 & 1.0172 & 2.7110 \\
\hline & SDRC_LN_Equity & 1.0473 & 1.0518 & 1.0521 & 1.0521 & 1.6974 \\
\hline & SHP_LN_Equity & 0.9908 & 1.0069 & 0.9951 & 0.9950 & 1.1068 \\
\hline & SGC_LN_Equity & $0.9509^{* *}$ & $0.9456^{* *}$ & $0.9432^{* *}$ & $0.9432^{* *}$ & 1.7897 \\
\hline & SKY_LN_Equity & $0.9835^{* * *}$ & 1.1103 & $0.9487^{* *}$ & $0.9487^{* *}$ & 6.1554 \\
\hline & SL._LN_Equity & 0.9982 & 1.0127 & 1.0136 & 1.0135 & 1.3004 \\
\hline & SGRO_LN_Equity & 1.0547 & 1.0298 & 1.0300 & 1.0298 & 2.1317 \\
\hline & SMIN_LN_Equity & $0.8349^{* * *}$ & $0.8801^{* * *}$ & $0.8323^{* * *}$ & $0.8323^{* * *}$ & 1.3430 \\
\hline & SN._LN_Equity & 1.0654 & 1.0131 & 1.0130 & 1.0130 & 1.6523 \\
\hline & SRP_LN_Equity & $0.8477^{* * *}$ & $0.8668^{* *}$ & $0.8329^{* * *}$ & $0.8329^{* * *}$ & 1.2035 \\
\hline & SSE_LN_Equity & 1.0159 & 1.0138 & 1.0169 & 1.0168 & 1.4398 \\
\hline & SPD_LN_Equity & 0.9936 & 1.0029 & 1.0125 & 1.0125 & 1.7200 \\
\hline & SVT_LN_Equity & 1.0117 & 0.9960 & 0.9966 & 0.9966 & 3.0775 \\
\hline & TATE_LN_Equity & $0.7286^{* * *}$ & $0.7570^{* * *}$ & $0.7577^{* * *}$ & $0.7577^{* * *}$ & 1.3761 \\
\hline & TLW_LN_Equity & $0.8735^{* * *}$ & $0.8999^{* *}$ & $0.8222^{* * *}$ & $0.8222^{* * *}$ & 1.4784 \\
\hline & STJ_LN_Equity & $0.9985^{*}$ & 0.9987 & 0.9989 & 0.9989 & 1.6121 \\
\hline & TPK_LN_Equity & 1.0112 & 0.9821 & 0.9920 & 0.9919 & 3.1002 \\
\hline & SPT_LN_Equity & $0.8284^{* * *}$ & $0.9071^{* * *}$ & $0.7893^{* * *}$ & $0.7875^{* * *}$ & 2.4432 \\
\hline & TSCO_LN_Equity & 0.9855 & 0.9503 & $0.9491^{*}$ & $0.9482^{*}$ & 1.7836 \\
\hline & TT._LN_Equity & 1.2246 & 1.1464 & 1.2154 & 1.1469 & 2.5005 \\
\hline & ULVR_LN_Equity & 0.9764 & $0.9683^{*}$ & $0.9687^{*}$ & $0.9687^{*}$ & 1.5964 \\
\hline & UU._LN_Equity & 1.0304 & 1.0296 & 1.0294 & 1.0294 & 1.3906 \\
\hline & TW._LN_Equity & 1.1662 & 1.1914 & 1.0352 & 1.0213 & 4.9087 \\
\hline & VED_LN_Equity & $0.9379^{*}$ & $0.9391^{*}$ & $0.9142^{* *}$ & $0.9135^{* *}$ & 2.4347 \\
\hline & VOD_LN_Equity & 1.0149 & 0.9886 & 0.9891 & 0.9890 & 1.7648 \\
\hline & UBM_LN_Equity & 1.0378 & 1.0246 & 1.0250 & 1.0250 & 2.7535 \\
\hline & WEIR_LN_Equity & $0.7545^{* * *}$ & $0.8246^{* * *}$ & $0.7639^{* * *}$ & $0.7638^{* * *}$ & 1.9144 \\
\hline & WG._LN_Equity & $0.8621^{* * *}$ & $0.8454^{* * *}$ & $0.8452^{* * *}$ & $0.8452^{* * *}$ & 1.7529 \\
\hline & WOS_LN_Equity & 1.0724 & 1.2028 & 1.0293 & 1.0913 & 4.6376 \\
\hline & WMH_LN_Equity & 0.9688 & 0.9853 & 0.9860 & 0.9860 & 1.3986 \\
\hline
\end{tabular}

(Continues on next page) 


\begin{tabular}{cllllll}
\hline Index & Bloomberg Ticker & DMA & DMS & BMA & BMS & OLS \\
\hline & WPP_LN_Equity & 1.0155 & 1.0068 & 1.0021 & 1.0017 & 2.3956 \\
& WTB_LN_Equity & 1.0518 & 1.0282 & 1.0292 & 1.0292 & 1.9651 \\
& XTA_LN_Equity & $0.9242^{*}$ & $0.9208^{*}$ & $0.9206^{*}$ & $0.9206^{*}$ & 2.5115 \\
\hline
\end{tabular}

(Table 4 Continued from previous page) This table shows detailed test results of the CW - statistic for all equities that are analysed in each equity index of interest for all models $\ell=\{$ DMA, DMS, BMA, BMS, OLS $\}$ that we consider, relative to the forecasts of the historic average (HA) benchmark. The out-of-sample evaluation period is from 2011:06 to $2015: 07$. We use $\left\{{ }^{*},{ }^{* *},{ }^{* * *}\right\}$ to denote significance at the $10 \%, 5 \%$, and $1 \%$, respectively, using one sided (upper tail) $t$-tests. 


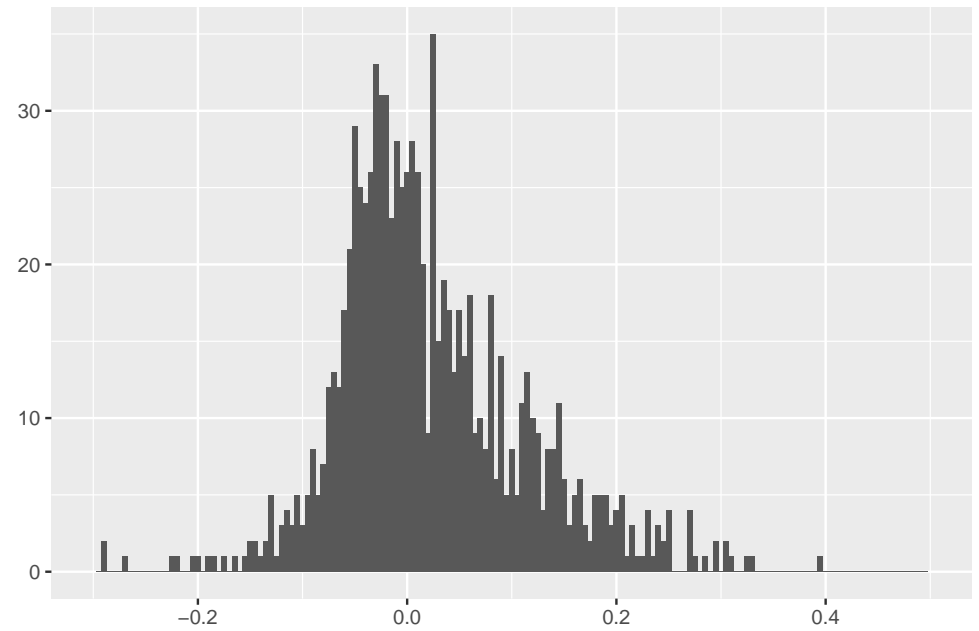

(a) DMA

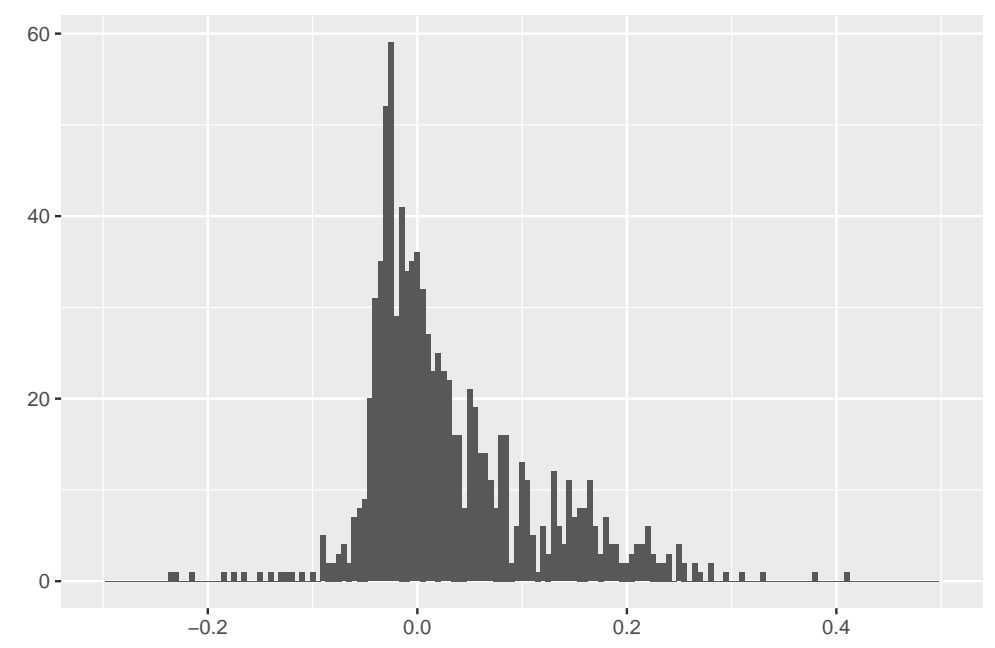

(c) BMA

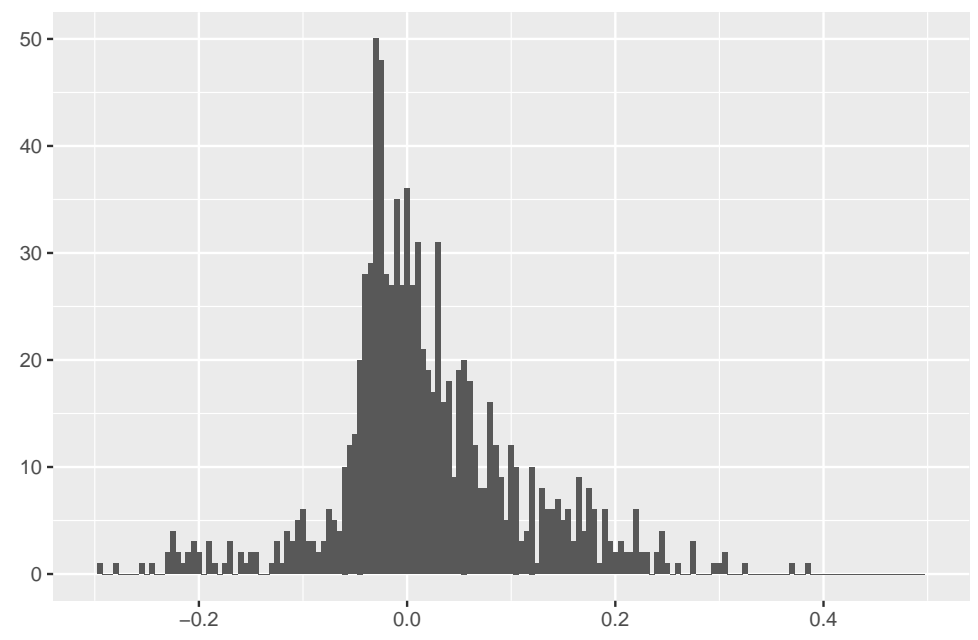

(b) DMS

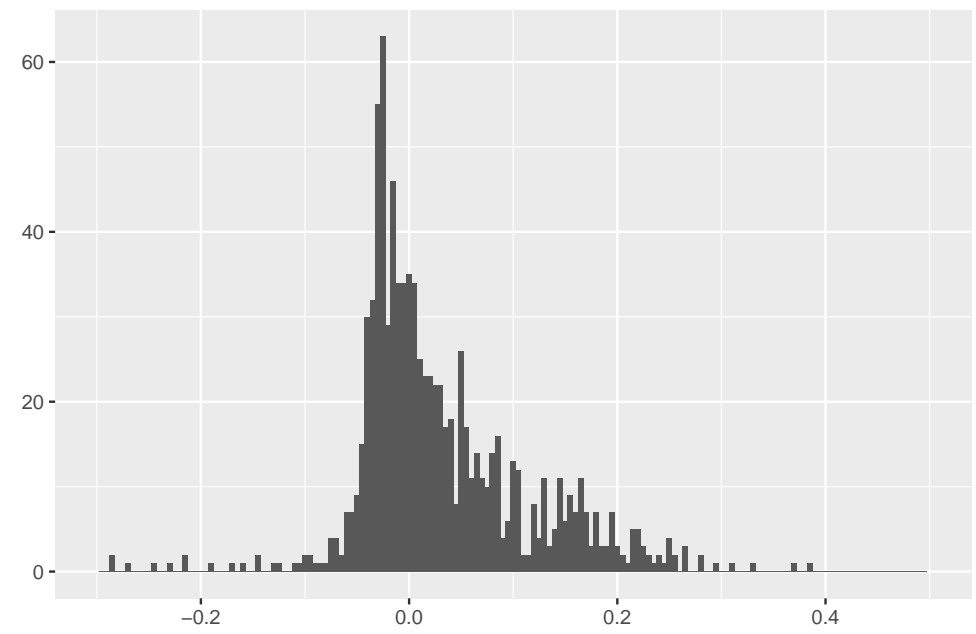

(d) BMS

Figure 2: Empirical distributions (histograms) of the out-of-sample $R^{2}$ values for All $(N=896)$ equities. 


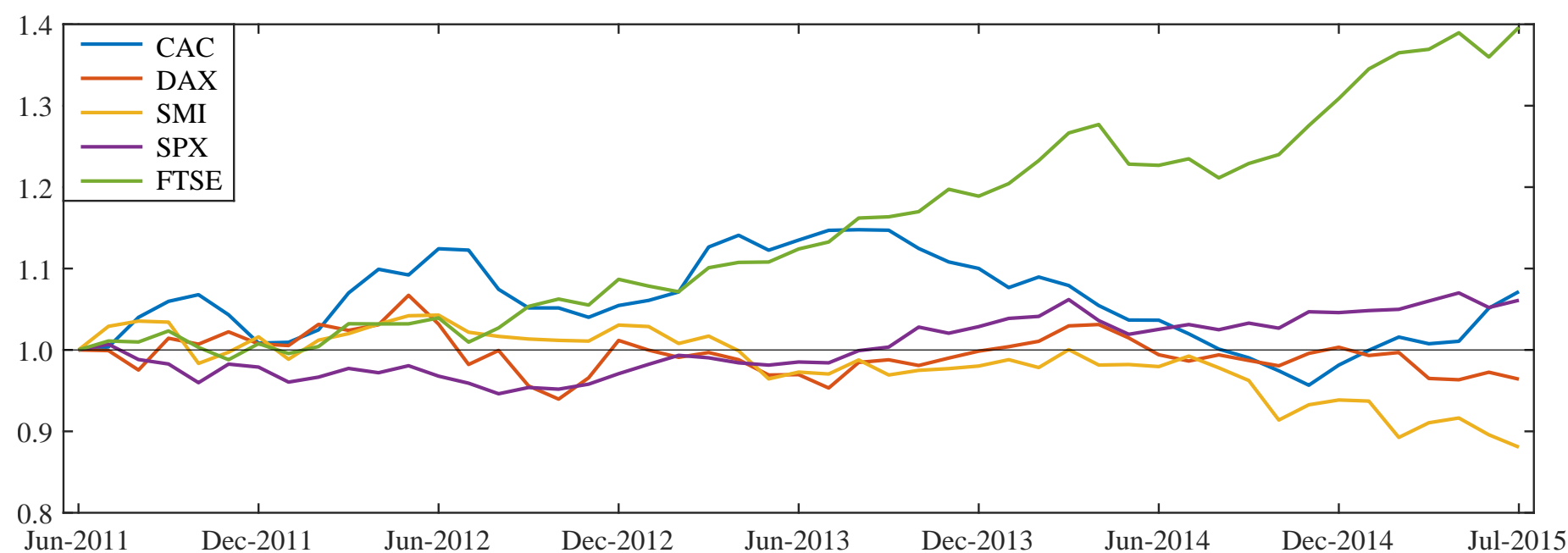

(a) DMA

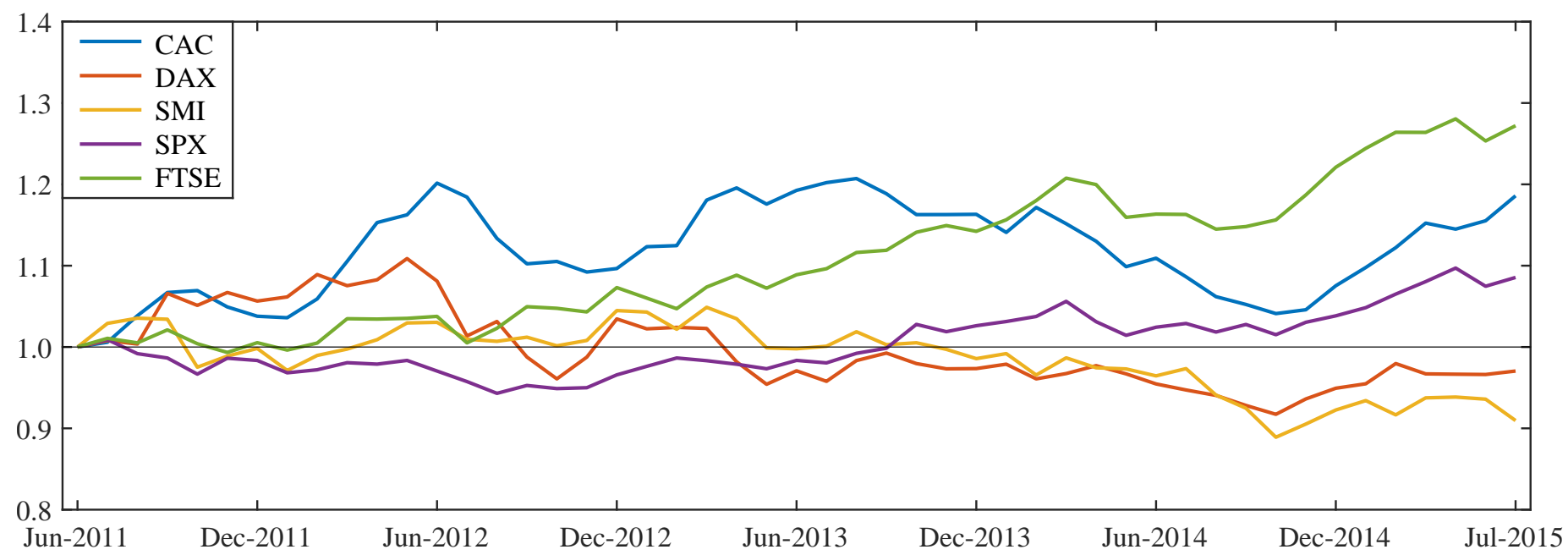

(b) DMS

Figure 3: Portfolio value of DMA/DMS forecast based long strategy for each index in excess of the respective benchmark indices and accounting for trading costs. The value of the first period is normalized to 1 . The out-ofsample period of the portfolio is from 2011:06 to 2016:07. 
Table 5: Results of the portfolio trading model with transaction costs

\begin{tabular}{|c|c|c|c|c|c|c|c|c|c|c|c|c|c|c|}
\hline \multirow{2}{*}{ Index Name } & \multirow{2}{*}{ Year } & \multicolumn{3}{|c|}{ Return } & \multicolumn{3}{|c|}{ Standard Deviation } & \multicolumn{3}{|c|}{ Max. Drawdown } & \multicolumn{2}{|c|}{ Alpha } & \multicolumn{2}{|c|}{ Info. Ratio } \\
\hline & & Index & DMA & DMS & Index & DMA & DMS & Index & DMA & DMS & DMA & DMS & $\overline{D M A}$ & DMS \\
\hline \multirow{6}{*}{ CAC } & All & $22.61 \%$ & $34.04 \%$ & $44.24 \%$ & $15.29 \%$ & $15.55 \%$ & $15.60 \%$ & $25.58 \%$ & $20.61 \%$ & $20.42 \%$ & $1.85 \%$ & $4.60 \%$ & 0.26 & 0.62 \\
\hline & 2011 & $-16.50 \%$ & $-36.90 \%$ & $-32.62 \%$ & $20.35 \%$ & $19.03 \%$ & $18.83 \%$ & $27.45 \%$ & $20.61 \%$ & $20.42 \%$ & $1.08 \%$ & $4.16 \%$ & 0.04 & 0.15 \\
\hline & 2012 & $15.19 \%$ & $20.41 \%$ & $23.47 \%$ & $14.12 \%$ & $15.67 \%$ & $14.79 \%$ & $12.61 \%$ & $9.86 \%$ & $8.17 \%$ & $5.87 \%$ & $9.72 \%$ & 0.70 & 1.00 \\
\hline & 2013 & $17.24 \%$ & $18.71 \%$ & $18.86 \%$ & $11.33 \%$ & $11.13 \%$ & $11.84 \%$ & $5.31 \%$ & $4.31 \%$ & $4.55 \%$ & $1.75 \%$ & $1.84 \%$ & 0.25 & 0.27 \\
\hline & 2014 & $0.05 \%$ & $-7.14 \%$ & $-3.68 \%$ & $11.34 \%$ & $13.14 \%$ & $12.44 \%$ & $6.34 \%$ & $14.86 \%$ & $12.79 \%$ & $-7.11 \%$ & $-3.76 \%$ & -1.26 & -0.54 \\
\hline & 2015 & $10.19 \%$ & $56.62 \%$ & $59.09 \%$ & $20.87 \%$ & $11.90 \%$ & $17.02 \%$ & $12.34 \%$ & $0.00 \%$ & $0.00 \%$ & $26.62 \%$ & $29.81 \%$ & 4.15 & 5.75 \\
\hline \multirow{6}{*}{ DAX } & All & $47.08 \%$ & $48.21 \%$ & $48.84 \%$ & $17.50 \%$ & $18.72 \%$ & $18.78 \%$ & $25.41 \%$ & $24.82 \%$ & $22.21 \%$ & $-1.02 \%$ & $-0.84 \%$ & -0.15 & -0.11 \\
\hline & 2011 & $-12.54 \%$ & $-30.97 \%$ & $-22.29 \%$ & $25.83 \%$ & $30.37 \%$ & $28.91 \%$ & $26.78 \%$ & $24.82 \%$ & $22.21 \%$ & $0.64 \%$ & $7.50 \%$ & 0.02 & 0.22 \\
\hline & 2012 & $26.79 \%$ & $27.02 \%$ & $23.73 \%$ & $14.81 \%$ & $19.85 \%$ & 19.8 & $9.82 \%$ & $12.66 \%$ & 13.5 & $-0.72 \%$ & -4.77 & -0.06 & -0.41 \\
\hline & 2013 & $23.49 \%$ & $24.22 \%$ & $19.42 \%$ & $11.25 \%$ & $13.86 \%$ & $14.26 \%$ & $4.67 \%$ & $6.28 \%$ & $5.94 \%$ & $0.54 \%$ & $-5.34 \%$ & 0.11 & -0.81 \\
\hline & 2014 & $3.18 \%$ & $2.17 \%$ & $0.87 \%$ & $11.09 \%$ & $11.95 \%$ & $12.89 \%$ & $6.20 \%$ & $6.93 \%$ & $8.45 \%$ & $-1.11 \%$ & $-2.53 \%$ & -0.26 & -0.57 \\
\hline & 2015 & $11.70 \%$ & $30.87 \%$ & $42.76 \%$ & $23.65 \%$ & $17.53 \%$ & $21.09 \%$ & $19.27 \%$ & $4.54 \%$ & $4.31 \%$ & $-9.91 \%$ & $5.74 \%$ & -1.69 & 1.07 \\
\hline \multirow{6}{*}{ SMI } & All & $31.87 \%$ & $24.92 \%$ & $28.10 \%$ & $11.28 \%$ & $12.90 \%$ & $12.82 \%$ & $15.66 \%$ & $17.01 \%$ & $17.70 \%$ & $-3.41 \%$ & $-2.55 \%$ & -0.52 & -0.37 \\
\hline & 2011 & $-7.26 \%$ & $-17.93 \%$ & $-20.91 \%$ & $13.07 \%$ & $14.32 \%$ & $14.51 \%$ & $16.37 \%$ & $17.01 \%$ & $17.70 \%$ & $-1.65 \%$ & $-4.13 \%$ & -0.07 & -0.18 \\
\hline & 2012 & $14.37 \%$ & $18.43 \%$ & $21.68 \%$ & $9.03 \%$ & $9.31 \%$ & $9.91 \%$ & $6.18 \%$ & $5.18 \%$ & $4.19 \%$ & $4.67 \%$ & $8.50 \%$ & 1.11 & 1.60 \\
\hline & 2013 & $19.02 \%$ & $14.98 \%$ & $14.00 \%$ & $10.04 \%$ & $10.47 \%$ & $10.74 \%$ & $3.32 \%$ & $4.47 \%$ & $4.88 \%$ & $-4.76 \%$ & $-5.89 \%$ & -0.85 & -0.99 \\
\hline & 2014 & $9.34 \%$ & $4.25 \%$ & $3.62 \%$ & $6.92 \%$ & $9.87 \%$ & $10.85 \%$ & $3.05 \%$ & $4.97 \%$ & $6.11 \%$ & $-5.64 \%$ & $-6.38 \%$ & -0.80 & -0.86 \\
\hline & 2015 & $-0.53 \%$ & $-5.45 \%$ & $2.37 \%$ & $17.07 \%$ & $26.13 \%$ & $22.81 \%$ & $9.70 \%$ & $11.11 \%$ & $8.41 \%$ & $-14.85 \%$ & $-6.62 \%$ & -1.66 & -0.95 \\
\hline \multirow{6}{*}{ SPX } & All & $45.58 \%$ & $54.87 \%$ & $57.08 \%$ & $11.49 \%$ & $13.97 \%$ & $13.78 \%$ & $15.89 \%$ & $19.28 \%$ & $18.70 \%$ & $1.67 \%$ & $2.32 \%$ & 0.40 & 0.53 \\
\hline & & $1.15 \%$ & $-15.73 \%$ & $-14.50 \%$ & $15.97 \%$ & $25.00 \%$ & $24.32 \%$ & $17.03 \%$ & $19.28 \%$ & $18.70 \%$ & $-5.95 \%$ & $-4.79 \%$ & -0.20 & -0.16 \\
\hline & 2012 & $13.16 \%$ & $15.56 \%$ & $14.12 \%$ & $10.56 \%$ & $11.67 \%$ & $11.75 \%$ & $6.97 \%$ & $7.49 \%$ & $7.77 \%$ & $2.58 \%$ & $0.93 \%$ & 0.74 & 0.25 \\
\hline & 2013 & $26.54 \%$ & $32.37 \%$ & $32.28 \%$ & $8.56 \%$ & $9.92 \%$ & $9.93 \%$ & $3.13 \%$ & $2.70 \%$ & $2.51 \%$ & $7.44 \%$ & $7.32 \%$ & 2.18 & 1.93 \\
\hline & 2014 & $11.14 \%$ & $12.31 \%$ & $13.05 \%$ & $8.11 \%$ & $11.02 \%$ & $11.15 \%$ & $3.56 \%$ & $3.33 \%$ & $2.98 \%$ & $1.03 \%$ & $1.84 \%$ & 0.23 & 0.39 \\
\hline & 2015 & $0.11 \%$ & $9.13 \%$ & $14.61 \%$ & $13.66 \%$ & $12.65 \%$ & $12.25 \%$ & $8.89 \%$ & $2.96 \%$ & $1.56 \%$ & $3.10 \%$ & $9.22 \%$ & 0.78 & 1.70 \\
\hline \multirow{6}{*}{ FTSE } & All & $11.28 \%$ & $57.73 \%$ & $51.03 \%$ & $11.77 \%$ & $12.50 \%$ & $12.34 \%$ & $14.38 \%$ & $14.20 \%$ & $14.06 \%$ & $10.65 \%$ & $8.79 \%$ & 1.84 & 1.59 \\
\hline & 2011 & $-4.88 \%$ & $-10.36 \%$ & $\overline{-10.49 \%}$ & $13.39 \%$ & $15.84 \%$ & $15.92 \%$ & $15.51 \%$ & $14.20 \%$ & $14.06 \%$ & $0.79 \%$ & $\overline{0.67 \%}$ & 0.04 & 0.03 \\
\hline & 2012 & $6.18 \%$ & $16.09 \%$ & $15.60 \%$ & $10.26 \%$ & $11.58 \%$ & $11.93 \%$ & $9.38 \%$ & $8.16 \%$ & $8.29 \%$ & $10.78 \%$ & $10.17 \%$ & 1.78 & 1.57 \\
\hline & 2013 & $14.24 \%$ & $27.14 \%$ & $25.21 \%$ & $12.26 \%$ & $14.27 \%$ & $13.36 \%$ & $5.58 \%$ & $4.70 \%$ & $4.69 \%$ & $15.19 \%$ & $12.89 \%$ & 3.63 & 2.90 \\
\hline & 2014 & $-2.36 \%$ & $10.10 \%$ & $7.08 \%$ & $9.20 \%$ & $10.86 \%$ & $11.04 \%$ & $4.35 \%$ & $5.04 \%$ & $5.80 \%$ & $12.71 \%$ & $9.45 \%$ & 1.75 & 1.44 \\
\hline & 2015 & $-4.23 \%$ & $25.06 \%$ & $22.23 \%$ & $13.27 \%$ & $7.64 \%$ & $7.47 \%$ & $13.21 \%$ & $1.00 \%$ & $1.13 \%$ & $11.89 \%$ & $8.39 \%$ & 1.85 & 1.52 \\
\hline
\end{tabular}

Notes: This table provides summary results of the DMA/DMS forecast ranked tailored portfolios. Entries under column one and two show the index of interest and the time period (Year) that is analysed. Column blocks (3-5), (6-8), and (9-11) report, respectively, the annualized return, the annualized standard deviation, and the maximum drawdown as defined in (16) for the indices of interest $\iota=\{$ DAX, SPX, FTSE, CAC, SMI $\}$ as well as the respective DMA/DMS forecast ranked portfolios on those indices. The last two column blocks under the headings Alpha and Info. Ratio give the benchmark Alpha and the information ratio (IR) as defined in (17) and (18), respectively, which are computed relative to the index of interest $\iota$. The out-of-sample evaluation period is from 2011:06 to 2015:07. 